Cochrane Database of Systematic Reviews

\title{
Compulsory community and involuntary outpatient treatment for people with severe mental disorders (Review)
}

Kisely SR, Campbell LA, O'Reilly R

Kisely SR, Campbell LA, O'Reilly R.

Compulsory community and involuntary outpatient treatment for people with severe mental disorders.

Cochrane Database of Systematic Reviews 2017, Issue 3. Art. No.: CD004408.

DOI: 10.1002/14651858.CD004408.pub5.

www.cochranelibrary.com 
TABLE OF CONTENTS

ABSTRACT

PLAIN LANGUAGE SUMMARY

SUMMARY OF FINDINGS

BACKGROUND

OBJECTIVES

METHODS

RESULTS

Figure 1.

Figure 2.

Figure 3.

DISCUSSION

AUTHORS' CONCLUSIONS

ACKNOWLEDGEMENTS

REFERENCES

CHARACTERISTICS OF STUDIES

DATA AND ANALYSES

Analysis 1.1. Comparison 1 COURT ORDERED OUTPATIENT COMMITMENT compared with ENTIRELY VOLUNTARY CARE, OutCome

1 Health service outcomes: 1 . Readmission to hospital - by 11 to 12 months.

Analysis 1.2. Comparison 1 COURT ORDERED OUTPATIENT COMMITMENT compared with ENTIRELY VOLUNTARY CARE, Outcome 2 Health service outcomes: 2. Hospital bed-days.

Analysis 1.3. Comparison 1 COURT ORDERED OUTPATIENT COMMITMENT compared with ENTIRELY VOLUNTARY CARE, OutCome 3 Health service outcomes: 3. Number with multiple readmissions by 12 months.

Analysis 1.4. Comparison 1 COURT ORDERED OUTPATIENT COMMITMENT compared with ENTIRELY VOLUNTARY CARE, OutCome 4 Health service outcomes: 4. Compliance with medication by 11 to 12 months.

Analysis 1.5. Comparison 1 COURT ORDERED OUTPATIENT COMMITMENT compared with ENTIRELY VOLUNTARY CARE, Outcome 5 Participant level outcomes: 1 . Mental state - psychiatric symptoms and global state at 11 to 12 months.

Analysis 1.6. Comparison 1 COURT ORDERED OUTPATIENT COMMITMENT compared with ENTIRELY VOLUNTARY CARE, Outcome 6 Participant level outcomes: 2. Social functioning: trouble with police by 11 to 12 months.

Analysis 1.7. Comparison 1 COURT ORDERED OUTPATIENT COMMITMENT compared with ENTIRELY VOLUNTARY CARE, Outcome 7 Participant level outcomes: 3. Social functioning: homeless by 11 to 12 months.

Analysis 1.8. Comparison 1 COURT ORDERED OUTPATIENT COMMITMENT compared with ENTIRELY VOLUNTARY CARE, Outcome 8 Participant level outcomes: 4. Quality of life: Lehman Quality of Life Scale.

Analysis 1.9. Comparison 1 COURT ORDERED OUTPATIENT COMMITMENT compared with ENTIRELY VOLUNTARY CARE, Outcome 9 Participant level outcomes: 5. Quality of life: victimisation by 11 to 12 months.

Analysis 1.10. Comparison 1 COURT ORDERED OUTPATIENT COMMITMENT compared with ENTIRELY VOLUNTARY CARE,

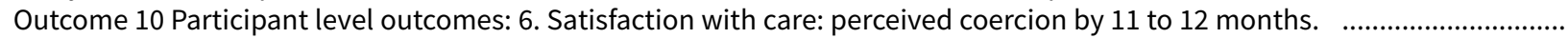

Analysis 2.1. Comparison 2 COMMUNITY TREATMENT ORDERS compared with SUPERVISED DISCHARGE (SECTION 17), Outcome 1 Health service outcomes: 1a. Readmission to hospital - by 12 months.

Analysis 2.2. Comparison 2 COMMUNITY TREATMENT ORDERS compared with SUPERVISED DISCHARGE (SECTION 17), Outcome 2 Health service outcomes. 1b. Readmission to hospital by 36 months.

Analysis 2.3. Comparison 2 COMMUNITY TREATMENT ORDERS compared with SUPERVISED DISCHARGE (SECTION 17), Outcome 3 Health service outcomes: 2. Hospital bed-days by 12 months.

Analysis 2.4. Comparison 2 COMMUNITY TREATMENT ORDERS compared with SUPERVISED DISCHARGE (SECTION 17), OutCome 4 Health service outcomes: 3. Number of readmissions by 12 months.

Analysis 2.5. Comparison 2 COMMUNITY TREATMENT ORDERS compared with SUPERVISED DISCHARGE (SECTION 17), Outcome 5 Health service outcomes: 4. Number with multiple readmissions by 12 months.

Analysis 2.6. Comparison 2 COMMUNITY TREATMENT ORDERS compared with SUPERVISED DISCHARGE (SECTION 17), Outcome 6 Health service outcomes: 5a. Days in community till first admission by 12 months.

Analysis 2.7. Comparison 2 COMMUNITY TREATMENT ORDERS compared with SUPERVISED DISCHARGE (SECTION 17), Outcome 7 Health service outcomes: 5 b. Days in community till first admission and mean duration of bed-days by 36 months. ............. Analysis 2.8. Comparison 2 COMMUNITY TREATMENT ORDERS compared with SUPERVISED DISCHARGE (SECTION 17), Outcome 8 Participant level outcomes: 1. Mental state - psychiatric symptoms at 12 months (BPRS).

Analysis 2.9. Comparison 2 COMMUNITY TREATMENT ORDERS compared with SUPERVISED DISCHARGE (SECTION 17), Outcome 9 Participant level outcomes: 2. Global state: GAF at 12 months. 
Analysis 2.10. Comparison 2 COMMUNITY TREATMENT ORDERS compared with SUPERVISED DISCHARGE (SECTION 17), Outcome 10 Participant level outcomes: 3. Satisfaction with care: perceived coercion at 11 to 12 months.

Analysis 2.11. Comparison 2 COMMUNITY TREATMENT ORDERS compared with SUPERVISED DISCHARGE (SECTION 17), Outcome 11 Participant level outcomes: 4. Satisfaction with care: leverage at 11 to 12 months.

Analysis 2.12. Comparison 2 COMMUNITY TREATMENT ORDERS compared with SUPERVISED DISCHARGE (SECTION 17), Outcome 12 Participant level outcomes: 5. Social Outcomes Index at 12 months.

Analysis 3.1. Comparison 3 COMPULSORY COMMUNITY TREATMENT compared with STANDARD CARE, Outcome 1 Health service outcomes: 1 . Readmission to hospital by 11 to 12 months.

Analysis 3.2. Comparison 3 COMPULSORY COMMUNITY TREATMENT compared with STANDARD CARE, Outcome 2 Health service outcomes: 2. Hospital bed-days.

Analysis 3.3. Comparison 3 COMPULSORY COMMUNITY TREATMENT compared with STANDARD CARE, Outcome 3 Health service outcomes: 3. Number with multiple readmissions by 12 months.

Analysis 3.4. Comparison 3 COMPULSORY COMMUNITY TREATMENT compared with STANDARD CARE, Outcome 4 Participant level outcomes: 1. global state: GAF at 12 months.

Analysis 3.5. Comparison 3 COMPULSORY COMMUNITY TREATMENT compared with STANDARD CARE, Outcome 5 Participant level outcomes: 2 . Satisfaction with care: perceived coercion or leverage at 11 to 12 months.

APPENDICES

WHAT'S NEW

HISTORY

CONTRIBUTIONS OF AUTHORS 
[Intervention Review]

\section{Compulsory community and involuntary outpatient treatment for people with severe mental disorders}

Steve R Kisely¹, Leslie A Campbell², Richard O'Reilly³

1School of Medicine, The University of Queensland, Woolloongabba, Australia. 2Department of Community Health and Epidemiology, Dalhousie University, Halifax, Canada. ${ }^{3}$ Western University, London, Ontario, Canada

Contact: Steve R Kisely, School of Medicine, The University of Queensland, Princess Alexandra Hospital, Ipswich Road, Woolloongabba, Queensland, QLD 4102, Australia.s.kisely@uq.edu.au, steve.kisely@health.qld.gov.au.

Editorial group: Cochrane Schizophrenia Group.

Publication status and date: Edited (no change to conclusions), published in Issue 6, 2017.

Citation: Kisely SR, Campbell LA, O'Reilly R. Compulsory community and involuntary outpatient treatment for people with severe mental disorders. Cochrane Database of Systematic Reviews 2017, Issue 3. Art. No.: CD004408. DOI: 10.1002/14651858.CD004408.pub5.

Copyright @ 2017 The Cochrane Collaboration. Published by John Wiley \& Sons, Ltd.

\section{A B S T R A C T}

\section{Background}

It is controversial whether compulsory community treatment (CCT) for people with severe mental illness (SMI) reduces health service use, or improves clinical outcome and social functioning.

\section{Objectives}

To examine the effectiveness of compulsory community treatment (CCT) for people with severe mental illness (SMI).

\section{Search methods}

We searched the Cochrane Schizophrenia Group's Study-Based Register of Trials (2003, 2008, 2012, 8 November 2013, 3 June 2016). We obtained all references of identified studies and contacted authors where necessary.

\section{Selection criteria}

All relevant randomised controlled clinical trials (RCTs) of CCT compared with standard care for people with SMI (mainly schizophrenia and schizophrenia-like disorders, bipolar disorder, or depression with psychotic features). Standard care could be voluntary treatment in the community or another pre-existing form of CCT such as supervised discharge.

\section{Data collection and analysis}

Authors independently selected studies, assessed their quality and extracted data. We used Cochrane's tool for assessing risk of bias. For binary outcomes, we calculated a fixed-effect risk ratio (RR), its $95 \%$ confidence interval $(95 \% \mathrm{Cl})$ and, where possible, the number needed to treat for an additional beneficial outcome (NNTB). For continuous outcomes, we calculated a fixed-effect mean difference (MD) and its $95 \% \mathrm{Cl}$. We used the GRADE approach to create 'Summary of findings' tables for key outcomes and assessed the risk of bias of these findings.

\section{Main results}

The review included three studies $(n=749)$. Two were based in the USA and one in England. The English study had the least bias, meeting three out of the seven criteria of Cochrane's tool for assessing risk of bias. The two other studies met only one criterion, the majority being rated unclear.

Two trials from the USA $(n=416)$ compared court-ordered 'outpatient commitment' (OPC) with entirely voluntary community treatment. There were no significant differences between OPC and voluntary treatment by 11 to 12 months in any of the main health service or participant level outcome indices: service use - readmission to hospital ( 2 RCTs, $n=416, \mathrm{RR} 0.98,95 \% \mathrm{Cl} 0.79$ to 1.21 , low-quality evidence); 
service use - compliance with medication ( $2 \mathrm{RCTs}, \mathrm{n}=416$, RR $0.99,95 \% \mathrm{Cl} 0.83$ to 1.19 , low-quality evidence); social functioning - arrested at least once ( $2 \mathrm{RCTs}, \mathrm{n}=416, \mathrm{RR} 0.97,95 \% \mathrm{Cl} 0.62$ to 1.52 , low-quality evidence); social functioning - homelessness $(2 \mathrm{RCTs}, \mathrm{n}=416, \mathrm{RR}$ $0.67,95 \% \mathrm{Cl} 0.39$ to 1.15 , low-quality evidence); or satisfaction with care - perceived coercion ( $2 \mathrm{RCTs}, \mathrm{n}=416, \mathrm{RR} 1.36,95 \% \mathrm{Cl} 0.97$ to 1.89 , low-quality evidence). However, one trial found the risk of victimisation decreased with OPC ( $1 \mathrm{RCT}, \mathrm{n}=264, \mathrm{RR} 0.50,95 \% \mathrm{Cl} 0.31$ to 0.80 , low-quality evidence).

The other RCT compared community treatment orders (CTOs) with less intensive and briefer supervised discharge (Section 17) in England. The study found no difference between the two groups for either the main health service outcomes including readmission to hospital by 12 months ( $1 \mathrm{RCT}, \mathrm{n}=333$, RR $0.99,95 \% \mathrm{Cl} 0.74$ to 1.32 , moderate-quality evidence), or any of the participant level outcomes. The lack of any difference between the two groups persisted at 36 months' follow-up.

Combining the results of all three trials did not alter these results. For instance, participants on any form of CCT were no less likely to be readmitted than participants in the control groups whether on entirely voluntary treatment or subject to intermittent supervised discharge (3 RCTs, $n=749$, RR for readmission to hospital by 12 months $0.98,95 \% \mathrm{Cl} 0.82$ to 1.16 moderate-quality evidence). In terms of NNTB, it would take 142 orders to prevent one readmission. There was no clear difference between groups for perceived coercion by 12 months ( 3 RCTs, $\mathrm{n}=645$, RR $1.30,95 \% \mathrm{Cl} 0.98$ to 1.71 , moderate-quality evidence).

There were no data for adverse effects.

\section{Authors' conclusions}

These review data show CCT results in no clear difference in service use, social functioning or quality of life compared with voluntary care or brief supervised discharge. People receiving CCT were, however, less likely to be victims of violent or non-violent crime. It is unclear whether this benefit is due to the intensity of treatment or its compulsory nature. Short periods of conditional leave may be as effective (or non-effective) as formal compulsory treatment in the community. Evaluation of a wide range of outcomes should be considered when this legislation is introduced. However, conclusions are based on three relatively small trials, with high or unclear risk of blinding bias, and low- to moderate-quality evidence. In addition, clinical trials may not fully reflect the potential benefits of this complex intervention.

\section{PLAIN LANGUAGE SUMMARY}

\section{Compulsory community and involuntary outpatient treatment for people with severe mental disorders}

\section{Background}

Many countries use compulsory community treatment (CCT) for people with severe mental health problems, including Australia, Canada, Israel, New Zealand, the UK, and the US. Supporters of this approach suggest that CCT is necessary due to the shift to community care of people with severe mental illness and that it is less restrictive to compulsorily treat someone in the community than to subject them to repeated hospital admissions. They also argue that it is effective in bringing stability to the lives of people with severe mental illness. Opponents of CCT fear treatment and support will be replaced by a greater emphasis on control, restraint and threat. There is also a fear that CCT may undermine the relationship between healthcare professionals and patients, leading to feelings of mistrust and being controlled, which may drive people with severe mental illnesses away from care services.

Given the widespread use of such powers, which compel people to follow-up with mental health services and undergo treatment while living in the community, it is important to assess the benefits, effectiveness or possible hazards of compulsory treatment.

\section{Searches}

This review is based on searches run in 2012 and 2013, and updated in 2016.

\section{Study characteristics}

This review now includes three trials with 749 people, with follow-up in one study extending to 36 months. Two of these trials compared forms of CCT versus standard care or voluntary care and the third trial compared a form of CCT called 'community treatment order' to supervised discharge.

\section{Results}

Results from the trials showed overall CCT was no more likely to result in better service use, social functioning, mental state or quality of life compared with standard 'voluntary' care. People in the trial receiving CCT were less likely to be victims of violent or non-violent crime. Short periods of conditional leave may be as effective (or non-effective) as compulsory treatment in the community.

\section{Conclusions}

There was very limited information available, all results were based on three relatively small trials of low to medium quality, making it difficult to draw firm conclusions, so further research into the effects of different types of CCT is much needed. 


\begin{tabular}{|c|c|c|c|c|c|c|c|}
\hline \multirow{15}{*}{ 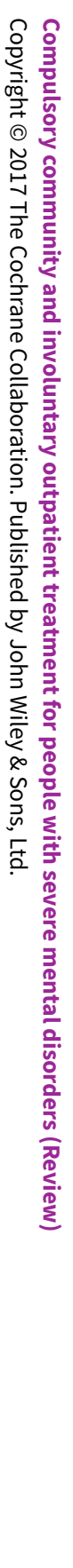 } & $\begin{array}{l}\text { S U M M A R Y O F F I N D I N G S } \\
\text { Summary of findings for the mai } \\
\text { with severe mental disorders }\end{array}$ & comparison. & T ORDERED OUTPATIEN & MITMENT comp & ed with ENTI & LY VOLUNTARY & ARE for people \\
\hline & COMPULSORY COMMUNITY AND INV & LUNTARY OUTPATIEI & ГREATMENT FOR PEOPLE V & ERE MENTAL DISC & DERS & & \\
\hline & $\begin{array}{l}\text { Patient or population: people with } \\
\text { Settings: patients in community set } \\
\text { Intervention: COURT ORDERED OUT } \\
\text { Comparison: ENTIRELY VOLUNTARY }\end{array}$ & $\begin{array}{l}\text { evere mental disorde } \\
\text { ings } \\
\text { PATIENT COMMITMEN } \\
\text { CARE }\end{array}$ & & & & & \\
\hline & Outcomes & Illustrative compa & ve risks ${ }^{\star}(95 \% \mathrm{Cl})$ & Relative effect & No of partici- & Quality of the & Comments \\
\hline & & Assumed risk & Corresponding risk & & (studies) & (GRADE) & \\
\hline & & VOLUNTARY CARE & $\begin{array}{l}\text { COURT ORDERED OUT- } \\
\text { PATIENT COMMITMENT }\end{array}$ & & & & \\
\hline & Health service outcomes: 1 . & Study population & & RR 0.98 & & $\oplus \oplus \ominus \ominus$ & - \\
\hline & 12 months & 460 per 1000 & $\begin{array}{l}\mathbf{4 5 1} \text { per } \mathbf{1 0 0 0} \\
\text { (363 to } 557)\end{array}$ & & & & \\
\hline & & Medium risk popul & & & & & \\
\hline & & 446 per 1000 & $\begin{array}{l}\mathbf{4 3 7} \text { per } \mathbf{1 0 0 0} \\
\text { (352 to } 540)\end{array}$ & & & & \\
\hline & Health service outcomes: 4. Com- & Study population & & RR 0.99 & & $\oplus \oplus \ominus \ominus$ & - \\
\hline & 12 months & 505 per 1000 & $\begin{array}{l}\mathbf{5 0 0} \text { per } 1000 \\
\text { (419 to } 601)\end{array}$ & & & & \\
\hline & & Medium risk popul & & & & & \\
\hline & & 554 per 1000 & $\begin{array}{l}\mathbf{5 4 8} \text { per } 1000 \\
\text { (460 to } 659)\end{array}$ & & & & \\
\hline & $\begin{array}{l}\text { Participant level outcomes: } 2 \text {. } \\
\text { Social functioning: trouble with }\end{array}$ & Study population & & $\begin{array}{l}\text { RR } 0.97 \\
\text { (0.62 to } 1.52)\end{array}$ & $\begin{array}{l}416 \\
\text { (2 studies) }\end{array}$ & $\begin{array}{l}\oplus \oplus \ominus \ominus \\
\text { Low } 1,2\end{array}$ & - \\
\hline
\end{tabular}




\begin{tabular}{|c|c|c|c|c|c|c|c|}
\hline \multirow{3}{*}{\multicolumn{2}{|c|}{ 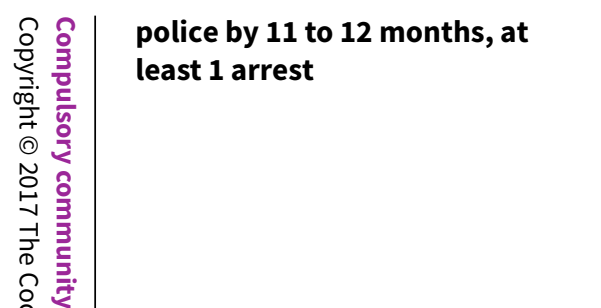 }} & 158 per 1000 & $\begin{array}{l}153 \text { per } 1000 \\
(98 \text { to } 240)\end{array}$ & & & & \\
\hline & & \multicolumn{2}{|c|}{ Medium risk population } & & & & \\
\hline & & 156 per 1000 & $\begin{array}{l}151 \text { per } \mathbf{1 0 0 0} \\
\text { (97 to } 237 \text { ) }\end{array}$ & & & & \\
\hline 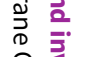 & \multirow{4}{*}{$\begin{array}{l}\text { Participant level outcomes: } 2 \text {. } \\
\text { Social functioning: trouble with } \\
\text { police by } 11 \text { to } 12 \text { months, ever } \\
\text { arrested/picked up by police for } \\
\text { violence against a person }\end{array}$} & \multicolumn{2}{|c|}{ Study population } & \multirow{4}{*}{$\begin{array}{l}\text { RR } 0.82 \\
(0.56 \text { to } 1.21)\end{array}$} & \multirow{4}{*}{$\begin{array}{l}416 \\
\text { ( } 2 \text { studies) }\end{array}$} & \multirow{4}{*}{$\begin{array}{l}\oplus \oplus \ominus \ominus \\
\text { Low } 1,2\end{array}$} & \multirow[t]{4}{*}{-} \\
\hline 章 & & 208 per 1000 & $\begin{array}{l}\mathbf{1 7 1} \text { per } \mathbf{1 0 0 0} \\
\text { (116 to } 252)\end{array}$ & & & & \\
\hline סृ & & \multicolumn{2}{|c|}{ Medium risk population } & & & & \\
\hline 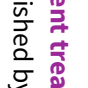 & & 156 per 1000 & $\begin{array}{l}\mathbf{1 2 8} \text { per } \mathbf{1 0 0 0} \\
\text { (87 to } 189)\end{array}$ & & & & \\
\hline 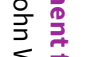 & \multirow{4}{*}{$\begin{array}{l}\text { Participant level outcomes: } 3 \text {. } \\
\text { Social functioning: homeless by } \\
11 \text { to } 12 \text { months }\end{array}$} & \multicolumn{2}{|c|}{ Study population } & \multirow{4}{*}{$\begin{array}{l}\text { RR } 0.67 \\
(0.39 \text { to } 1.15)\end{array}$} & \multirow{4}{*}{$\begin{array}{l}416 \\
\text { ( } 2 \text { studies) }\end{array}$} & \multirow{4}{*}{$\begin{array}{l}\oplus \oplus \ominus \ominus \\
\text { Low } 1,2\end{array}$} & \multirow[t]{4}{*}{-} \\
\hline 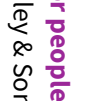 & & 134 per 1000 & $\begin{array}{l}\mathbf{9 0} \text { per } 1000 \\
(52 \text { to } 154)\end{array}$ & & & & \\
\hline $\overrightarrow{\underline{2}}$ & & \multicolumn{2}{|c|}{ Medium risk population } & & & & \\
\hline 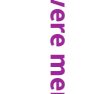 & & 145 per 1000 & $\begin{array}{l}\mathbf{9 7} \text { per } \mathbf{1 0 0 0} \\
\text { (57 to } 167)\end{array}$ & & & & \\
\hline$\frac{2}{2}$ & \multirow{4}{*}{$\begin{array}{l}\text { Participant level outcomes: } 5 \text {. } \\
\text { Quality of life: victimisation by } \\
11 \text { to } 12 \text { months }\end{array}$} & \multicolumn{2}{|c|}{ Study population } & \multirow{4}{*}{$\begin{array}{l}\text { RR } 0.5 \\
(0.31 \text { to } 0.8)\end{array}$} & \multirow{4}{*}{$\begin{array}{l}264 \\
\text { (1 study) }\end{array}$} & \multirow{4}{*}{$\begin{array}{l}\oplus \oplus \odot \odot \\
\text { Low } 1,3\end{array}$} & \multirow[t]{4}{*}{-} \\
\hline$\frac{\frac{0}{0}}{\frac{0}{0}}$ & & 311 per 1000 & $\begin{array}{l}\mathbf{1 5 6} \text { per } \mathbf{1 0 0 0} \\
\text { (96 to } 249 \text { ) }\end{array}$ & & & & \\
\hline$\sum^{\overline{0}}$ & & \multicolumn{2}{|c|}{ Medium risk population } & & & & \\
\hline & & 311 per 1000 & $\begin{array}{l}\mathbf{1 5 6} \text { per } 1000 \\
\text { (96 to } 249 \text { ) }\end{array}$ & & & & \\
\hline & \multirow{2}{*}{$\begin{array}{l}\text { Participant level outcomes: } 6 \text {. } \\
\text { Satisfaction with care/adverse } \\
\text { events: perceived coercion by } 11 \\
\text { to } 12 \text { months }\end{array}$} & \multicolumn{2}{|c|}{ Study population } & \multirow{2}{*}{$\begin{array}{l}\text { RR } 1.36 \\
\text { (0.97 to } 1.89)\end{array}$} & \multirow{2}{*}{$\begin{array}{l}416 \\
\text { ( } 2 \text { studies) }\end{array}$} & \multirow{2}{*}{$\begin{array}{l}\oplus \oplus \ominus \ominus \\
\text { Low } 1,2\end{array}$} & \multirow[t]{2}{*}{-} \\
\hline & & 218 per 1000 & $\begin{array}{l}\mathbf{2 9 6} \text { per } \mathbf{1 0 0 0} \\
\text { ( } 211 \text { to } 412 \text { ) }\end{array}$ & & & & \\
\hline
\end{tabular}

Participant level outcomes: 2. sted/picked up by police for

Medium risk population

128 per 1000

to 189

Participant level outcomes: 3 .

Social functioning: homeless by

90 per 1000

RR 0.67

$\oplus \oplus \ominus \ominus$

11 to 12 months

Medium risk population

145 per $1000 \quad 97$ per 1000

(57 to 167)

Participant level outcomes: 5.

Quality of life: victimisation by

11 to 12 months

156 per 1000

RR 0.5

264

$\oplus \oplus \ominus \ominus$

Medium risk population

311 per $1000 \quad 156$ per 1000

Study population

RR 1.36

416

218 per 100

296 per 1000

events: perceived coercion by 11

(18) 1000 


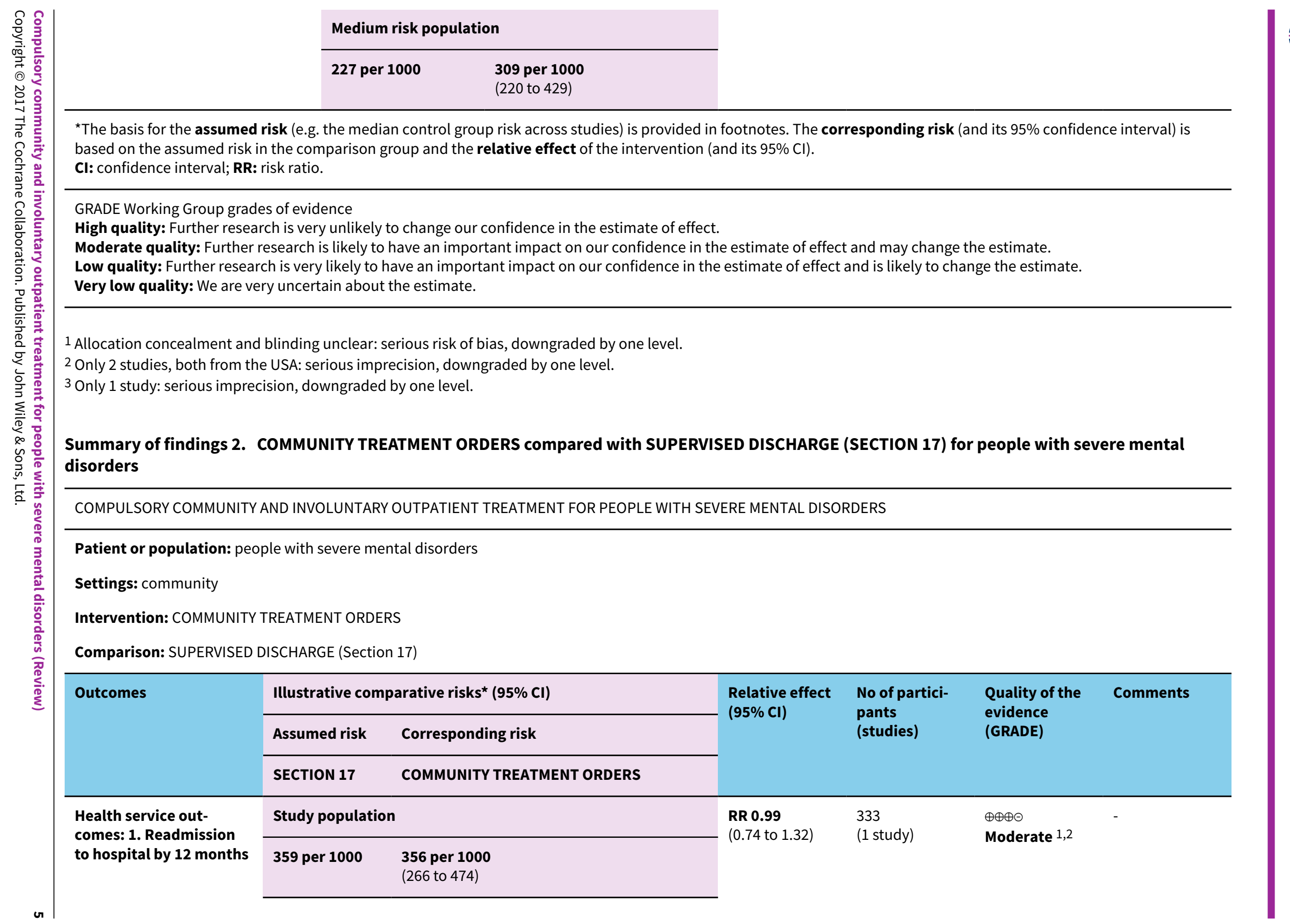




\begin{tabular}{|c|c|c|c|c|c|c|}
\hline$\frac{0}{3}$ & Moderate risl & pulation & & & & \\
\hline 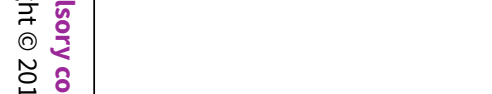 & 359 per 1000 & $\begin{array}{l}\mathbf{3 5 5} \text { per } 1000 \\
\text { (266 to } 474)\end{array}$ & & & & \\
\hline $\begin{array}{l}\text { Health service out- } \\
\text { comes: } 2 \text {. Hospital bed- } \\
\text { days by } 12 \text { months }\end{array}$ & - & $\begin{array}{l}\text { The mean health service outcomes: } 2 \text {. total } \\
\text { duration of psychiatric hospital stays over } 12 \\
\text { months in the intervention groups was } \\
\text { 8.7 lower } \\
\text { (30.88 lower to } 13.48 \text { higher) }\end{array}$ & - & $\begin{array}{l}333 \\
\text { (1 study) }\end{array}$ & $\begin{array}{l}\oplus \oplus \oplus \ominus \\
\text { Moderate 1,2 }\end{array}$ & - \\
\hline $\begin{array}{l}\text { Health service out- } \\
\text { comes: } 3 \text {. Number of } \\
\text { readmissions by } 12 \\
\text { months }\end{array}$ & - & $\begin{array}{l}\text { The mean health service outcomes: } 3 \text {. num- } \\
\text { ber of readmissions by } 12 \text { months in the inter- } \\
\text { vention groups was } \\
\mathbf{0 . 2} \text { lower } \\
\text { ( } 0.45 \text { lower to } 0.05 \text { higher) }\end{array}$ & - & $\begin{array}{l}119 \\
\text { (1 study) }\end{array}$ & $\begin{array}{l}\oplus \oplus \oplus \ominus \\
\text { Moderate 1,2 }\end{array}$ & - \\
\hline Health service out- & Study popula & & RR 0.56 & & $\oplus \oplus \oplus \odot$ & - \\
\hline $\begin{array}{l}\text { multiple readmissions } \\
\text { by } 12 \text { months }\end{array}$ & 108 per 1000 & $\begin{array}{l}60 \text { per } 1000 \\
(29 \text { to } 126)\end{array}$ & & & & \\
\hline$\sum_{\sum}^{\frac{\hbar}{0}}$ & Moderate risI & pulation & & & & \\
\hline$?_{\substack{0 \\
0}}^{0}$ & 108 per 1000 & $\begin{array}{l}60 \text { per } 1000 \\
(29 \text { to } 126)\end{array}$ & & & & \\
\hline $\begin{array}{l}\text { Health service out- } \\
\text { comes: } 5 \text {. Days in com- } \\
\text { munity to first admission } \\
\text { by } 12 \text { months }\end{array}$ & - & $\begin{array}{l}\text { The mean days in community to } 1 \text { st admis- } \\
\text { sion in the intervention groups was } \\
\mathbf{5} \text { higher } \\
\text { ( } 21.74 \text { lower to } 31.74 \text { higher) }\end{array}$ & - & $\begin{array}{l}333 \\
\text { (1 study) }\end{array}$ & $\begin{array}{l}\oplus \oplus \oplus \ominus \\
\text { Moderate 1,2 }\end{array}$ & - \\
\hline $\begin{array}{l}\text { Participant level out- } \\
\text { comes: } 1 \text {. Mental state - } \\
\text { psychiatric symptoms at } \\
12 \text { months (BPRS) }\end{array}$ & - & $\begin{array}{l}\text { The mean patierticipant level outcomes: } \\
\text { BPRS in the intervention groups was } \\
\text { 0.1 lower } \\
\text { (3.17 lower to } 2.97 \text { higher) }\end{array}$ & - & $\begin{array}{l}234 \\
\text { (1 study) }\end{array}$ & $\begin{array}{l}\oplus \oplus \oplus \ominus \\
\text { Moderate 1,2 }\end{array}$ & \\
\hline $\begin{array}{l}\text { Participant level out- } \\
\text { comes: } 3 \text {. Satisfaction } \\
\text { with care: perceived co- } \\
\text { ercion at } 11 \text { - } 12 \text { months }\end{array}$ & - & $\begin{array}{l}\text { The mean participant level outcomes: Satis- } \\
\text { faction with care: perceived coercion inter- } \\
\text { vention groups was } \\
\text { 0.5 lower } \\
\text { (1.71 lower to } 0.71 \text { higher) }\end{array}$ & - & $\begin{array}{l}182 \\
\text { (1 study) }\end{array}$ & $\begin{array}{l}\oplus \oplus \oplus \ominus \\
\text { Moderate } 1,2\end{array}$ & \\
\hline
\end{tabular}




\begin{tabular}{|c|c|c|c|c|c|c|}
\hline & \multicolumn{6}{|c|}{$\begin{array}{l}\text { Other pre-stated participant level outcomes of interest: Social functioning: trouble with police, homeless; Quality of life: victimisation; not re- } \\
\text { ported }\end{array}$} \\
\hline \multicolumn{7}{|c|}{$\begin{array}{l}\text { *The basis for the assumed risk (e.g. the median control group risk across studies) is provided in footnotes. The corresponding risk (and its } 95 \% \text { confidence interval) is } \\
\text { based on the assumed risk in the comparison group and the relative effect of the intervention (and its } 95 \% \mathrm{CI} \text { ). } \\
\text { BPRS: Brief Psychiatric Rating Scale; Cl: confidence interval; GAF: Global Assessment of Functioning Scale; RR: risk ratio. }\end{array}$} \\
\hline \multicolumn{7}{|c|}{$\begin{array}{l}\text { GRADE Working Group grades of evidence } \\
\text { High quality: Further research is very unlikely to change our confidence in the estimate of effect. } \\
\text { Moderate quality: Further research is likely to have an important impact on our confidence in the estimate of effect and may change the estimate. } \\
\text { Low quality: Further research is very likely to have an important impact on our confidence in the estimate of effect and is likely to change the estimate. } \\
\text { Very low quality: We are very uncertain about the estimate. }\end{array}$} \\
\hline \multicolumn{7}{|c|}{$\begin{array}{l}1 \text { Forty people ( } 25 \%) \text { allocated to Section } 17 \text { were subsequently placed on a CTO during the study. } \\
235 \text { people randomised to CTOs (22\%) did not actually receive the intervention. } \\
3 \text { No adverse events reported. }\end{array}$} \\
\hline \multicolumn{7}{|c|}{ COMPULSORY COMMUNITY AND INVOLUNTARY OUTPATIENT TREATMENT FOR PEOPLE WITH SEVERE MENTAL DISORDERS } \\
\hline \multicolumn{7}{|c|}{$\begin{array}{l}\text { Patient or population: people with severe mental disorders } \\
\text { Settings: community } \\
\text { Intervention: COMPULSORY COMMUNITY TREATMENT } \\
\text { Comparison: STANDARD CARE }\end{array}$} \\
\hline \multirow[t]{3}{*}{ Outcomes } & \multicolumn{2}{|c|}{ Illustrative comparative risks* $(95 \% \mathrm{Cl})$} & \multirow{3}{*}{$\begin{array}{l}\text { Relative effect } \\
(95 \% \mathrm{Cl})\end{array}$} & \multirow{3}{*}{$\begin{array}{l}\text { No of partici- } \\
\text { pants } \\
\text { (studies) }\end{array}$} & \multirow{3}{*}{$\begin{array}{l}\text { Quality of the } \\
\text { evidence } \\
\text { (GRADE) }\end{array}$} & \multirow[t]{2}{*}{ Comments } \\
\hline & Assumed risk & Corresponding risk & & & & \\
\hline & $\begin{array}{l}\text { STANDARD } \\
\text { CARE }\end{array}$ & COMPULSORY COMMUNITY TREATMENT & & & & \\
\hline \multirow{3}{*}{$\begin{array}{l}\text { Health service outcomes: } \\
\text { 1. Readmission to hospital } \\
\text { by } 11 \text { to } 12 \text { months }\end{array}$} & \multicolumn{2}{|c|}{ Study population } & \multirow{3}{*}{$\begin{array}{l}\text { RR } 0.98 \\
(0.83 \text { to } 1.17)\end{array}$} & \multirow{3}{*}{$\begin{array}{l}749 \\
(3)\end{array}$} & \multirow{3}{*}{$\begin{array}{l}\oplus \oplus \oplus \odot \\
\text { Moderate } 1,2\end{array}$} & \multirow[t]{2}{*}{-} \\
\hline & 415 per 1000 & $\begin{array}{l}406 \text { per } 1000 \\
\text { (344 to } 485)\end{array}$ & & & & \\
\hline & Moderate & & & & & \\
\hline
\end{tabular}




\begin{tabular}{|c|c|c|c|c|c|c|}
\hline \multirow{2}{*}{ 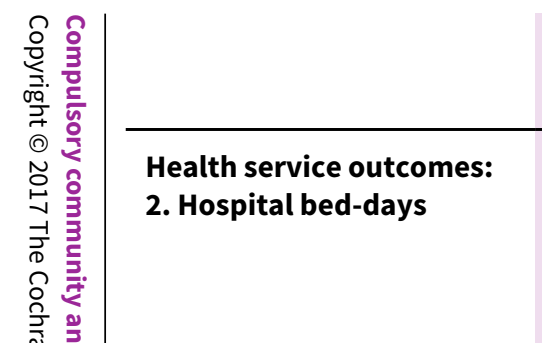 } & \multirow{2}{*}{\multicolumn{2}{|c|}{ 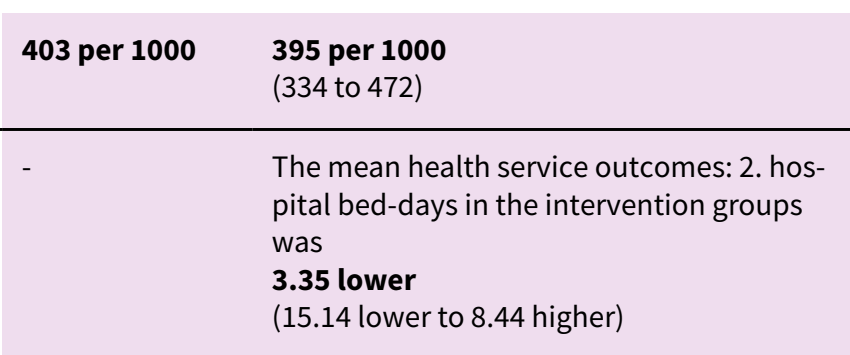 }} & \multirow{2}{*}{-} & \multirow{2}{*}{$\begin{array}{l} \\
597 \\
(2)\end{array}$} & \multirow[b]{2}{*}{$\begin{array}{l}\oplus \oplus \oplus \odot \\
\text { Moderate 1,2 }\end{array}$} & \multirow[b]{2}{*}{-} \\
\hline & & & & & & \\
\hline \multirow{4}{*}{$\begin{array}{l}\text { Health service outcomes: } \\
\text { 3. Number with multi- } \\
\text { ple readmissions by } 12 \\
\text { months }\end{array}$} & \multicolumn{2}{|c|}{ Study population } & \multirow{4}{*}{$\begin{array}{l}\text { RR } 1.0 \\
\text { (0.6 to } 1.66)\end{array}$} & \multirow{4}{*}{$\begin{array}{l}485 \\
(2)\end{array}$} & \multirow{4}{*}{$\begin{array}{l}\oplus \oplus \oplus \odot \\
\text { Moderate } 1,2\end{array}$} & \multirow[t]{4}{*}{-} \\
\hline & 111 per 1000 & $\begin{array}{l}111 \text { per } 1000 \\
(67 \text { to } 184)\end{array}$ & & & & \\
\hline & \multicolumn{2}{|l|}{ Moderate } & & & & \\
\hline & 114 per 1000 & $\begin{array}{l}114 \text { per } 1000 \\
(68 \text { to } 189)\end{array}$ & & & & \\
\hline $\begin{array}{l}\text { Participant level out- } \\
\text { comes: } 1 \text {. Global state: } \\
\text { GAF at } 12 \text { months }\end{array}$ & - & $\begin{array}{l}\text { The mean participant level outcomes: glob- } \\
\text { al state: GAF at } 12 \text { months in the interven- } \\
\text { tion groups was } \\
\text { 1.36 lower } \\
\text { (4.07 lower to } 1.35 \text { higher) }\end{array}$ & - & $\begin{array}{l}335 \\
(2)\end{array}$ & $\begin{array}{l}\oplus \oplus \oplus \odot \\
\text { Moderate 1,2 }\end{array}$ & \\
\hline \multirow{4}{*}{$\begin{array}{l}\text { Participant level out- } \\
\text { comes: } 2 \text {. Satisfaction } \\
\text { with care: perceived coer- } \\
\text { cion or leverage at } 11 \text { to } 12 \\
\text { months }\end{array}$} & \multicolumn{2}{|c|}{ Study population } & \multirow{4}{*}{$\begin{array}{l}\text { RR } 1.3 \\
(0.98 \text { to } 1.71)\end{array}$} & \multirow{4}{*}{$\begin{array}{l}645 \\
(3)\end{array}$} & \multirow{4}{*}{$\begin{array}{l}\oplus \oplus \oplus \odot \\
\text { Moderate } 1,2\end{array}$} & - \\
\hline & 212 per 1000 & $\begin{array}{l}\mathbf{2 7 5} \text { per } 1000 \\
\text { (207 to } 362)\end{array}$ & & & & \\
\hline & \multicolumn{2}{|l|}{ Moderate } & & & & \\
\hline & 200 per 1000 & $\begin{array}{l}\mathbf{2 6 0} \text { per } 1000 \\
(196 \text { to } 342)\end{array}$ & & & & \\
\hline & \multicolumn{6}{|c|}{$\begin{array}{l}\text { Other pre-stated participant level outcomes of interest: Social functioning: trouble with police, homeless; Quality of life: victimisation; not } \\
\text { reported }\end{array}$} \\
\hline $\begin{array}{l}{ }^{*} \text { The basis for the assumed } \mathbf{r} \\
\text { based on the assumed risk in } \\
\text { Cl: confidence interval; GAF: }\end{array}$ & $\begin{array}{l}\text { sk (e.g. the med } \\
\text { the comparison } \\
\text { jlobal Assessme }\end{array}$ & $\begin{array}{l}\text { ontrol group risk across studies) is provided i } \\
\text { ip and the relative effect of the intervention } \\
\text { f Functioning Scale; RR: risk ratio. }\end{array}$ & $\begin{array}{l}\text { footnotes. The } \\
\text { nd its } 95 \% \mathrm{Cl}) \text {. }\end{array}$ & & nd its $95 \%$ confic & e interval) is \\
\hline
\end{tabular}

GRADE Working Group grades of evidence

High quality: Further research is very unlikely to change our confidence in the estimate of effect.

Moderate quality: Further research is likely to have an important impact on our confidence in the estimate of effect and may change the estimate. 


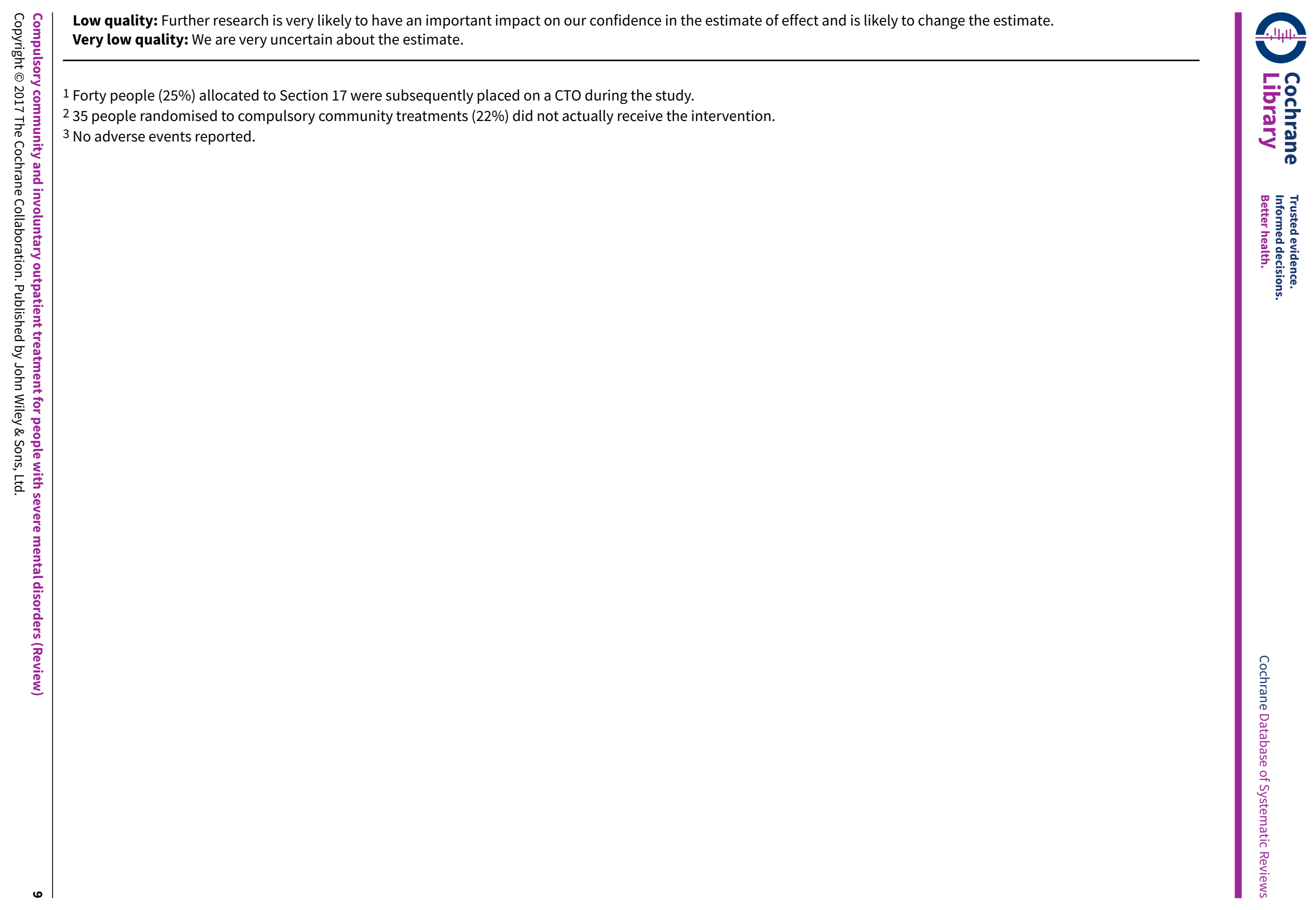




\section{B A C K G R O U N D}

\section{Description of the condition}

Compulsory treatment for people with severe mental disorders in the community is used in many countries, including Australia, Canada, Israel, New Zealand, the UK, and the USA (Kanter 1995; Torrey 1995; Light 2012; Gray 2016). In the USA, the majority of states have some form of compulsory community treatment (CTT) (Torrey 1995), and there are similar provisions in Australia, Canada and New Zealand (Dedman 1990; Mulvany 1993; Torrey 1995; Gray 2016). Early initiatives in the UK included extended leave for people leaving hospital and a 'supervision register' (Sensky 1991; Holloway 1996), with the more recent implementation of legislation for CCT in Scotland, England and Wales (Lawton-Smith 2008; Woolley 2010).

Supporters of this approach suggest that it is less restrictive to compulsorily treat someone in the community than to subject them to repeated hospital admissions (Pinfold 2001a). They also argue that it is effective in bringing stability to the lives of people with severe mental illness (SMI) (O'Reilly 2000). Opponents of CCT fear treatment and support will be replaced by a greater emphasis on control, restraint and threat (Pinfold 2001a). They argue that compulsion may be used as an alternative to intensive case management or assertive community treatment, which may be all that is needed (Swartz 1995). Opponents also argue that CCT may adversely affect the therapeutic alliance between healthcare professionals and patients and drive people with SMIs away from services (Pinfold 2001a), although the available evidence suggests that this does not happen (O'Reilly 2005; Kisely 2013a).

\section{Description of the intervention}

Extended leave or supervised discharge is applied at the time of discharge from compulsory inpatient treatment. These forms of CCT are used in Canada (Gray 2016), the UK (Sensky 1991), and New Hampshire, USA (Torrey 1995). They give mental health professionals the right to return a person to hospital against their wishes if they do not comply with treatment.

Community treatment orders (CTOs) are used in Australia (Vaughan 2000; Light 2012), Canada (Gray 2016), and other international jurisdictions that give mental health professionals the ability to place a person on an order, whether they are in hospital or not (Gray 2010). This is in contrast to extended leave or supervised discharge, which only applies to people who are being discharged from inpatient care (Gray 2016). CTOs are designed to divert people from possibly having to be admitted as inpatients. In addition, unlike leave, the person may not have to meet the same criteria for treatment as an inpatient (Gray 2016). Involuntary outpatient treatment or commitment is the preferred term in the USA and covers court-ordered community treatment. In this case, a judge, not a healthcare professional, decides on the appropriateness of the order.

The range of different interventions and ways of reporting frequency of use make it difficult to estimate how often CCT is used. The situation is complicated by the fact that in some jurisdictions, different forms of community treatment such as extended release and involuntary outpatient treatment exist in parallel. Use varies widely across jurisdictions with the highest rates being recorded in the Australian state of Victoria with a prevalence of 98.8 per 100,000 population. New Zealand also has a high rate of CTO at 84 per 100,000 (O'Brien 2014). By contrast, in the USA, involuntary outpatient treatment was only used in approximately three per 100,000 of the general population, $9.8 \%$ of new outpatient admissions and $7.1 \%$ of continuing outpatients (Ridgely 2001). However, even within the USA, the use of involuntary outpatient treatment varied. For instance, survey data from respondents in 13 states and the District of Columbia indicated they used it commonly or very commonly, while in a further 21 states, use was rare or very rare. Some of this variation may be explained by using alternative provisions such as extended release (Torrey 1995).

\section{How the intervention might work}

Many clinicians believe that CCT works by ensuring that people are adherent to their medication regimens for sufficient time to allow stability to develop in their lives (Manning 2011). It has also been suggested that CCT works by "persuading the persuadable" (Pinfold 2001b). A person may agree to follow-up with clinicians and take the recommended treatment when these requirements have legal imprimatur. It has been suggested that such compliance is particularly likely when a person is brought to court and the order comes directly from a judge: the so-called "black robe effect" (Tsai 2017). Other clinicians suggest that CCT commits the clinicians as much as it does patients (Manning 2011). They propose that much of the improvement on CCT is the result of increased expectations on clinicians to try to engage people and ensue that they follow the legal treatment order. Furthermore, clinical services may feel obliged to prioritise people on CCT because of the legal order. Clearly, CCT is a complex intervention. The form of CCT is determined by legal statutes that vary among jurisdictions on key issues such as the type of person deemed eligible and the options available to clinicians to ensure treatment adherence. CCT requires the cooperation of not only patients but of multiple other participants including: clinicians; substitute decision makers; community agencies; police and courts or review boards. The success or failure of CCT depends on the interaction of these participants each of whom must appropriately implement their part of the process.

Importantly, there are also variations between jurisdictions in how CCT is implemented. Involuntary outpatient treatment in many US states does not include the power to give medication forcibly in a community setting, but CTOs in Australasia do.

\section{Why it is important to do this review}

Mirror-image studies use people as their own controls and consistently report reduced use of admission and other improved outcomes after placement on a CTO. Many of these have been large studies (Swartz 2010), and some have included all people on CTOs within a jurisdiction (Fernandez 1990a; Taylor 2016). Because mirror-image studies do not use a control group, they do not take into account the possibility that participants were recruited when particularly disturbed and that subsequent reductions in hospital use may simply reflect regression to the mean. Studies that used matched controls have reported more mixed results (Maughan 2014). This may in part reflect the difficulty in retrospectively matching important characteristics, such as insight or refusal to accept treatment voluntarily, that often determine a clinician's decision to use a СTO. However, even when studies have used control groups, it is difficult to know whether to attribute any improvement to CCT, or to the non-specific effects of increased 
contact with healthcare professionals (Swartz 1995; Torrey 1995; Geller 1998).

In summary, it remains unclear whether CCT can improve participant outcome or reduce health service use. Given the widespread use of such powers in Australasia, Israel, North America and the UK, it is important to assess the benefit and potential harms of this type of legislation.

\section{OB JECTIVES}

To examine the effectiveness of compulsory community treatment (CCT) for people with severe mental illness (SMI)

1. To compare compulsory community treatment of any form with standard voluntary care.

2. To compare different types of compulsory treatment (see Types of Compulsory community treatment 1.1 in Types of interventions).

\section{METHODS}

\section{Criteria for considering studies for this review}

\section{Types of studies}

We considered all relevant randomised controlled trials (RCTs). We excluded quasi-randomised studies, such as those allocating by using alternate days of the week.

\section{Types of participants}

We included trials of adults with SMIs (mainly schizophrenia and schizophrenia-like disorders, bipolar disorder or depression with psychotic features), however diagnosed, who were managed in a community setting. Substance abuse was not considered to be a severe mental disorder in its own right. However, studies were eligible if they dealt with people with both diagnoses (i.e. people with SMI plus substance abuse).

\section{Types of interventions}

\section{Comparison I: compulsory community treatment versus entirely voluntary care}

\subsection{Compulsory community treatment}

For an intervention to be accepted as $\mathrm{CCT}$, it had to be described in the trial using the following terms: СTO, involuntary outpatient treatment, involuntary outpatient commitment (OPC), supervised community treatment, extended leave, extended release or supervised discharge.

\section{2. entirely voluntary care}

The care that a person would normally receive had they not been included in the research trial, as long as it did not involve CCT in any form.

\section{Comparison II: community treatment orders versus supervised discharge}

Two different types of compulsory treatment, CTOs and supervised discharge, however brief (see Types of interventions).
3. Comparison III: community treatment orders versus standard care (encompassing both voluntary care and supervised discharge)

In pragmatic clinical trials, it may not be possible to make a clear determination on whether standard care bore a closer resemblance to comparison I (CCT versus entirely voluntary care) or II (CTOs versus supervised discharge). In line with previous work, we therefore combined studies from both comparisons if there was uncertainty about the exact nature of the control condition (Kisely 2014a).

\section{Types of outcome measures}

We did not plan to report highly specific outcomes (e.g. 'sense of safety') because multiple testing of sub-components of outcome scales carries a risk of type I errors (finding a difference when none was present). Outcomes relating to the process of the interventions themselves, such as number of outpatient visits, were not reported (Wagner 2003).

In the original protocol for this study we stated we would group outcomes into short term (within 12 weeks of the start of therapy), medium term (between 13 and 24 weeks after the beginning of therapy) and long term (more than 24 weeks after the start of therapy). Only the Swartz 1999 study reported results of intermediate periods of follow-up, and these were not from their RCT. We have therefore only been able to report outcomes in the medium term (11 to 12 months of follow-up). Only one study reported on outcomes at 36 months' follow-up (Burns 2013)

\section{Primary outcomes}

\section{Health service contact and utilisation.}

1.1. Admission/readmission to hospital.

1.2. Bed-days spent in hospital.

\section{Social functioning.}

2.1. Specific - imprisonment, police contact and arrests.

\section{Secondary outcomes}

\section{Health service contact and utilisation.}

1.1. Remaining in contact with psychiatric services - leaving the study early.

1.2. Number with multiple readmissions - see Differences between protocol and review

1.3. Compliance with medication

\section{Social functioning.}

2.1. General.

2.2. Specific - employment.

2.3. Specific - accommodation status.

\section{Quality of life.}

5.1. General.

5.2. Self-esteem.

\section{Satisfaction.}

6.1. Number of needs for care.

6.2. Patierticipant satisfaction. 
6.3. Carer satisfaction.

6.4. Perceived coercion.

\section{Adverse events.}

7.1. Mortality.

\section{Economic outcomes.}

\section{'Summary of findings' table}

We used the GRADE approach to interpret findings (Schünemann 2008) and used the GRADE profiler to import data from Review Manager 5 (RevMan) to create 'Summary of findings' tables. These tables provide outcome-specific information concerning the overall quality of evidence from each included study in the comparison, the magnitude of effect of the interventions examined and the sum of available data on all outcomes we rated as important to patient care and decision making. We have been able to add more outcomes to the table and selected the following main outcomes for inclusion in the 'Summary of findings' tables.

\section{Health service outcomes.}

1.1. Admission/readmission to hospital.

1.2. Bed-days in hospital.

1.3. Compliance with treatment.

1.4. Number with multiple readmissions by 12 months.

1.5. Days in community before first admission.

2. Participant level outcomes.

2.1. Mental state

2.2. Global state

2.3. Social functioning: trouble with police, homeless.

2.4. Quality of life: victimisation.

2.5. Satisfaction with care; perceived coercion.

\section{Search methods for identification of studies}

\section{Electronic searches}

\section{Cochrane Schizophrenia Group's Study-Based Register of Trials}

On 3 June 2016, the Information Specialist searched the register using the following search strategy which has been developed based on literature review and consultation with the authors of the review:

(*Involuntary ${ }^{\star} \quad$ OR *Treatment Order ${ }^{\star} \quad$ OR *Outpatient Commitment ${ }^{\star}$ ) in Intervention Field of STUDY

In such study-based register, searching the major concept retrieves all the synonyms and relevant studies because all the studies have already been organised based on their interventions and linked to the relevant topics.

This register is compiled by systematic searches of major resources (including MEDLINE, Embase, AMED, BIOSIS, 95\% CINAHL, PsycINFO, PubMed, and registries of clinical trials) and their monthly updates, handsearches, grey literature and conference proceedings (see Group's Module). There is no language, date, document type, or publication status limitations for inclusion of records into the register.

For previous searches, see Appendix 1.

\section{Searching other resources}

\section{Reference searching}

We also inspected the references of all identified studies (including those rejected from the review).

\section{Personal contact}

We contacted the first author of each included study and known experts who had published reviews in the field for information regarding unpublished trials and extra data on the published trials.

\section{Data collection and analysis}

For previous data collection and analysis, see Appendix 2.

\section{Selection of studies}

Two review authors (SK, LAC) independently inspected the citations identified from the search. They identified potentially relevant abstracts, ordered full papers, and reassessed these for inclusion and methodological quality. They discussed and reported any disagreement. Where the two reviewers disagreed about the inclusion of a study, we resolved by consensus, and consultation with a third reviewer if a dispute could not be resolved. Where resolution was not possible we contacted the author to obtain more information and clarification. In order to restrict selection bias, we printed out a list of all titles and abstracts excluding the author's names, institutions, and journal titles. We rejected the article if the title and abstract contained sufficient information to determine that the article did not meet the inclusion criteria. We kept a record of all rejected papers and the reasons for rejection.

For the 2013 and 2016 updates only a few citations were found during the searches, one review author (SK) independently inspected these citations from the electronic search and identified relevant abstracts. SK also inspected full articles of the abstracts meeting inclusion criteria.

\section{Data extraction and management}

\section{Extraction}

Two review authors (SK and LAC) independently extracted data from included studies. Again, we discussed any disagreement, documented our decisions and, if necessary, we contacted the authors of studies for clarification. Whenever possible we extracted data presented in graphs and figures but we only included such data if two review authors independently had the same result. We made attempts to contact authors through an open-ended request in order to obtain any missing information or for clarification whenever necessary. Where possible, we extracted data relevant to each component centre of multi-centre studies separately.

\section{Management}

\subsection{Forms}

We extracted data onto standard, simple forms. 


\subsection{Scale-derived data}

We included continuous data from rating scales only if:

1. the psychometric properties of the measuring instrument had been described in a peer-reviewed journal (Marshall 2000); and

2. the measuring instrument had not been written or modified by one of the trialists for that particular trial.

Ideally, the measuring instrument should have either been a selfreport or completed by an independent rater or relative (not the therapist). We realise that this is not often reported clearly; we have noted whether or not this is the case in Description of studies.

\subsection{Endpoint versus change data}

There are advantages of both endpoint and change data. Change data can remove a component of between-person variability from the analysis. However, calculation of change needs two assessments (baseline and endpoint), which can be difficult in unstable and difficult to measure conditions such as schizophrenia. We decided primarily to use endpoint data, and only use change data if endpoint data were not available. We combined endpoint and change data in the analysis as we used mean differences (MD) rather than standardised mean differences (SMD) throughout (Higgins 2011, Section 9.4.5.2).

\subsection{Skewed data}

Continuous data on clinical and social outcomes are often not normally distributed. To avoid the problem of applying parametric tests to non-parametric data, we aimed to apply the following standards to all data before inclusion:

1. standard deviations (SDs) and means were reported in the paper or obtainable from the authors;

2. when a scale starts from the finite number zero, the SD, when multiplied by two, is less than the mean (as otherwise the mean is unlikely to be an appropriate measure of the centre of the distribution (Altman 1996));

3. if a scale started from a positive value (such as the Positive and Negative Syndrome Scale (PANSS, Kay 1986), which can have values from 30 to 210), we planned to modify the calculation described above to take the scale starting point into account. In these cases, skew is present if $2 \mathrm{SD}>\left(\mathrm{S}-\mathrm{S}_{\mathrm{min}}\right)$, where $\mathrm{S}$ is the mean score and $S_{\min }$ is the minimum score.

Endpoint scores on scales often have a finite start and endpoint and these rules can be applied. We planned to enter skewed endpoint data from studies of fewer than 200 participants in additional tables rather than into an analysis. Skewed data pose less of a problem when looking at means if the sample size is large; we entered such endpoint data into syntheses.

When continuous data are presented on a scale that includes a possibility of negative values (such as change data), it is difficult to determine whether data are skewed or not. Therefore, we entered skewed change data into analyses regardless of size of study.

\subsection{Common measure}

To facilitate comparison between trials, we intended to convert variables that can be reported in different metrics, such as days in hospital (mean days per year, per week or per month) to a common metric (e.g. mean days per month).

\subsection{Conversion of continuous to binary}

Where possible, we converted outcome measures to binary data. This can be done by identifying cut-off points on rating scales and dividing participants accordingly into 'clinically improved' or 'not clinically improved'. It is generally assumed that if there is a $50 \%$ reduction in a scale-derived score such as the BPRS (Overall 1962) or the PANSS (Kay 1986), this could be considered as a clinically significant response (Leucht 2005a; Leucht 2005b). If data based on these thresholds were not available, we used the primary cut-off presented by the original authors.

\subsection{Direction of graphs}

Where possible, we entered data in such a way that the area to the left of the line of no effect indicated a favourable outcome for compulsory community and involuntary outpatient treatment. Where keeping to this made it impossible to avoid outcome titles with clumsy double-negatives (e.g. 'Not worsened'), we reported data where the left of the line indicates an unfavourable outcome. This was noted in the relevant graphs.

\section{Assessment of risk of bias in included studies}

Two review authors (SK and LAC) independently assessed risk of bias using the tool described in the Cochrane Handbook for Systematic Reviews of Interventions (Higgins 2008). This tool encourages consideration of how the sequence was generated, how allocation was concealed, the integrity of blinding at outcome, the completeness of outcome data, selective reporting and other biases. We would have excluded studies where allocation was clearly not concealed.

For the updates one review author (SK) worked independently to update the risk of bias using criteria described in the Cochrane Handbook for Systematic Reviews of Interventions (Higgins 2011). This new set of criteria is based on evidence of associations between overestimate of effect and high risk of bias of the article such as sequence generation, allocation concealment, blinding, incomplete outcome data and selective reporting.

Where inadequate details of randomisation and other characteristics of trials were provided, we contacted authors of the studies in order to obtain additional information.

We have noted the level of risk of bias in both the text of the review and in Summary of findings for the main comparison.

\section{Measures of treatment effect}

\section{Binary data}

For binary outcomes, we calculated a standard estimation of the risk ratio (RR) and its 95\% confidence interval $(\mathrm{Cl})$. It has been shown that RR is more intuitive (Boissel 1999) than odds ratios (OR) and that ORs tend to be interpreted as RR by clinicians (Deeks 2000). The number needed to treat for an additional beneficial outcome (NNTB) or harmful outcome (NNTH) is intuitively attractive to clinicians but needs to be interpreted with caution (Hutton 2009). For binary data presented in the 'Summary of findings' tables, where possible, we calculated illustrative comparative risks.

\section{Continuous data}

For continuous outcomes, we estimated MD between groups. We preferred not to calculate effect size measures (standardised mean 
difference). However, if scales of very considerable similarity were used, we presumed there was a small difference in measurement, calculated effect size, and transformed the effect back to the units of one or more of the specific instruments.

\section{Unit of analysis issues}

\section{Cluster trials}

Studies increasingly employ 'cluster randomisation' (such as randomisation by clinician or practice), but analysis and pooling of clustered data poses problems. Authors often fail to account for intraclass correlation in clustered studies, leading to a unit of analysis error (Divine 1992) whereby P values are spuriously low, $\mathrm{Cls}$ unduly narrow and statistical significance overestimated. This causes type I errors (Bland 1997; Gulliford 1999).

Cluster trials were eligible for inclusion; however, the three studies identified in our review were randomised by participant, not by clinician or practice. Had we included cluster trials, where clustering was not accounted for in primary studies, we planned to present data in a table, indicating the presence of a probable unit of analysis error. In subsequent versions of this review, and if relevant, we will seek to contact first authors of studies to obtain intraclass correlation coefficients (ICCs) for their clustered data and to adjust for this by using accepted methods (Gulliford 1999). Where clustering had been incorporated into the analysis of primary studies, we planned to present these data as if from a non-cluster randomised study, but adjust for the clustering effect.

We have sought statistical advice and have been advised that if the binary data are presented in a report, they should be divided by a 'design effect'. This is calculated using the mean number of participants per cluster $(\mathrm{m})$ and the ICC (design effect $=1+(\mathrm{m}-1)$ $\times$ ICC) (Donner 2002). If the ICC is not reported, we willassume it to be 0.1 (Ukoumunne 1999).

If cluster studies are appropriately analysed taking into account ICCS and relevant data documented in the report, data can be synthesised with other studies using the generic inverse variance technique.

\section{Cross-over trials}

A major concern of cross-over trials is the carry-over effect. It occurs if an effect (e.g. pharmacological, physiological or psychological) of the treatment in the first phase is carried over to the second phase. As a consequence, on entry to the second phase, the participants can differ systematically from their initial state despite a washout phase. For the same reason, cross-over trials are not appropriate if the condition of interest is unstable (Elbourne 2002). As both effects are very likely in SMI, had we included cross-over trials, we planned to use only the data of the first phase of any cross-over studies.

\section{Studies with multiple treatment groups}

If we had included any studies that involved more than two treatment arms, if relevant, we planned to present the additional treatment arms in comparisons. If data were binary, we would have added these and combined them within the two-by-two table. If data were continuous, we would have combined data following the formula in Section 7.7.3.8 (Combining groups) of the Cochrane Handbook for Systemic Reviews of Interventions (Higgins 2011). Where additional treatment arms were not relevant, we would not have presented these data.

\section{Dealing with missing data \\ 1. Overall loss of credibility}

At some degree of loss of follow-up, data must lose credibility (Xia 2009). We chose that, for any particular outcome, should more than $50 \%$ of data be unaccounted for, we would not reproduce these data or use them within analyses. However, if more than $50 \%$ of participants in one arm of a study were lost, but the total loss was less than $50 \%$, we addressed this within the 'Summary of findings' tables by downgrading quality. Finally, we also downgraded quality within the 'Summary of findings' tables should loss be 25\% to 50\% in total.

\section{Binary}

In the case where attrition for a binary outcome was between $0 \%$ and $50 \%$ and where these data were not clearly described, we presented data on a 'once-randomised-always-analyse' basis (an intention-to-treat analysis). Participants leaving the study early were all assumed to have the same rates of negative outcome as participants who completed, with the exception of the outcome of death and adverse effects. For these outcomes, the rate of participants who stay in the study - in that particular arm of the trial - were used for those who did not. We undertook a sensitivity analysis to test how prone the primary outcomes were to change when data only from people who completed the study to that point were compared to the intention-to-treat analysis using the above assumptions.

\section{Continuous}

\subsection{Attrition}

In the case where attrition for a continuous outcome was between $0 \%$ and $50 \%$, and data only from people who completed the study to that point were reported, we presented and used these data.

\subsection{Standard deviations}

If SDs were not reported, we first tried to obtain the missing values from the authors. If not available, where there were missing measures of variance for continuous data, but an exact standard error (SE) and Cls available for group means, and either a $\mathrm{P}$ value or $\mathrm{T}$ value available for differences in mean, we calculated them according to the rules described in the Cochrane Handbook for Systemic Reviews of Interventions (Higgins 2011): when only the SE was reported, we calculated SDs by the formula SD $=$ SE $\times$ square root (n). Sections 7.7.3 and 16.1.3 of the Cochrane Handbook for Systemic Reviews of Interventions present detailed formulae for estimating SDs from $\mathrm{P}$ values, $\mathrm{T}$ or $\mathrm{F}$ values, Cls, ranges or other statistics (Higgins 2011). If these formulae did not apply, we calculated the SDs according to a validated imputation method which is based on the SDs of the other included studies (Furukawa 2006). If the number of studies was very low, we imputed a missing SD from an alternative study with similar results. Although some of these imputation strategies can introduce error, the alternative was to exclude a given study's outcome and thus to lose information. We nevertheless examined the validity of the imputations in a sensitivity analysis excluding imputed values.

\subsection{Last observation carried forward}

We anticipated that some studies would employ the method of last observation carried forward (LOCF). As with all methods of imputation to deal with missing data, LOCF introduces uncertainty 
about the reliability of the results (Leucht 2007). Therefore, where LOCF data were used in the trial, if less than $50 \%$ of the data had been assumed, we intended to reproduce these data and indicate that they were the product of LOCF assumptions.

\section{Assessment of heterogeneity}

\section{Clinical heterogeneity}

We considered all included studies initially, without seeing comparison data, to judge clinical heterogeneity. We simply inspected all studies for clearly outlying people or situations which we had not predicted would arise. When such situations or participant groups arose, we fully discussed these.

\section{Methodological heterogeneity}

We considered all included studies initially, without seeing comparison data, to judge methodological heterogeneity. We simply inspected all studies for clearly outlying methods which we had not predicted would arise. When such methodological outliers arose, we fully discussed these.

\section{Statistical heterogeneity}

\subsection{Visual inspection}

We visually inspected graphs to investigate the possibility of statistical heterogeneity.

\subsection{Employing the $I^{2}$ statistic}

We investigated heterogeneity between studies by considering the $\mathrm{I}^{2}$ statistic alongside the $\mathrm{P}$ value of the $\mathrm{Chi}^{2}$ test. The $\mathrm{I}^{2}$ statistic provides an estimate of the percentage of inconsistency thought to be due to chance (Higgins 2003). The importance of the observed value of the $1^{2}$ statistic depends on the magnitude and direction of effects and on the strength of evidence for heterogeneity (e.g. $\mathrm{P}$ value from $\mathrm{Chi}^{2}$ test, or a $\mathrm{Cl}$ for the $\mathrm{I}^{2}$ statistic). An $\mathrm{I}^{2}$ statistic estimate of around $50 \%$ or greater accompanied by a statistically significant $\mathrm{Chi}^{2}$ statistic was interpreted as evidence of substantial levels of heterogeneity (Higgins 2011). When there were substantial levels of heterogeneity in the primary outcomes, we explored reasons for heterogeneity (Subgroup analysis and investigation of heterogeneity).

\section{Assessment of reporting biases}

Reporting biases arise when the dissemination of research findings is influenced by the nature and direction of results (Egger 1997). These are described in Section 10 of the Cochrane Handbook for Systemic Reviews of Interventions (Higgins 2011). We are aware that funnel plots may be useful in investigating reporting biases but are of limited power to detect small-study effects. Only three trials were included in this version of the review. We planned to use funnel plots for outcomes where there were 10 or more studies, or where all studies were of similar sizes. In other cases, where funnel plots are possible, we would have sought statistical advice in their interpretation.

\section{Data synthesis}

We understand that there is no closed argument for preference for use of fixed-effect or random-effects models. The random-effects method incorporates an assumption that the different studies are estimating different, yet related, intervention effects. This often seems to be true to us and the random-effects model takes into account differences between studies even if there is no statistically significant heterogeneity. However, there is a disadvantage to the random-effects model: it puts added weight onto small studies which often are the most biased ones. Depending on the direction of effect, these studies can either inflate or deflate the effect size. We chose the fixed-effect model for all but one of the analyses given the similarity of participants and interventions in each comparison. The exception was for quality of life in Comparison I (CCT versus entirely voluntary care) and multiple readmissions in Comparison III (CTOs versus standard care encompassing both voluntary care and supervised discharge) (see below) where we used the randomeffects model. However, the reader is able to choose to inspect the data using the random-effects model.

\section{Subgroup analysis and investigation of heterogeneity}

\section{Subgroup analyses - only primary outcomes}

\subsection{Clinical state, stage or problem}

We investigated the effect of different types of intervention (e.g. CTOs, involuntary outpatient treatment, involuntary OPC or supervised discharge).

\section{Investigation of heterogeneity}

If inconsistency was high, we reported this. First, we investigated whether data had been entered correctly. Second, if data were correct, we visually inspected the graph and successively removed outlying studies to see if homogeneity was restored. For this review, we had decided that should this occur with data contributing to the summary finding of no more than around $10 \%$ of the total weighting, we would present data. If not, then we would not pool data but would discuss issues. We know of no supporting research for this 10\% cut-off, but we used prediction intervals as an alternative to this unsatisfactory state.

\section{Sensitivity analysis}

We applied all sensitivity analyses to the primary outcomes of this review.

\section{Implication of randomisation}

We aimed to include trials in a sensitivity analysis if they were described in some way so as to imply randomisation. For the primary outcomes, we included these studies and if there was no substantive difference when the implied randomised studies were added to those with a better description of randomisation, we entered all data from these studies.

\section{Assumptions for lost binary data}

Where assumptions had to be made regarding people lost to followup (see Dealing with missing data), we compared the findings of the primary outcomes when we used our assumption/s and when we used data only from people who completed the study to that point. If there was a substantial difference, we reported results and discussed them but continued to employ our assumption.

Where assumptions had to be made regarding missing SDs data (see Dealing with missing data), we compared the findings of the primary outcomes when we used our assumption/s and when we used data only from people who completed the study to that point. We undertook a sensitivity analysis to test how prone results were to change when completer-only data were compared 
to the imputed data using the above assumption. If there was a substantial difference, we reported results and discussed them but continued to employ our assumption

\section{Risk of bias}

We analysed the effects of excluding trials that were at high risk of bias across one or more of the domains of randomisation (see also Assessment of risk of bias in included studies) for the meta-analysis of the primary outcome. If the exclusion of trials at high risk of bias did not substantially alter the direction of effect or the precision of the effect estimates, then we included data from these trials in the analysis.

\section{Imputed values}

We also planned to undertake a sensitivity analysis to assess the effects of including data from trials where we used imputed values for ICC in calculating the design effect in cluster randomised trials but this was not required for the current version of the review.

If we noted substantial differences in the direction or precision of effect estimates in any of the sensitivity analyses listed above, we did not pool data from the excluded trials with the other trials contributing to the outcome, but presented them separately.

\section{RES U L T S}

\section{Description of studies}

See Characteristics of included studies and Characteristics of excluded studies tables.

\section{Results of the search}

Figure 1 gives details of our search results. We found 74 papers that were potentially relevant in our original 2003 search. Later searches in 2013, 2014 and 2016 identified nine further possible publications. Of these, we excluded 66 articles because they did not meet our inclusion criteria, lacked relevant data or were evaluating different types of treatment such as joint crisis plans. This left 18 articles covering three studies (Figure 1). Two of the studies were identified in the original search of 2003 (Swartz 1999; Steadman 2001) and the third in the 2014 search (Burns 2013). 
Figure 1. Study flow diagram.

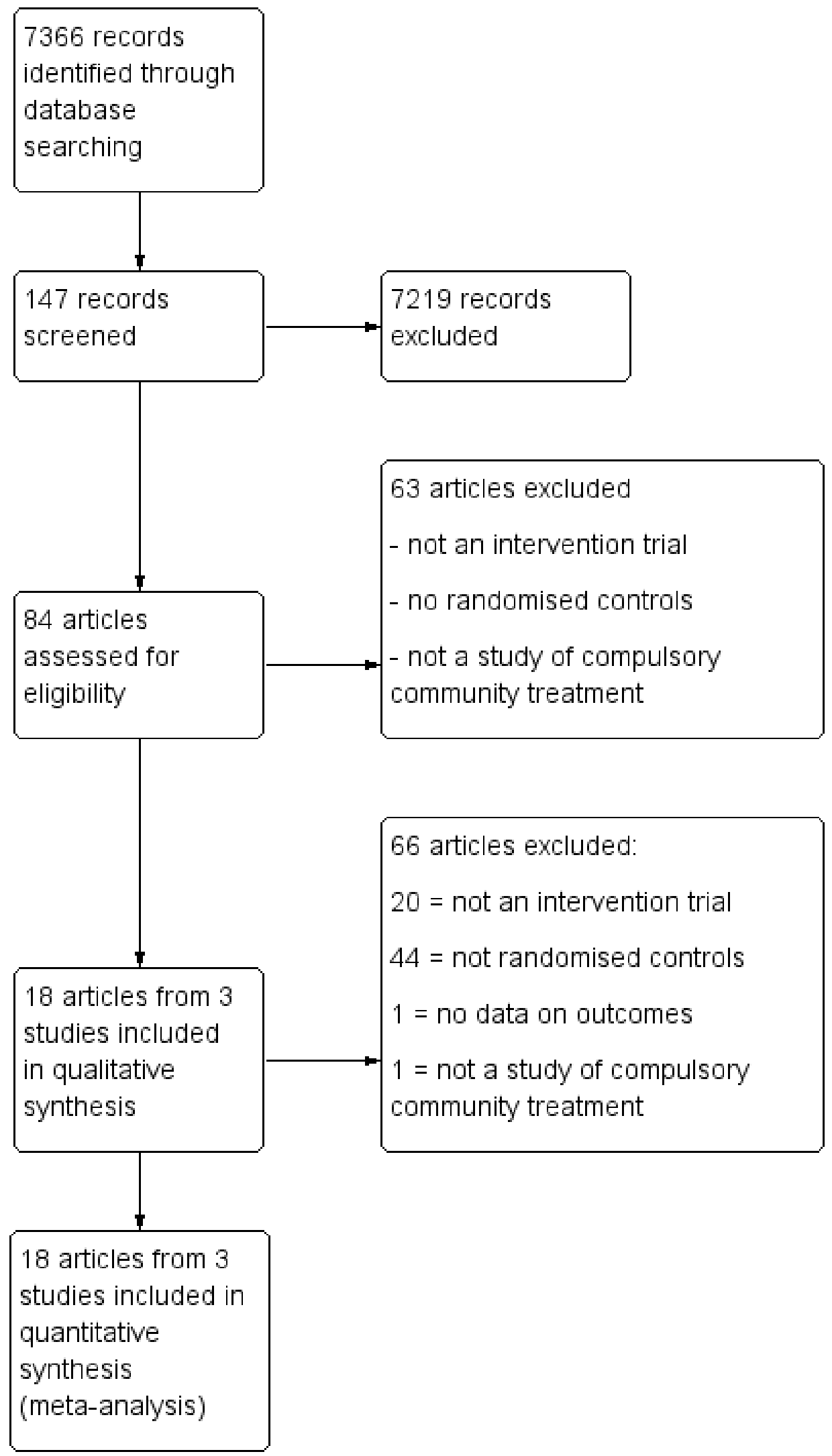




\section{Included studies}

We included three studies involving 749 participants: two studies from the USA comparing OPC with entirely voluntary treatment (Swartz 1999; Steadman 2001), and one UK study, the Oxford Community Treatment Order Evaluation Trial (OCTET), comparing two types of CCT interspaced with voluntary care (Burns 2013). OCTET randomised participants discharged from hospital to an experimental group (СТО) or a control group (extended leave under section 17 of the Mental Health Act) and compared their outcomes at 12 months (Burns 2013). "Leave of absence" under Section 17 of the Act allows an involuntarily detained person to leave hospital for a period of days to weeks while remaining subject to the inpatient committal order. The person can be returned to hospital if he or she does not follow the treatment plan or shows signs of significant deterioration.

\section{Excluded studies}

We excluded 66 articles. All but two were excluded as they were not RCTs, did not contain primary data or were reviews of intervention studies. Of the two excluded RCTs, one trial reported outcomes inherent to the process of OPC, namely the number of outpatient visits for medication review, counselling and case management (Wagner 2003). The other RCT was a study of joint crisis plans (Thornicroft 2013).

\section{Risk of bias in included studies}

We assessed risk of bias using the Cochrane assessment of 'Risk of bias' tool.

\section{Allocation}

Steadman 2001, the New York study, used a random number list to identify assignment to either the intervention or control group. The random number list was generated by computer, which then split 200 numbers between the groups. The printed list was maintained in the research team's office in a locked file. When the treatment team had completed their treatment plan, they called the research team who checked the computer list to see whether the client was to be assigned to the intervention or control group.

In the OCTET study, consenting participants were randomly assigned (ratio 1:1) by an independent statistician to be discharged from hospital either on СTO or Section 17 leave (Burns 2013). Randomisation used random permuted blocks with lengths of two, four and six, and stratified for sex (male or female), diagnosis of schizophrenia (yes or no) and duration of illness (less than two years or two years or greater). Assignments were enclosed in sequentially numbered, opaque, sealed envelopes and stored by a researcher independent to the trial team. The details of the sequence remained unknown to all members of the trial team until completion of recruitment, data collection and analyses. Randomisation took place after consent was obtained and the baseline interview was done. The envelope was opened on the day of the interview by the independent researcher after recording the participant's trial identification number on the envelope. She then communicated the randomised allocation to the recruiting researcher by telephone.

Swartz 1999 stated it was randomised but did not provide a description of the randomisation method.

We rated Steadman 2001 and Burns 2013 at low risk and Swartz 1999 at unclear risk of bias (Figure 2; Figure 3).

Figure 2. 'Risk of bias' graph: review authors' judgements about each risk of bias item presented as percentages across all included studies.

Random sequence generation (selection bias)

Allocation concealment (selection bias)

Blinding (performance bias and detection bias)

Incomplete outcome data (attrition bias)

Selective reporting (reporting bias)

Other bias

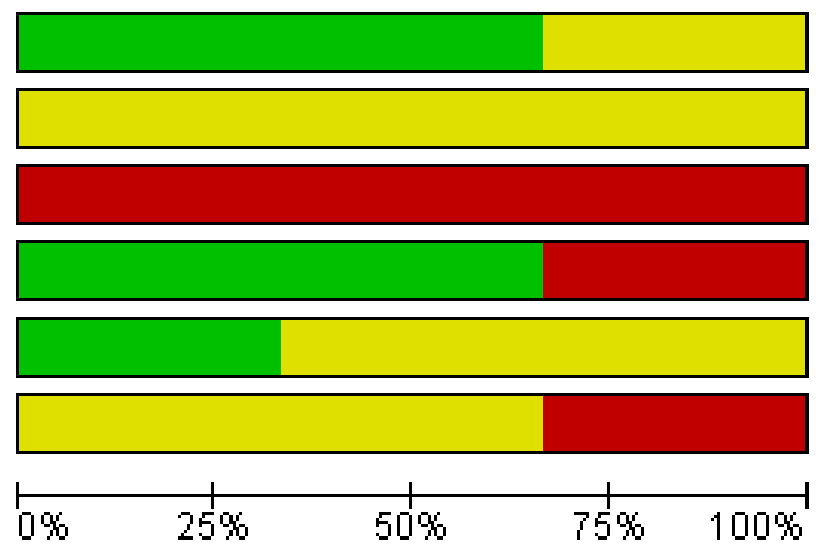


Figure 3. 'Risk of bias' summary: review authors' judgements about each risk of bias item for each included study.

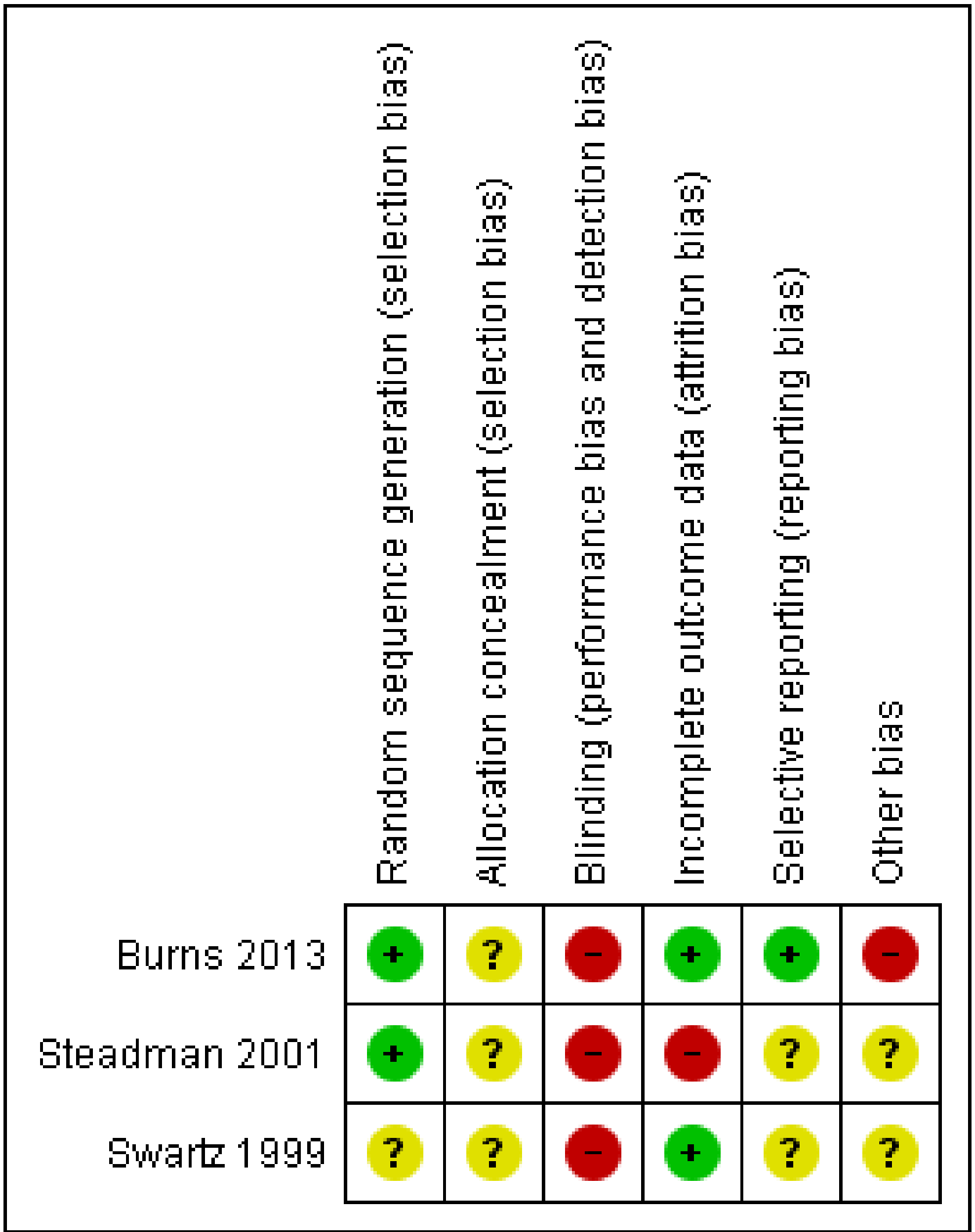




\section{Blinding}

Two studies did not mentioned blinding (Swartz 1999; Steadman 2001). Although all three studies used some self-report measures, it is unlikely participants, clinicians or assessors were blind to treatment status. Therefore, we rated the risk of bias as high. Burns 2013 involved allocation to two different types of legal status. Therefore, it was both impossible and unlawful to mask research assistants, treating clinicians or participants, thus we rated this as high risk.

\section{Incomplete outcome data}

Attrition rates for Steadman 2001 were $45 \%$. In the case of OCTET, follow-up for the main outcomes reached $100 \%$ although data on psychiatric symptoms, the Global Assessment of Functioning Scale (GAF) and measures of participant satisfaction were only available on $70 \%$ of the sample. Reporting on numbers leaving the Swartz 1999 study early was sometimes unclear. We attempted to undertake an intention-to-treat analysis of all the main outcomes including health service use and psychiatric symptoms. We rated Steadman 2001 at high risk and Swartz 1999 and Burns 2013 at low risk of attrition bias.

\section{Selective reporting}

We could not use continuous data for several outcomes, as no variance was reported. In Swartz 1999, data from randomised and non-randomised analyses were sometimes amalgamated and reported percentages rather than absolute numbers of people who had been followed up. We contacted the authors who confirmed that, at follow-up, there were 114 people in the control group, 102 in the court-ordered OPC group and 46 who were not randomised. Similarly, the authors of the Steadman 2001 study supplied the additional data for an intention-to-treat analysis of their paper (67 people in the controls, 85 in the OPC group). Our overall rating was unclear risk of reporting bias.

\section{Other potential sources of bias}

None of the studies reported conflicts of interest.

One potential source of bias in the OCTET study was that participants were only included if they were thought to be equally suitable for a relatively short Section 17 or CTO (Burns 2013). The authors acknowledged that clinicians held back participants who they felt needed a CTO. The number of such excluded participants was unknown and this may have excluded particularly suitable people.

A second potential source of bias in the OCTET study was allowing clinicians to make decisions independent of initial randomisation whereby 40 participants (25\%) allocated to Section 17 were subsequently placed on a CTO during the study and 35 participants randomised to CTOs (22\%) did not actually receive the intervention (Burns 2013). A sensitivity analysis to remove these protocol violations may, in turn, have left the study underpowered. Furthermore, removing these participants in a sensitivity analysis does not resolve the possibility that participants in the Section 17 group swapped to a CTO might have been more severely ill than those remaining on Section 17 as per the protocol. For instance, they may have been more difficult to manage or refusing to comply with follow-up when discharged from hospital. In the case of the $22 \%$ of people on CTOs who received no CTO, there is the possibility that these were good prognosis cases who were doing well and who clinicians predicted would adhere to follow-up. Removing them in a sensitivity analysis potentially excluded the participants with the best-outcome from the СTO group. All these factors may have reduced any differences in outcomes between the Section 17 and CTO participants.

A third potential source of bias in the OCTET study was that clinicians could keep participants on Section 17 for a variable period of time (Burns 2013). It is possible that participants who were most likely to default on treatment were maintained on Section 17 and that for these participants it acted more like a СTO thus reducing the chance of the study finding an effect of CTOs.

There was also uncertainty concerning the control condition within OCTET (Burns 2013). Although the length of initial compulsory outpatient treatment differed widely between the two groups (medians of 183 days versus eight days), Section 17 patients reported spending a mean of four months on some form of compulsory treatment during the 12 months. This comprised the mean of eight days of Section 17 on discharge plus periods of compulsory care during follow-up (outcome) - overall half the time in compulsory care as the people allocated to CTOs. An interpretation of this finding is that the participants in the control group still spent the majority of the study in voluntary treatment.

In addition, around $20 \%$ of the participants were ineligible or refused to take part in OCTET (Burns 2013). These people may have been the most ill, uncooperative or lacking in insight, and therefore, the ones most likely to benefit from CTOs.

Finally, the intervention was not manualised, or fidelity checked. it is possible that in any of the three studies, participating clinicians had varying levels of commitment to, or familiarity with, the use of CCT and thus may have not used the intervention optimally.

\section{Effects of interventions}

See: Summary of findings for the main comparison COURT ORDERED OUTPATIENT COMMITMENT compared with ENTIRELY VOLUNTARY CARE for people with severe mental disorders; Summary of findings 2 COMMUNITY TREATMENT ORDERS compared with SUPERVISED DISCHARGE (SECTION 17) for people with severe mental disorders; Summary of findings 3 COMPULSORY COMMUNITY TREATMENT compared with STANDARD CARE for people with severe mental disorders

\section{Comparison 1. Court ordered outpatient commitment compared with entirely voluntary care}

Attrition rates for Steadman 2001 were $45 \%$. As we included only two studies in this comparison, we decided that, rather than excluding data from this study, we would carry out a sensitivity analysis and, if the high attrition data substantially changed the estimate of effect, we would present them separately. However, the inclusion of data from Steadman 2001 did not alter the overall effect and so we added them to data from Swartz 1999. Results are presented as fixed-effect RRs with $95 \% \mathrm{Cls}$ or fixed-effect MD with $95 \% \mathrm{Cls}$ with the exception of quality of life on the Lehman Quality of Life Scale where there was evidence of heterogeneity. In this case, we used the random-effects model. 


\section{Health service outcomes by 11 to 12 months}

\subsection{Readmission to hospital}

Readmission rates were similar. By 11 to 12 months, the trials found no clear difference between groups (RR $0.98,95 \% \mathrm{Cl} 0.79$ to 1.2 , Analysis 1.1).

Steadman 2001 reported readmissions to acute facilities and state hospitals separately but it was unclear if participants could have been admitted to both during the follow-up period. Therefore, to avoid the possibility of double-counting, we used readmissions to acute facilities for our primary outcome. However, we also conducted a sensitivity analysis of the effect of including state hospital admissions - see 'Subgroup and sensitivity analyses' section.

\subsection{Bed-days spent in hospital}

Only one study reported means and SDs (Swartz 1999). There was no difference in bed-days spent in hospital by the end of followup (MD $-1.24,95 \% \mathrm{Cl}-15.16$ to 12.68 , Analysis 1.2). The other study reported medians. Although there was a large difference between people allocated to CTOs and controls (median: 43 days to CTO versus 101 days to control), this did not reach statistical significance.

\subsection{Number with multiple readmissions}

Steadman 2001 reported the number of participants with multiple admissions. There was no clear difference between people allocated to CTOs and controls (RR $1.87,95 \% \mathrm{Cl} 0.87$ to 4.01 , Analysis 1.3).

\subsection{Compliance with treatment}

At 12-month follow-up, there was no difference between groups for compliance with medication (RR $0.99,95 \% \mathrm{Cl} 0.83$ to 1.19 , Analysis 1.4).

\section{Participant level outcomes at 11 to 12 months}

\subsection{Psychiatric symptoms and global state at 11 to 12 months}

Steadman 2001 provided data on symptoms using the BPRS and GAF. In both cases, there was no clear difference between allocation to CTO and controls at follow-up. It was only possible to impute SDs for the GAF scores (MD $-3.00,95 \% \mathrm{Cl}-8.08$ to 2.08, Analysis 1.5).

\subsection{Social functioning: trouble with police}

People receiving CCT were no more likely to be arrested than people receiving standard care (RR outcome 'arrested at least once' 0.97, $95 \% \mathrm{Cl} 0.62$ to 1.52 , Analysis 1.6). Results also showed people allocated CCT were no more likely to commit a violent act than people in standard care (RR 0.82, $95 \% \mathrm{Cl} 0.56$ to 1.21 , Analysis 1.6).

\subsection{Social functioning: accommodation status}

Although the results appeared to favour the CCT group, we found no clear difference in the risk of being homeless between groups (RR 0.67, 95\% Cl 0.39 to 1.15 , Analysis 1.7).

\subsection{Quality of life: Lehman Quality of Life Scale}

Both studies provided information on quality of life although only one gave SDs (Swartz 1999). However, given the similarity of results from both studies, we imputed the missing SD from one study to the other. At follow-up, there was no difference between people allocated to CTOs and controls (RR $-0.22,95 \% \mathrm{Cl}-0.95$ to 0.50 , Analysis 1.8).

\subsection{Quality of life: victimisation}

Swartz 1999 provided data for victimisation. Participants receiving CCT were significantly less likely to have been victimised (been a victim once or more of either violent or non-violent crime) than participants in the standard care group ( $\mathrm{RR} 0.50,95 \% \mathrm{Cl} 0.31$ to 0.8 , Analysis 1.9).

\subsection{Satisfaction with care: perceived coercion}

For this review, we defined perceived coercion as a participant feeling lack of autonomy in seeking outpatient care or negative pressures (or both), captured threats or force pertaining to treatment (or both). Process exclusion consisted of participants' feelings of lack of involvement and validation in treatment decisions. We found no clear difference in the perception of being coerced between the two groups (RR $1.36,95 \% \mathrm{Cl} 0.97$ to 1.89 , Analysis 1.10).

\subsection{Additional analyses}

All the papers from Swartz 1999 reported the results of a nonrandom post hoc analysis of the intervention group based on duration of involuntary outpatient treatment. In two papers, this was supplemented with a follow-up of an additional nonrandomised group of participants with a recent history of violence who were placed on CCT (Swartz 2001; Hiday 2002). These papers suggested that an OPC of greater than 180 days' duration was associated with improved outcomes in terms of readmission rate, compliance with medication, homelessness and contacts with the criminal justice system. However, such analyses are subject to the bias that randomised trials are designed to minimise. For instance, an analysis of people who have been not randomly assigned to OPC groups of less than, and more than, 180 days may reflect a bias where OPC was selectively extended when it seemed to be helping the participant (Szmukler 2001) despite assurances from the Swartz and colleagues that participants who had OPC extended were less tractable than participants who did not (Swartz 1999).

\section{Comparison 2. Community treatment orders versus supervised discharge (Section 17)}

We found one relevant trial comparing CCT versus supervised discharge (Section 17) ( $n=333$ ) (Burns 2013).

\section{Health service outcomes by 12-month follow-up}

\subsection{Readmission to hospital by 12 -month follow-up}

There was no clear difference between CTOs and Section 17 by $12-$ month follow-up in readmission to hospital by 12 -month follow-up (RR 0.99, 95\% $\mathrm{Cl} 0.74$ to 1.32 , Analysis 2.1).

\subsection{Bed-days spent in hospital by 12 months}

There was no clear difference between СTOs and Section 17 in hospital bed-days by 12 -month follow-up (MD -8.70, 95\% Cl -30.88 to 13.48 , Analysis 2.3 ).

\subsection{Number of readmissions by 12 months}

There was no clear difference between CTOs and Section 17 in number of readmissions by 12 -month follow-up (MD $-0.20,95 \% \mathrm{Cl}$ -0.45 to 0.05 , Analysis 2.4). 


\subsection{Number with multiple readmissions by 12 months}

There was no clear difference between CTOs and Section 17 in number with multiple readmissions by 12 months (RR $0.56,95 \% \mathrm{Cl}$ 0.27 to 1.17 , Analysis 2.5).

\subsection{Days in community to first admission at 12-month follow-up}

There was no clear difference between CTOs and Section 17 in days in the community to first admission at 12-month follow-up (MD $5.00,95 \% \mathrm{Cl}-21.74$ to 31.74 , Analysis 2.6 ).

\section{Health service outcomes by 36 months}

\subsection{Health service outcomes: 1b. Readmission to hospital by 36} months

2.7 Health service outcomes: 5 b. Days in community till first admission and mean duration of bed-days at $\mathbf{3 6}$ months

The authors were able to follow-up all but three people who had been included in their original intention-to-treat analysis (total $n=330$ ). There were no clear differences between participants originally randomised to CTO or Section 17 in terms of readmission to hospital (RR $0.71,95 \% \mathrm{Cl} 0.45$ to 1.11 , Analysis 2.2), numbers with multiple readmissions (RR $1.07,95 \% \mathrm{Cl} 0.62$ to 1.85 , Analysis 2.2), days in community to first admission (MD $60.00,95 \% \mathrm{Cl}-27.62$ to 147.62, Analysis 2.7) or bed-days (MD $-15.10,95 \% \mathrm{Cl}-89.39$ to 59.19 , Analysis 2.7).

\section{Participant level outcomes by 12-month follow-up}

\subsection{Brief Psychiatric Rating Scale at 12-month follow-up}

There was no clear difference between CTOs and Section 17 in BPRS scores at 12-month follow-up (MD -0.10, 95\% Cl-3.17 to 2.97, Analysis 2.8).

\subsection{Global Assessment of Functioning Scale at 12-month follow-up}

There was no clear difference between CTOs and Section 17 in terms of GAF scores at 12-month follow-up (MD -0.70 95\% Cl-3.91 to 2.51, Analysis 2.9).

\subsection{Satisfaction with care: perceived coercion at 11 to 12 month follow-up}

We used the Perceived Coercion Scale from the Admission Experience Schedule. There was no statistical difference between participants randomised to CTOs or Section 17 at 12-month followup (MD -0.50, 95\% Cl-1.71, to 0.71, Analysis 2.10).

\subsection{Satisfaction with care: leverage at 11 to 12 months}

Another measure of coercion is the experience of leverage in terms of pressure to have treatment. There was no statistical difference between the two treatment groups (OR $1.2395 \% \mathrm{Cl} 0.66$ to 2.31 ).

\subsection{Social Outcomes Index at 12 months}

Finally, there was no difference between groups in terms of alcohol or substance use, insight, psychotropic medication, experience of services and participant satisfaction as measured by standardised questionnaires. For example, the scores on the Objective Social Outcomes Index were almost identical (MD-0.10 95\% Cl -0.40 to 0.20 , Analysis 2.12).

\section{Additional analyses}

At 36-month follow-up, Burns 2013 also compared anyone in the trial who had experienced a CTO $(n=198)$ and those who had not $(n=132)$ irrespective of their original randomisation. The study authors used negative binomial regression to calculate incident density ratios (IDRs). People who had experienced a CTO had significantly more readmissions than those who had not (IDR 1.39, $95 \% \mathrm{Cl} 1.07$ to 1.79 ) but otherwise there were no clear differences between groups in readmission rates, duration of readmission or time to first readmission. In addition, they did not identify a linear relationship between readmission outcomes and duration of СTO although participants who were on CTOs for between six and 12 months did better than participants with other durations of CTOs (less than six months, 12 to 24 months and 24 to 36 months). However, the major drawback of these analyses was that they were not adjusted for potential confounders given that participants in these two groups were not randomly allocated.

Comparison 3. Community Treatment Orders versus standard care (encompassing both voluntary care and supervised discharge)

Results are presented as fixed-effect RR with $95 \% \mathrm{Cls}$ or fixed-effect MD with $95 \%$ Cls with the exception of bed-days where there was evidence of heterogeneity. In this case, we used the random-effects model.

\section{Health service outcomes}

\subsection{Readmission to hospital by 11 to 12 months}

All three studies contributed to this outcome $(n=749)$ (Swartz 1999; Steadman 2001; Burns 2013). There was no clear difference between participants on CTOs and controls in readmission to hospital by 12 months (RR $0.98,95 \% \mathrm{Cl} 0.83$ to 1.17 , Analysis 3.1). In terms of NNTB, it would take 142 orders to prevent one readmission.

\subsection{Bed-days spent in hospital by 12 months}

Two studies contributed to this meta-analysis (Swartz 1999; Burns 2013). There was no clear difference between participants on CTOs and controls in bed-days by 12 months (MD $-3.35,95 \% \mathrm{Cl}-15.14$ to 8.44, Analysis 3.2).

\subsection{Number with multiple readmissions by 12 months}

Two studies contributed to this meta-analysis (Steadman 2001; Burns 2013). There was no clear (statistical) difference in the number of people who required more than one readmission by 12 months (RR $1.02,95 \% \mathrm{Cl} 0.31$ to 3.33 , Analysis 3.3).

\section{Participant level outcomes}

\subsection{Global Assessment of Functioning Scale at 12 months}

Only one study gave SDs (Burns 2013). However, given the similarity of results from the other study that reported this outcome (Steadman 2001), we imputed the missing SDs from one study to the other. At follow-up, there was no difference between people allocated to CTOs and controls in global state (GAF) (MD -1.36 95\% $\mathrm{Cl}-4.07$ to 1.35 , Analysis 3.4). 
3.5. Satisfaction with care: perceived coercion or leverage at 11 to 12 months

We combined the relevant dichotomous variables from all three studies (Swartz 1999; Steadman 2001; Burns 2013). This showed that participants on CCT did not feel more coerced that participants in the control group at 11 to 12 months (RR $1.30,95 \% \mathrm{Cl} 0.98$ to 1.71 , Analysis 3.5).

\section{Subgroup and sensitivity analyses}

There were no differences in outcome between types of CCT as comparison I was restricted to court-ordered OPC in the USS while comparison II was of clinician-initiated CTOs in the UK. Similarly, the sensitivity analyses outlined in the Methods section did not change any of the results. The authors of the Burns 2013 study stated they used an intention-to-treat analysis in 166 CTO cases and 167 controls. However, immediately after randomisation two participants were found to be ineligible and one withdrew. These participants were not included in the intention-to-treat analysis. As a precaution, we undertook sensitivity analyses of the effect of including the 167 CTO cases and 169 controls who were randomised and, again, this did not alter the results. Finally, we studied the effect of including admissions to both acute facilities and state hospitals for people allocated to CTOs (49/85) and controls (42/67) in the New York study (Steadman 2001). This made no difference to the results ( 3 RCTs, $n=749$, RR $0.93,95 \% \mathrm{Cl} 0.80$ to 1.09 ).

\section{Missing outcomes}

There were no data available for adverse effects or economic costs.

\section{DISCUSSION}

Despite of the widespread use of CCT and the continued controversy as to its effectiveness, we were struck by the limited number of studies that have been conducted. This is possibly due to the difficulties of conducting RCTs in this area. Therefore, we attempted to draw modest conclusions, based on available evidence, and to highlight areas requiring further study, rather than draw firm conclusions that may not be based on evidence of high quality.

This review revealed little evidence for the effectiveness of CCT in any of the main outcome indices: health service use, costs, social functioning, mental state, quality of life or satisfaction with care. We were only able to establish a clear and statistically significant effect for one outcome, social functioning (victimisation).

Although we identified 15 papers, these represented only three trials. Two of these were of court-ordered 'outpatient commitment' (OPC) in the USA with limited generalisability to jurisdictions where CCT is ordered by clinicians. The third trial, from the UK, was a study of clinician-initiated, rather than court-ordered, treatment as in the US RCTs and thus, more relevant to other jurisdictions such as Australia, Canada and New Zealand. However, this was a comparison of two different types of compulsory intervention of different durations rather than a comparison of compulsory intervention with entirely voluntary treatment. Problems common to all three studies included relatively small numbers of participants and questions concerning bias. This illustrates the difficult, but not impossible, task of using trial methods to study the effect of such legislation.
In the case of the North Carolina study (Swartz 1999), the study was supplemented by follow-up of an additional non-randomised group of participants with a recent history of violence who were also placed on OPC. It was sometimes difficult to separate the results of the randomised trials from the non-randomised study. In the case of the New York study (Steadman 2001), there was a relatively small number of participants and the suggestion that members of the control group and their case managers thought that they were actually on OPC (NASMHPD 2001). These factors would minimise any effect of the intervention. In addition to the question around the voluntary or compulsory nature of the controls in the OCTET study, the other major issue was that a quarter of participants did not receive the intervention to which they were initially randomised. This was because treating physicians were able to make clinical decisions irrespective of initial randomisation, a requirement for the trial to be lawful.

\section{Summary of main results}

All three studies were of people in community settings who were followed up over 11 to 12 months. One study included 36-month follow-up data (Burns 2013). Two trials from the USA were of courtordered OPC compared with voluntary community treatment. The third study compared clinician-initiated CTOs with another type of supervised discharge in England.

\section{Comparison 1. Court ordered outpatient commitment compared with entirely voluntary care}

\subsection{Health service outcomes}

Only data for two health service outcomes (readmission to hospital and compliance with medication) were usable. In both cases there were no differences between groups. By 12 months, people were no more likely to be readmitted to hospital if they were placed on OPC than if they had received standard care. They were also just as likely to comply with medication. However, it should be noted that these results were based on two studies only and in one attrition rates were $45 \%$ (Steadman 2001), so no firm conclusions can be made.

\subsection{Participant level outcomes}

Four participant level outcomes (trouble with the police, homelessness, coercion and victimisation) were presented.

By 12 months, the number of arrests by police were similar for both groups and people in the CCT group did not commit any more acts of violence than people in standard care. A problem with the data in this area was a possibility of selection bias as people with a history of violence were explicitly excluded from both trials. This limits their applicability as recent dangerousness, particularly violence against others, is often the reason for compulsory treatment in hospital or the community (Sensky 1991; Lansing 1997; DeRidder 2016). There is also a risk of bias when outcome data are not assessed blind to group status and the results of people who were not randomised or post hoc analyses are included in papers.

The numbers of people who were homeless by 12 months were similar in both groups.

The only significant benefit from CCT was for victimisation. People on CCT were less likely to be victims of a violent or non-violent crime by 12 months in the North Carolina study (Swartz 1999). 
In terms of possible adverse effects of CCT, perceived coercion was higher in the North Carolina study (Swartz 1999), but not in the New York study (Steadman 2001). The lack of any difference of perceived coercion in the New York study may have been due to the reported confusion that many case managers and community agencies had in distinguishing a person being in the study and being assigned to CCT (NASMHPD 2001). Further, the police in New York refused to bring to hospital for assessment people who breached their treatment orders. Combining the findings for perceived coercion from both studies in a meta-analysis gave a non-significant result.

\section{Comparison 2. Compulsory community treatment versus supervised discharge (Section 17)}

\subsection{Health service outcomes}

There were no differences between participants on CTO and supervised discharge in terms of readmissions, bed-days or survival in the community.

\subsection{Participant-level outcomes}

There were no differences between the two groups in terms of psychiatric symptoms or social functioning as measured by standardised instruments.

\section{Comparison 3. Community Treatment Orders versus standard care (encompassing both voluntary care and supervised discharge)}

Entering the relevant data from all three studies did not affect the non-significant results for both health service and participant-level outcomes. In terms of NNTBs, it would take 142 orders to prevent one readmission.

\section{Overall completeness and applicability of evidence}

Two trials were of OPC in the USA. This is a court-ordered compulsory treatment plan and the findings may not be applicable to other jurisdictions where CCT is initiated by clinicians. In addition, both trials explicitly excluded people with a history of violence. Although understandable from an ethical and legal standpoint, this limits applicability, as recent dangerousness, particularly violence against others, is often the reason for compulsory treatment in hospital or the community.

The OCTET study was a comparison of two types of clinicianordered community treatment, СTOs and intermittent supervised discharge in England. This may be more applicable to other jurisdictions. However, around $20 \%$ of the sample were ineligible or refused to take part. These people may have been the most unwell or particularly lacking in insight, and therefore the ones most likely to benefit from CTOs.

Other important issues to be considered when applying the findings from all three studies to other jurisdictions include whether there are differing criteria for inpatient or outpatient committal, whether CCT can be imposed on people who are capable of making treatment decisions, powers conferred by CCT and if there is a requirement for prior hospitalisation.

\section{Quality of the evidence}

This is a difficult area to research using RCTs and so all three studies contained a number of potential biases. OCTET met three out of the seven criteria of Cochrane's tool for assessing risk of bias, the others only one, the majority being rated as unclear. There was no difference in these ratings by outcome. One issue in all three RCTs was selection and blindness bias and consequent applicability to everyday care. Depending on the study, people with a history of dangerousness were excluded and around 20\% of eligible people lacked capacity to consent to the study, or refused to take part. This limits their applicability as recent dangerousness, particularly violence against others, is often the reason for compulsory treatment in hospital or the community (Sensky 1991; Lansing 1997; DeRidder 2016). Only two of the three studies described the process of randomisation in detail (Steadman 2001; Burns 2013). There is also a risk of bias when outcome data are not assessed blind to group status and the results of people who were not randomised or post hoc analyses are included in papers. All three studies used intention-to-treat analyses for all (Swartz 1999; Burns 2013), or at least some (Steadman 2001), of the outcomes of interest.

In the case of the North Carolina study (Swartz 1999), it was sometimes difficult to separate the results of the randomised trial from those of the follow-up of an additional non-randomised group of participants with a recent history of violence who were also placed on OPC. In the case of the New York study (Steadman 2001), there was a relatively small number of participants and the suggestion that members of the control group and their case managers thought that they were actually on OPC (NASMHPD 2001). These factors would minimise any effect of the intervention.

There were also fewer data on psychosocial outcomes as measured by standardised instruments.

All these issues illustrate the difficult, but not impossible, task of using trial methods to study the effect of such legislation. Nevertheless, RCTs may not always give a complete picture as some important or rare outcomes, such as mortality, cannot easily be assessed by a clinical trial (Kisely 2015). For instance, epidemiological studies have suggested that people on CTOs have reduced mortality compared with people receiving control interventions even after adjusting for confounders (Segal 2006a; Kisely 2013a). This is possibly by improving physical care through increased contact with community psychiatric services (Kisely 2013a). In addition, none of the studies in this review included the views of carers and families who are often supportive of CCT (O'Reilly 2006).

\section{Potential biases in the review process}

\section{Post hoc decisions}

We changed the level of acceptable loss to follow-up. We felt that, in retrospect, the cut-off of $35 \%$ was too restricting and changed this to $50 \%$. We also added an additional comparison of two different types of CCT. We took both decisions since we found only three studies. We have tried to present data in a way as to allow the reader to evaluate the effects of doing this.

\section{Authors' area of interest}

Two authors of this review were also authors of some of the papers considered for inclusion (Preston 2002; Kisely 2004; Kisely 2005; Kisely 2006a; Kisely 2007a). We excluded all these papers because none of them were RCTs. It is possible that we, through detailed knowledge of these studies, excluded them, but for others, where our knowledge is not first hand, we allowed inclusion. 


\section{Agreements and disagreements with other studies or reviews}

Our findings of limited effectiveness of CCT based on the three RCTs are consistent with several other independent reviews of CCT, which have concluded that CCT has little positive effect on outcomes such as hospital admissions, length of stay or compliance with medication (Ridgely 2001; Churchill 2007; Maughan 2014). Our finding that CCT does not cause an increase in perceived coercion is not compatible with one review of quantitative and qualitative studies (Pridham 2015).

\section{AUTHORS' CONCLUSIONS}

\section{Implications for practice}

\section{For people with serious mental illnesses}

People with severe mental disorders and carers should remain sceptical about the effectiveness of compulsory community treatment (CCT). Brief supervised discharge may be as effective (or non-effective) as formal community treatment orders (CTOs).

\section{For clinicians}

People on CCT may show an increase in admissions in the year following initial use, possibly because of increased monitoring by clinicians. Any reduction of hospital admissions may only come later and after a prolonged period of use. The limited evidence should make clinicians judicious about using CCT. One possible interpretation of the results from the Oxford Community Treatment Order Evaluation Trial (OCTET) study is that a short period of conditional leave may suffice for some people, and should therefore be considered when both CTO and conditional leave are available.

\section{For policy makers}

Based on results from this review, there is no strong evidence to support the claims made for CCT that make it so attractive for legislators. It does not appear to reduce health service use or improve people's social functioning. However, despite concerns of some patient groups and mental health advocates, CCT does not appear to increase perceived coercion. Lack of data made it impossible to assess its effect on costs, mental state and other aspects of patient/carer satisfaction. Legislation in this area may detract from the introduction of interventions that are of benefit to people with severe mental disorder such as intensive case management (Dieterich 2010), but which are more expensive than legislative solutions to the problem. However, there may be a subgroup of people who require both CCT and intensive community services (O'Reilly 2016). If governments continue to introduce this type of legislation, some evaluation of outcome should be included. CTOs may be no more effective than briefer supervised discharge (Burns 2013).

\section{Implications for research}

\section{General}

Greater adherence to CONSORT standards of reporting (Begg 1996; Moher 2001) would have enabled us to include more data from one of the included studies (Steadman 2001).

\section{Specific}

Despite of the widespread use of CCT, the only studies we could find were two of court-ordered community treatment (outpatient commitment (OPC)) in the USA, and one of CTOs in England. There were much fewer data, and no randomised trials, on other forms of CCT. Further research into the clinical effects of different types of $\mathrm{CCT}$ is required.

\subsection{Types of studies}

The trials presented in this review show that this methodology is difficult, but not impossible, to apply to CCT. However, it has been argued that the level of difficulty involved means that further studies using this methodology may not be feasible (Bindman 2002). The analysis of routine administrative datasets may be an alternative. Although the analysis of such data is subject to biases and difficulties of its own, the use of epidemiological sampling frames that cover all people placed on CCT would help to minimise selection or follow-up bias (Preston 2002). In particular, using these would have meant that people who refused to take part in or who were incapable of consenting to the randomised controlled trials (RCT) could have been included. It also would have allowed inclusion of people with a history of violence who were explicitly excluded from two trials. The difficulty of such studies is the identification of suitable controls. Quasi-experimental designs comparing people from jurisdictions with similar health systems where one allows CCT and the other does not, may be an answer. Regardless of the source, rigorous multivariable statistical controls are essential (Swanson 2014).

If further RCTs are attempted, all eligible people should be randomised, with adequate sample sizes, entirely voluntary controls and efforts made to minimise protocol violations (Rugkasa 2014). Further RCTs should examine multiple outcomes, not simply hospitalisation, and consider if there is an optimum length of treatment for different cases.

In addition to quantitative research, qualitative techniques may give additional insights into the effect of CCT on patients, carers and healthcare professionals. We may also need to consider the place of CCT in the range of coercive measures used to improve compliance with treatment, and look at additional outcomes such as risk reduction (Bindman 2002).

\subsection{Setting}

Another interesting finding was the absence of any work from outside the English-speaking world, even though our literature search was not restricted to publications in English. We do not know whether this is due to publication bias, or because such legislation is either absent or accepted without controversy.

\subsection{Participants}

Further research may determine whether there are people with specific characteristics who are best managed with CTOs.

\subsection{Interventions}

We require further well-conducted studies to establish whether it is the intensity of treatment, its compulsory nature or legislative framework that affects outcomes. 


\subsection{Outcomes}

Although the outcomes that were recorded were highly appropriate, it was not always possible to include data on psychosocial outcomes as measured by standardised instruments in the meta-analyses. Studies should use wellvalidated instruments to measure outcome, and should also collect and report categorical and 'count' data, such as days in hospital. Data should be in a form that can easily be incorporated into a systematic review with means and standard deviations (or standard errors) of all continuous outcome variables. Despite of the ethical and practical issues, the ideal evaluation of CTOs would be RCT comparisons of involuntary versus voluntary treatment for each different type of CCT given the wide variations across jurisdictions. At present, the only RCT evidence that compares CCT with entirely voluntary care concerns court-ordered OPC in the USA. Elsewhere, the OCTET study compared two forms of CCT of varying intensity and duration in England, and there is no RCT evidence from any other jurisdiction.

\section{ACKNOWLEDGEMENTS}

SK is employed by the University of Queensland, Australia and previously by Dalhousie University, Canada and the University of Western Australia.

LAC is employed by Capital District Health Authority, Halifax, Canada.

RO'R is employed by the Faculty of Medicine, Western University, London, Ontario, Canada.

We also wish to thank Neil Preston from Fremantle Hospital, Western Australia who was an author on earlier versions of this review. The principal investigators of two groups who conducted RCTs in this area kindly confirmed that we had all the relevant papers and supplied additional data.

The Cochrane Schizophrenia Group provides a standard template for its Methods, which we have used and adapted for this update. 


\section{R E F E R E N C E S}

\section{References to studies included in this review}

\section{Burns 2013 \{published data only\}}

* Burns T, Rugkasa J, Molodynski A, Dawson J, Yeeles K, Vazquez-Montes $\mathrm{M}$, et al. Community treatment orders for patients with psychosis (OCTET): a randomised controlled trial. Lancet 2013;381(9878):1627-33. [PUBMED: 23537605]

Burns T, Yeeles K, Koshiaris C, Vazquez-Montes M, Molodynski A, Puntis $S$, et al. Effect of increased compulsion on readmission to hospital or disengagement from community services for patients with psychosis: follow-up of a cohort from the OCTET trial. Lancet Psychiatry 2015;2:881-90.

ISRCTN73110773. 10PRT/0496: Oxford Community Treatment Order Evaluation Trial (OCTET): a single-outcome randomised controlled trial of compulsory outpatient treatment in psychosis, 2010. www.thelancet.com/protocolreviews/10PRT-0496 (accessed 16 February 2017). [CRS: 9000100000013971]

ISRCTN73110773. Oxford community treatment order evaluation trial, 2011. www.isrctn.com/ISRCTN73110773 (accessed 16 February 2017).

Rugkasa J, Molodynski A, Yeeles K, Vazquez Montes M, Visser C, Burns T. Community treatment orders: clinical and social outcomes, and a subgroup analysis from the OCTET RCT. Acta Psychiatrica Scandinavica 2015;131:321-9.

Ryan A, Patel R, Russell L, Turnpenny L, Visser C. Community treatment orders on trial: the OCTET RCT. Psychiatrische Praxis 2011;38:1.

\section{Steadman 2001 \{published data only\}}

Steadman HJ. Final Report: Research Study of the New York City Involuntary Outpatient Commitment Pilot Program. Delmar, NY: Policy Research Associates Inc, 1998.

* Steadman HJ, Gounis K, Dennis D, Hopper K, Roche B, Swartz M, et al. Assessing the New York City involuntary outpatient commitment pilot program. Psychiatric Services 2001;52(3):330-6.

\section{Swartz 1999 \{published data only\}}

Compton SN, Swanson JW, Wagner HR, Swartz MS, Burns BJ, Elbogen EB. Involuntary outpatient commitment and homelessness in persons with severe mental illness. Mental Health Services Research 2003;5(1):27-38.

Hiday VA, Swartz MS, Swanson JW, Borum R, Wagner HR. Impact of outpatient commitment on victimization of people with severe mental illness. American Journal of Psychiatry 2002;159:1403-11.

Swanson JW, Borum R, Swartz MS, Hiday VA, Ryan Wagner H, Burns BJ. Can involuntary outpatient commitment reduce arrests among persons with severe mental illness?. Criminal Justice and Behaviour 2001;28(2):156-89.

Swanson JW, Swartz MS, Elbogen EB, Wagner HR, Burns BJ. Effects of involuntary outpatient commitment on subjective quality of life in persons with severe mental illness. Behavioral Sciences \& the Law 2003;21:473-91.

Swanson JW, Swartz MS, Wagner HR, Burns BJ. Involuntary out-patient commitment and reduction of violent behaviour in persons with severe mental illness. British Journal of Psychiatry 2000;174:324-31.

Swartz MS, Hiday VA, Swanson JW, Wagner HR, Borum R, Burns B. Measuring coercion under involuntary outpatient commitment. Initial findings from a randomised controlled trial. Research in Community and Mental Health 1999;10:52-77.

Swartz MS, Swanson JW, Wagner HR, Burns BJ, Hiday VA. Effects of involuntary outpatient commitment and depot antipsychotics on treatment adherence in persons with severe mental illness. Journal of Nervous and Mental Disease 2001;189(9):583-92.

Swartz MS, Swanson JW, Wagner HR, Burns BJ, Hiday VA, Borum R. A randomised controlled trial of outpatient commitment in North Carolina. Psychiatric Services 2001;52(3):325-9.

* Swartz MS, Swanson JW, Wagner HR, Burns BJ, Hiday VA, Borum R. Can involuntary outpatient commitment reduce hospital recidivism? Findings from a randomised trial with severely mentally ill individuals. American Journal of Psychiatry 1999;156:1968-75.

Swartz MS, Wagner HR, Swanson J, Hiday VA, Burns BJ. The perceived coerciveness of involuntary outpatient commitment: findings from an experimental study. Journal of the American Academy of Psychiatry and the Law 2002;30(2):207-17.

\section{References to studies excluded from this review}

Bindman 2002 \{published data only\}

Bindman J. Involuntary outpatient treatment in England and Wales. Current Opinion in Psychiatry 2002;15:595-8.

\section{Borum 1999 \{published data only\}}

Borum R, Swartz M, Riley S, Swanson J, Hiday VA, Wagner R. Consumer perceptions of involuntary outpatient commitment. Psychiatric Services 1999;50(11):1489-91.

Brophy 2006 \{published data only\}

Brophy LM, Reece JE, McDermott F. A cluster analysis of people on community treatment orders in Victoria, Australia. International Journal of Law and Psychiatry 2006;29(6):469-81.

\section{Burgess 2006 \{published data only\}}

Burgess P, Bindman J, Leese M, Henderson C, Szmukler G. Do community treatment orders for mental illness reduce readmission to hospital? An epidemiological study. Social Psychiatry and Psychiatric Epidemiology 2006;41(7):574-9.

Bursten 1986 \{published data only\}

Bursten P. Post-hospital mandatory outpatient treatment. American Journal of Psychiatry 1986;143:1255-8. 


\section{Chaimowitz 2004 \{published data only\}}

Chaimowitz GA. Community treatment orders: an uncertain step. Canadian Journal of Psychiatry 2004; Vol. 49, issue 9:577-8.

\section{Dawson 2006 \{published data only\}}

Dawson J. Fault-lines in community treatment order legislation. International Journal of Law and Psychiatry 2006;29(6):482-94.

\section{Fernandez 1990b \{published data only\}}

Fernandez GA, Nygard S. Impact of involuntary outpatient commitment on the revolving-door syndrome in North Carolina. Hospital and Community Psychiatry 1990;41(9):1001-4.

\section{Frank 2005 \{published data only\}}

Frank D, Perry JC, Kean D, Sigman M, Geagea K. Effects of compulsory treatment orders on time to hospital readmission. Psychiatric Services 2005;56(7):867-9.

\section{Geller 1998 \{published data only\}}

Geller J, Grudzinskas AJJ, McDermeit M, Fisher WH, Lawlor T. The efficacy of involuntary outpatient treatment in Massachusetts. Administration Policy and Mental Health 1998:25:271-85.

\section{Georgieva 2013 \{published data only\}}

Georgieva I, Mulder CL, Noorthoorn E. Reducing seclusion through involuntary medication: a randomized clinical trial. Psychiatry Research 2013; Vol. 205, issue 1-2:48-53.

Gray 2005 \{published data only\}

Gray JE, O'Reilly RL. Canadian compulsory community treatment laws: recent reforms. International Journal of Law and Psychiatry 2005;28(1):13-22

\section{Greeman 1985 \{published data only\}}

Greeman M, McClellan T. The impact of a more stringent commitment code in Minnesota. Hospital and Community Psychiatry 1985;36(9):990-2.

\section{Hiday 1987 \{published data only\}}

Hiday VA, Scheid-Cook TL. The North Carolina experience with outpatient commitment: a critical appraisal. International Journal of Law and Psychiatry 1987;10(3):215-32.

Hiday 1989 \{published data only\} Hiday VA, Scheid-Cook TL. A follow-up of chronic patients committed to outpatient treatment. Hospital and Community Psychiatry 1989;40(1):52-9.

\section{Hiday 1999 \{published data only\}}

Hiday V, Swartz M, Swanson J, Borum R, Wagner HR. Criminal victimisation of persons with severe mental illness. Psychiatric Services 1999;50(1):62-8.

\section{Hunt 2007 \{published data only\}}

Hunt AM, da Silva A, Lurie S, Goldbloom DS. Community treatment orders in Toronto: the emerging data. Canadian Journal of Psychiatry. Revue Canadienne de Psychiatrie 2007;52(10):647-56. [PUBMED: 18020112]
Jethwa 2008 \{published data only\}

Jethwa K, Galappathie N. Community treatment orders. BMJ 2008; Vol. 337:613.

Kanter 1995 \{published data only\}

Kanter A, Aviram U. Israel's involuntary outpatient commitment law: lessons from the American experience. Israel Law Review 1995;29(4):565-635.

\section{Kisely 2004 \{published data only\}}

Kisely SR, Xiao J, Preston NJ. Impact of compulsory community treatment on admission rates: survival analysis using linked mental health and offender databases. British Journal of Psychiatry 2004;184:432-8.

\section{Kisely 2005 \{published data only\}}

Kisely S, Smith M, Preston NJ, Xiao J. A comparison of health service use in two jurisdictions with and without compulsory community treatment. Psychological Medicine 2005;35(9):1357-67.

\section{Kisely 2006a \{published data only\}}

Kisely S, Campbell LA, Preston NJ, Xiao J. Can epidemiological studies assist in the evaluation of community treatment orders? - The experience of Western Australia and Nova Scotia. International Journal of Law and Psychiatry 2006;29(6):507-15.

\section{Kisely 2006b \{published data only\}}

Kisely S, Campbell LA. Community treatment orders for psychiatric patients: the emperor with no clothes. Canadian Journal of Psychiatry 2006;51(11):683-5, 691.

Kisely 2007a \{published data only\}

Kisely S, Campbell LA, Scott A, Preston NJ, Xiao J. Randomized and non-randomized evidence for the effect of compulsory community and involuntary out-patient treatment on health service use: systematic review and meta-analysis. Psychological Medicine 2007;37(1):3-14.

\section{Kisely 2007b \{published data only\}}

Kisely S, Campbell LA. Does compulsory or supervised community treatment reduce 'revolving door' care? Legislation is inconsistent with recent evidence. British Journal of Psychiatry 2007; Vol. 191:373-4.

\section{Kisely 2013a \{published data only\}}

Kisely S, Preston N, Xiao J, Lawrence D, Louise S, Crowe E, et al. An eleven-year evaluation of the effect of community treatment orders on changes in mental health service use. Journal of Psychiatric Research 2013;47(5):650-6. [PUBMED: 23415453]

\section{Kisely 2013b \{published data only\}}

Kisely S, Preston N, Xiao J, Lawrence D, Louise S, Crowe E. Reducing all-cause mortality among patients with psychiatric disorders: a population-based study. CMAJ : Canadian Medical Association Journal 2013;185(1):E50-6. [PUBMED: 23148054]

\section{Lawton-Smith 2008 \{published data only\}}

Lawton-Smith S, Dawson J, Burns T. Community treatment orders are not a good thing. British Journal of Psychiatry 2008;193(2):96-100. 
Lidz 1998 \{published data only\}

Lidz CW. Coercion in psychiatric care: what have we learned from research?. Journal of the American Academy of Psychiatry \& the Law 1998;26(4):631-7.

\section{Link 2011 \{published data only\}}

Link BG, Epperson MW, Perron BE, Castille DM, Yang LH. Arrest outcomes associated with outpatient commitment in New York State. Psychiatric Services (Washington, D.C.) 2011;62(5):504-8. [PUBMED: 21532076]

\section{Miller 1984 \{published data only\}}

Miller R, Fiddleman P. Outpatient commitment: treatment in the least restrictive environment?. Hospital and Community Psychiatry 1984;35(2):147-51.

Miller 1985 \{published data only\}

Miller RD. Commitment to outpatient treatment: a national survey. Hospital and Community Psychiatry 1985;36(3):265-7.

\section{Muirhead 2006 \{published data only\}}

Muirhead D, Harvey C, Ingram G. Effectiveness of community treatment orders for treatment of schizophrenia with oral or depot antipsychotic medication: clinical outcomes. Australian and New Zealand Journal of Psychiatry 2006;40(6-7):596-605.

Mullen 2006 \{published data only\}

Mullen R, Dawson J, Gibbs A. Dilemmas for clinicians in use of community treatment orders. International Journal of Law and Psychiatry 2006;29(6):535-50.

\section{Munetz 1996 \{published data only\}}

Munetz MR, Grande T, Kleist J, Peterson G. The effectiveness of outpatient civil commitment. Psychiatric Services 1996;47(11):1251-3

\section{NASMHPD 2001 \{published data only\}}

Medical Directors Council of NASMHPD. Technical report on involuntary outpatient commitment. www.nasmhpd.org/ publicationsmeddir.cfm (accessed 1 May 2010).

NHPF 2000 \{published data only\}

National Health Policy Forum. Outpatient commitment in mental health: is coercion the price of community services?. Issue Brief (George Washington University. National Health Policy Forum) 2000, issue 757:1.

\section{O'Brien 2005 \{published data only\}}

O'Brien AM, Farrell SJ. Community treatment orders: profile of a Canadian experience. Canadian Journal of Psychiatry 2005;50(1):27-30.

\section{O'Keefe 1997 \{published data only\}}

O'Keefe C, Potonza DP, Mueser KT. Treatment outcomes for severely mentally ill patients on conditional discharge to community-based treatment. Journal of Nervous and Mental Disease 1997;185(6):409-11.

\section{O'Reilly 2004 \{published data only\}}

O'Reilly R. Why are community treatment orders controversial?. Canadian Journal of Psychiatry 2004;49(9):579-84.

\section{O'Reilly 2006 \{published data only\}}

O'Reilly RL, Keegan DL, Corring D, Shrikhande S, Natarajan D. A qualitative analysis of the use of community treatment orders in Saskatchewan. International Journal of Law and Psychiatry 2006;29(6):516-24

\section{Patel 2008 \{published data only\}}

Patel G. Community treatment orders in Victoria: a clinicoethical perspective. Australasian Psychiatry 2008;16(5):340-3.

Preston 2002 \{published data only\}

Preston N, Kisely S, Xiao J. Assessing the outcome of compulsory psychiatric treatment in the community: epidemiological study in Western Australia. BMJ 2002;324:1244-9.

Ridgely 2001 \{published data only\}

Ridgely S, Borum R, Pertila J. The Effectiveness of Involuntary Outpatient Treatment. Empirical Evidence and the Experience of Eight States. California: RAND, 2001.

Rohland 1998 \{published data only\}

Rohland BM. The Role of Outpatient Commitment in the Management of Persons with Schizophrenia. Des Moines, IA: lowa Consortium for Mental Health, 1998.

Romans 2004 \{published data only\}

Romans S, Dawson J, Mullen R, Gibbs A. How mental health clinicians view community treatment orders: a national New Zealand survey. Australian and New Zealand Journal of Psychiatry 2004;38(10):836-41.

Segal 2006a \{published data only\} Segal SP, Burgess PM. Effect of conditional release from hospitalization on mortality risk. Psychiatric Services 2006;57(11):1607-13.

\section{Segal 2006b \{published data only\}} Segal SP, Burgess PM. Factors in the selection of patients for conditional release from their first psychiatric hospitalization. Psychiatric Services 2006;57(11):1614-22.

Segal 2006c \{published data only\}

Segal SP, Burgess PM. Conditional hospital release: interpreting the message. Psychiatric Services 2006; Vol. 57, issue 12:1810-1.

\section{Segal 2006d \{published data only\}}

Segal SP, Burgess PM. Conditional release: a less restrictive alternative to hospitalization?. Psychiatric Services 2006;57(11):1600-6.

Segal 2006e \{published data only\} Segal SP, Burgess PM. The utility of extended outpatient civil commitment. International Journal of Law and Psychiatry 2006;29(6):525-34

\section{Segal $2006 f$ \{published data only\}}

Segal SP, Burgess P. Extended outpatient civil commitment and treatment utilization. Social Work in Health Care 2006;43(2-3):37-51. 
Segal 2008 \{published data only\}

Segal SP, Burgess PM. Use of community treatment orders to prevent psychiatric hospitalization. Australian and New Zealand Journal of Psychiatry 2008;42(8):732-9.

\section{Segal 2009 \{published data only\}}

Segal SP, Preston N, Kisely S, Xiao J. Conditional release in Western Australia: effect on hospital length of stay. Psychiatric Services 2009;60(1):94-9.

\section{Sensky 1991 \{published data only\}}

Sensky T, Hughes T, Hirsch S. Compulsory psychiatric treatment in the community. I. A controlled study of compulsory community treatment with extended leave under the Mental Health Act: special characteristics of patients treated and impact of treatment. British Journal of Psychiatry 1991;158:792-9.

\section{Swartz 1997 \{published data only\}}

Swartz MS, Burns BJ, George LK, Swanson J, Hiday VA, Borum R, et al. The ethical challenges of a randomized controlled trial of involuntary outpatient commitment. Journal of Mental Health Administration 1997;24(1):35-43.

\section{Swartz 2004 \{published data only\}}

Swartz MS, Swanson JW. Involuntary outpatient commitment, community treatment orders, and assisted outpatient treatment: what's in the data?. Canadian Journal of Psychiatry 2004;49(9):585-91.

\section{Swartz 2006 \{published data only\}}

Swartz MS, Swanson JW, Kim M, Petrila J. Use of outpatient commitment or related civil court treatment orders in five U.S. communities. Psychiatric Services 2006;57(3):343-9.

\section{Szmukler 2001 \{published data only\}}

Szmukler G, Hotopf M. Effectiveness of involuntary outpatient commitment. American Journal of Psychiatry 2001;158(4):653-4.

\section{Thornicroft 2013 \{published data only\}}

Thornicroft G, Farrelly S, Szmukler G, Birchwood M, Waheed W, Flach C, et al. Clinical outcomes of Joint Crisis Plans to reduce compulsory treatment for people with psychosis: a randomised controlled trial. Lancet 2013;381(9878):1634-41. [PUBMED: 23537606]

\section{Van Putten 1988 \{published data only\}}

Van Putten R, Santiago J, Berren M. Involuntary outpatient commitment in Arizona: a retrospective study. Hospital and Community Psychiatry 1988;39(9):953-8.

\section{Vaughan 2000 \{published data only\}}

Vaughan K, McConaghy N, Wolf C, Myhir C, Black T. Community treatment orders: relationship to clinical care, medication compliance, behavioural disturbance and readmission. Australian and New Zealand Journal of Psychiatry 2000;34:801-8.

\section{Wagner 2003 \{published data only\}}

Wagner HR, Swartz MS, Swanson JW, Burns BJ. Does involuntary outpatient commitment lead to more intensive treatment?. Psychology, Public Policy and Law 2003;9(1/2):145-58.

Wales 2006 \{published data only\}

Wales HW, Hiday VA. PLC or TLC: is outpatient commitment the/an answer?. International Journal of Law and Psychiatry 2006;29(6):451-68

\section{Xiao 2004 \{published data only\}}

Xiao J, Preston NJ, Kisely S. What determines compulsory community treatment? A logistic regression analysis using linked mental health and offender databases. Australian and New Zealand Journal of Psychiatry 2004;38(8):613-8.

\section{Zanni 1986 \{published data only\}}

Zanni G, De Veau L. Inpatient stays before and after outpatient commitment. Hospital and Community Psychiatry 1986;37(9):941-2.

\section{Additional references}

\section{Altman 1996}

Altman DG, Bland JM. Detecting skewness from summary information. BMJ 1996;313:1200.

\section{Begg 1996}

Begg C, Cho M, Eastwood S, Horton R, Moher D, Olkin I, et al. Improving the quality of randomized controlled trials. The CONSORT statement. JAMA 1996;276:637-9.

\section{Bland 1997}

Bland JM. Statistics notes. Trials randomised in clusters. BMJ 1997;315:600.

\section{Boissel 1999}

Boissel JP, Cucherat M, Li W, Chatellier G, Gueyffier F, Buyse $\mathrm{M}$, et al. The problem of therapeutic efficacy indices. 3. Comparison of the indices and their use [Apercu sur la problematique des indices d'efficacite therapeutique, 3 : comparaison des indices et utilisation. Groupe d'Etude des Indices D'efficacite]. Therapie 1999;54(4):405-11. [PUBMED: 10667106]

\section{Churchill 2007}

Churchill R. International experiences of using community treatment orders. London: Institute of Psychiatry, 2007.

\section{Cook 1995}

Cook RJ, Sackett DL. The number needed to treat: a clinically useful measure of treatment effect. BMJ 1995;310:452-4.

\section{Dedman 1990}

Dedman P. Community treatment orders in Victoria, Australia. Psychiatric Bulletin 1990;14:462-4.

\section{Deeks 2000}

Deeks J. Issues in the selection for meta-analyses of binary data. 8th International Cochrane Colloquium; 2000 Oct 25-28 Cape Town. Cape Town: The Cochrane Collaboration, 2000. 


\section{DeRidder 2016}

DeRidder R, Molodynski A, Manning C, McCusker P, Rugkåsa J. Community treatment orders in the UK 5 years on: a repeat national survey of psychiatrists. BJPsych Bulletin 2016;40:119-23.

\section{Dieterich 2010}

Dieterich M, Irving CB, Park B, Marshall M. Case management for people with severe mental disorders. Cochrane Database of Systematic Reviews 2010, Issue 3. [DOI: 10.1002/14651858.CD000050]

\section{Divine 1992}

Divine GW, Brown JT, Frazier LM. The unit of analysis error in studies about physicians' patient care behavior. Journal of General Internal Medicine 1992;7(6):623-9.

\section{Donner 2002}

Donner A, Klar N. Issues in the meta-analysis of cluster randomized trials. Statistics in Medicine 2002;21:2971-80.

\section{Egger 1997}

Egger M, Davey Smith G, Schneider M, Minder CE. Bias in meta-analysis detected by a simple, graphical test. BMJ 1997;315:629-34.

\section{Elbourne 2002}

Elbourne D, Altman DG, Higgins JPT, Curtina F, Worthingtond HV, Vaile A. Meta-analyses involving crossover trials: methodological issues. International Journal of Epidemiology 2002;31(1):140-9.

\section{Fernandez 1990a}

Fernandez GA, Nygard S. Impact of involuntary outpatient commitment on the revolving-door syndrome in North Carolina. Psychiatric Services 1990;41:1001-4.

\section{Furukawa 2006}

Furukawa TA, Barbui C, Cipriani A, Brambilla P, Watanabe N. Imputing missing standard deviations in meta-analyses can provide accurate results. Journal of Clinical Epidemiology 2006;59(7):7-10.

\section{Gray 2010}

Gray JE, McSherry BM, O'Reilly RL, Weller PJ. Australian and Canadian mental health Acts compared. Australian and New Zealand Journal of Psychiatry 2010;44:1126-31.

\section{Gray 2016}

Gray JE, Hastings TJ, Love S, O'Reilly RL. Clinically significant differences among Canadian mental health acts: 2016. Canadian Journal of Psychiatry. Revue Canadienne de Psychiatrie 2016;61:222-6.

\section{Gulliford 1999}

Gulliford MC. Components of variance and intraclass correlations for the design of community-based surveys and intervention studies: data from the Health Survey for England 1994. American Journal of Epidemiology 1999;149:876-83.

\section{Hiday 2002}

Hiday VA, Swartz MS, Swanson JW, Borum R, Wagner HR. Impact of outpatient commitment on victimization of people with severe mental illness. American Journal of Psychiatry 2002;159:1403-11.

\section{Higgins 2003}

Higgins JP, Thompson SG, Deeks JJ, Altman DG. Measuring inconsistency in meta-analyses. BMJ 2003;327(7414):557-60.

\section{Higgins 2008}

Higgins JPT, Green S, editor(s). Cochrane Handbook for Systematic Reviews of Interventions 5.0.1 (updated September 2008). The Cochrane Collaboration, 2008. Available from www.cochrane-handbook.org.

\section{Higgins 2011}

Higgins JPT, Green S, editor(s). Cochrane Handbook for Systematic Reviews of Interventions Version 5.1.0 (updated March 2011). The Cochrane Collaboration, 2011. Available from www.cochrane-handbook.org.

\section{Holloway 1996}

Holloway F. Supervised discharge - paper tiger?. Psychiatric Bulletin 1996;20:193-4.

\section{Hutton 2009}

Hutton JL. Number needed to treat and number needed to harm are not the best way to report and assess the results of randomised clinical trials. British Journal of Haematology 2009;146(1):27-30

\section{Kay 1986}

Kay SR, Opler LA, Fiszbein A. Positive And Negative Syndrome Scale (PANSS) Manual. North Tonawanda, NY: Multi-Health Systems, 1986.

\section{Kay 1987}

Kay SR, Fiszbein A, Opler LA. The Positive And Negative Syndrome Scale (PANSS) for schizophrenia. Schizophrenia bulletin 1987;13(2):261-76. [PUBMED: 3616518]

\section{Kisely 2014a}

Kisely S, Hall K. An updated meta-analysis of randomized controlled evidence for the effectiveness of community treatment orders. Canadian Journal of Psychiatry. Revue Canadienne de Psychiatrie 2014;59:561-4.

\section{Kisely 2015}

Kisely S, O'Reilly R. Reappraising community treatment orders - can there be consensus?. Medical Journal of Australia 2015;202:415-6.

\section{Lansing 1997}

Lansing AE, Lyons JS, Martens LC, O'Mahoney MT, Miller SI, Obolsky A. The treatment of dangerous patients in managed care. Psychiatric hospital utilization and outcome. General Hospital Psychiatry 1997;19(2):112-8. 


\section{Leucht 2005a}

Leucht S, Kane JM, Kissling W, Hamann J, Etschel E, Engel R. Clinical implications of Brief Psychiatric Rating Scale scores. British Journal of Psychiatry 2005;187:366-71. [PUBMED: 16199797]

\section{Leucht 2005b}

Leucht S, Kane JM, Kissling W, Hamann J, Etschel E, Engel RR. What does the PANSS mean?. Schizophrenia Research 2005;79(2-3):231-8. [PUBMED: 15982856]

\section{Leucht 2007}

Leucht S, Engel RR, Bauml J, Davis JM. Is the superior efficacy of new generation antipsychotics an artifact of LOCF?. Schizophrenia Bulletin 2007;33(1):183-91. [PUBMED: 16905632]

\section{Light 2012}

Light E, Kerridge I, Ryan C, Robertson M. Community treatment orders in Australia: rates and patterns of use. Australasian Psychiatry 2012;20:478-82.

\section{Manning 2011}

Manning C, Molodynski A, Rugkåsa J, Dawson J, Burns T. Community treatment orders in England and Wales: national survey of clinicians' views and use. The Psychiatrist 2011;35:328-33.

\section{Marshall 2000}

Marshall M, Lockwood A, Adams C, Bradley C, Joy C, Fenton M. Unpublished rating scales - a major source of bias in randomised controlled trials of treatments for schizophrenia?. British Journal of Psychiatry 2000;176:249-52.

\section{Maughan 2014}

Maughan D, Molodynski A, Rugkasa J, Burns T. A systematic review of the effect of community treatment orders on service use. Social Psychiatry and Psychiatric Epidemiology 2014;49:651-63.

\section{Moher 2001}

Moher D, Schulz KF, Altman D. The CONSORT statement: revised recommendations for improving the quality of reports of parallel-group randomized trials. JAMA 2001;285:1987-91.

\section{Mulvany 1993}

Mulvany J. Compulsory community treatment: implications for community health workers. Australian Journal of Mental Health Nursing 1993;2:183-9.

\section{O'Brien 2014}

O'Brien A J. Community treatment orders in New Zealand: regional variability and international comparisons. Australas Psychiatry 2014;22(4):352-6.

\section{O'Reilly 2000}

O'Reilly R, Keegan D, Elias J. A survey of the use of community treatment orders by psychiatrists in Saskatchewan. Canadian Journal of Psychiatry. Revue Canadienne de Psychiatrie 2000;45:79-81.

\section{O'Reilly 2005}

O'Reilly RL, Gray JE. Is mandatory outpatient treatment effective?. Canadian Journal of Community Mental Health 2005;24:77-83.

\section{O'Reilly 2016}

O'Reilly R, Corring D, Richard J, Plyley C, Pallaveshi L. Do intensive services obviate the need for CTOs?. International Journal of Law and Psychiatry 2016;47:74-8.

\section{Overall 1962}

Overall JE, Gorham DR. The Brief Psychiatric Rating Scale. Psychological Reports 1962;10:799-812.

\section{Pinfold 2001a}

Pinfold V, Bindman J. Is compulsory community treatment ever justified?. Psychiatric Bulletin 2001;25:268-70.

\section{Pinfold 2001b}

Pinfold V, Bindman J, Thornicroft G, Franklin D, Hatfield B. Persuading the persuadable: evaluating compulsory treatment in England using Supervised Discharge Orders. Social Psychiatry and Psychiatric Epidemiology 2001;36:260-6.

\section{Pridham 2015}

Pridham KM, Francombe BA, Simpson AIF, Law SF, Stergiopoulos V, Nakhost A. Perception of coercion among patients with a psychiatric community treatment order: a literature review. Psychiatric Services 2015;67:16-28.

\section{Ridgely 2001}

Ridgely S, Borum R, Petrila J Santa Monica. The Effectiveness of Involuntary Outpatient Treatment, Empirical Evidence and the Experience of Eight States. Santa Monica (CA): RAND Corporation, 2001.

\section{Rugkasa 2014}

Rugkasa J, Dawson J, Burns T. CTOs: what is the state of the evidence?. Social Psychiatry and Psychiatric Epidemiology 2014;49(12):1861-71. [PUBMED: 24562319]

\section{Rust 1989}

Rust J, Golonbok S. Modern Psychometrics. London: Routledge, 1989.

\section{Schünemann 2008}

Schünemann HJ, Oxman AD, Vist GE, Higgins JPT, Deeks JJ, Glasziou P, et al. Chapter 12: Interpreting results and drawing conclusions. In: Higgins JPT, Green S editor(s). Cochrane Handbook for Systematic Reviews of Interventions. The Cochrane Collaboration, 2008:359-83.

\section{Swanson 2014}

Swanson JW, Swartz MS. Why the evidence for outpatient commitment is good enough. Psychiatric services (Washington, D.C.) 2014;65(6):808-11. [PUBMED: 24881685]

\section{Swartz 1995}

Swartz MS, Burns BJ, Hiday VA, George LK, Swanson J, Wagner HR. New directions in research on involuntary outpatient commitment. Psychiatric Services 1995;46:381-5. 


\section{Swartz 2001}

Swartz MS, Swanson JW, Wagner HR, Burns BJ, Hiday VA. Effects of involuntary outpatient commitment and depot antipsychotics on treatment adherence in persons with severe mental illness. Journal of Nervous and Mental Disease 2001;189(9):583-92.

\section{Swartz 2010}

Swartz MS, Wilder CM, Swanson JW, Van Dorn RA, Robbins PC, Steadman $\mathrm{HJ}$, et al. Assessing outcomes for consumers in New York's assisted outpatient treatment program. Psychiatric Services 2010;61(10):976-81.

\section{Taylor 2016}

Taylor M, Macpherson M, Macleod C, Lyons D. Community treatment orders and reduced time in hospital: a nationwide study, 2007-2012. BJPsych Bulletin 2016;40:124-6.

\section{Torrey 1995}

Torrey EF, Kaplan RJ. A national survey of the use of outpatient commitment. Psychiatric Services 1995;46:778-84.

\section{Tsai 2017}

Tsai Gary, Quanbeck Cameron. Assisted outpatient treatment and outpatient commitment. In: Eds Rosner R, Scott CL editor(s). Principles and Practice of Forensic Psychiatry. Third Edition. CRC Press, 2017:136.

\section{Ukoumunne 1999}

Ukoumunne OC, Gulliford MC, Chinn S, Sterne JAC, Burney PGJ. Methods for evaluating area-wide and organisation-based intervention in health and health care: a systematic review. Health Technology Assessment 1999;3(5):1-75.

\section{Woolley 2010}

Woolley S. Involuntary treatment in the community: role of community treatment orders. Psychiatrist 2010;34:441-6. [DOI: 10.1192/pb.bp.109.028027]

\section{Xia 2009}

Xia J, Adams CE, Bhagat N, Bhagat V, Bhoopathi P, El-Sayeh H, et al. Loss to outcomes stakeholder survey: the LOSS study. Psychiatric Bulletin 2009;33(7):254-7.

\section{References to other published versions of this review}

\section{Kisely 2004}

Kisely S, Preston N. Compulsory community treatment and involuntary outpatient treatment for people with severe mental disorders. Cochrane Database of Systematic Reviews 2004, Issue 4. [DOI: 10.1002/14651858.CD004408.pub2]

\section{Kisely 2005}

Kisely S, Campbell LA, Preston N. Compulsory community and involuntary outpatient treatment for people with severe mental disorders. Cochrane Database of Systematic Reviews 2005, Issue 3. [DOI: 10.1002/14651858.CD004408.pub2]

\section{Kisely 2011}

Kisely SR, Campbell LA, Preston NJ. Compulsory community and involuntary outpatient treatment for people with severe mental disorders. Cochrane Database of Systematic Reviews 2011, Issue 2. [DOI: 10.1002/14651858.CD004408.pub3]

\section{Kisely 2014b}

Kisely SR, Campbell LA. Compulsory community and involuntary outpatient treatment for people with severe mental disorders. Cochrane Database of Systematic Reviews 2014, Issue 12. [DOI: $10.1002 / 14651858 . C D 004408 . p u b 4]$

* Indicates the major publication for the study

\section{CHARACTERISTICS OF STUDIES}

Characteristics of included studies [ordered by study ID]

\section{Burns 2013}

Methods Allocation: randomised (1:1 ratio).

Blinding: not blinded: randomisation involved allocation to 2 different types of legal status. Therefore, it was impossible and unlawful to mask research assistants, treating clinicians or participants.

Duration: 12 and 36 months

Participants

\begin{abstract}
Diagnosis: people with psychosis discharged from hospital; $84 \%$ had schizophrenia, diagnostic criteria not stated.

$\mathrm{n}=336$. However, on the 1st day, 1 participant assigned to a CTO withdrew and 2 on Section 17 were excluded ( 1 was already on a CTO and the other had been on a Section 17 too long). This left 333 for an ITT analysis.

Age: 18 to 65 years.

Sex: $225 \mathrm{M}, 111 \mathrm{~F}$
\end{abstract}


Burns 2013 (Continued)

History: involuntarily admitted to hospital with psychosis and deemed suitable for supervised outpatient care by the treating clinicians.

Exclusion criteria: none.

\begin{tabular}{ll}
\hline Interventions & 1. СCT. \\
2. Supervised discharge (Section 17 leave): participants allowed to leave hospital for some hours or \\
days, or even exceptionally weeks, while still subject to recall.
\end{tabular}

Service use: readmission to hospital, number of days in psychiatric hospital, number of readmissions,
time to admission.
Mental state: BPRS.
Global state: GAF.
Unable to use: loss to care, adherence to prescribed medication, satisfaction with services, engage-
ment with clinical services.

Notes

ITT analysis for 12 -month follow-up. All but 3 people were followed up at 36 months $(n=330)$ although not all completed all the secondary and tertiary outcome measures.

Both intervention and control groups were subject to some form of CCT for at least part of the study.

\section{Risk of bias}

\begin{tabular}{|c|c|c|}
\hline Bias & Authors' judgement & Support for judgement \\
\hline $\begin{array}{l}\text { Random sequence genera- } \\
\text { tion (selection bias) }\end{array}$ & Low risk & $\begin{array}{l}\text { Consenting participants were randomly assigned (ratio 1:1) by an independent } \\
\text { statistician to be discharged from hospital either on CTO or Section } 17 \text { leave. } \\
\text { Randomisation used random permuted blocks with lengths of } 2,4 \text { and } 6 \text {, and } \\
\text { stratified for sex (male or female), schizophrenic diagnosis (yes or no) and du- } \\
\text { ration of illness (< } 2 \text { years or } \geq 2 \text { years). Assignments were enclosed in sequen- } \\
\text { tially numbered, opaque, sealed envelopes and stored by a researcher inde- } \\
\text { pendent to the trial team. }\end{array}$ \\
\hline
\end{tabular}

Allocation concealment Unclear risk

The details of the sequence remained unknown to all members of the trial (selection bias) team until recruitment, data collection and analyses were completed.
Randomisation took place after consent was obtained and the baseline inter- view was done. The envelope was opened on the day of the interview by the independent researcher after recording the participant's trial identification number on the envelope. She then communicated the randomised allocation to the recruiting researcher by telephone.

\begin{tabular}{|c|c|c|}
\hline $\begin{array}{l}\text { Blinding (performance } \\
\text { bias and detection bias) } \\
\text { All outcomes }\end{array}$ & High risk & $\begin{array}{l}\text { See above; randomisation involved allocation to } 2 \text { different types of legal sta- } \\
\text { tus. Therefore, it was impossible and unlawful to mask research assistants, } \\
\text { treating clinicians or participants. }\end{array}$ \\
\hline
\end{tabular}

\begin{tabular}{lll}
\hline $\begin{array}{l}\text { Incomplete outcome data } \\
\text { (attrition bias) } \\
\text { All outcomes }\end{array}$ & Low risk & $\begin{array}{l}\text { There was no attrition for the primary outcome measure, or health service use; } \\
\text { outcome data on psychiatric symptoms and the GAF were only available on } \\
70 \% \text { of the sample. }\end{array}$ \\
\hline $\begin{array}{l}\text { Selective reporting (re- } \\
\text { porting bias) }\end{array}$ & Low risk & Not apparent \\
\hline Other bias & High risk & $\begin{array}{l}\text { Other potential sources of bias in the study included allowing clinicians to } \\
\text { make decisions independent of initial randomisation, whereby } 40 \text { participants } \\
(25 \%) \text { allocated to Section } 17 \text { were subsequently placed on a CTO during the } \\
\text { study and } 35 \text { participants randomised to CTOs (22\%) did not actually receive }\end{array}$ \\
\hline
\end{tabular}


the intervention. A sensitivity analysis to remove these protocol violations may, in turn, have left the study underpowered and not removed the possibility that Section 17 participants swapped to a CTO might have been more severely ill than participants remaining on Section 17 as per the protocol. Uncertainty concerning control condition.

Although length of initial compulsory outpatient treatment differed widely between the 2 groups (medians of 183 days with CCT versus 8 days with supervised discharge), Section 17 participants averaged 4 months on some form of compulsory treatment over the 12 months consisting of the mean of 8 days on Section 17 plus periods of compulsory care during follow-up (outcome).

Another potential source of bias was that clinicians could keep participants on Section 17 for a variable period of time. It is possible that participants who were most likely to default on treatment were maintained on Section 17 and that for these participants it acted more like a СTO thus reducing the chance of the study finding an effect of CTOs. A final issue was generalisability. Around $20 \%$ of the sample were ineligible or refused to take part. These participants may have been the most unwell or lacking in insight, and therefore the ones most likely to benefit from CTOs.

\section{Steadman 2001}

Methods Allocation: randomised, described.

Blinding: unclear*.

Duration: 11 months.

Participants Diagnosis: majority had psychosis; diagnostic criteria not stated.

$\mathrm{n}=152$. $^{*}$

Age: $>18$ years.

Sex: $94 \mathrm{M}, 48 \mathrm{~F}$.

History: poor compliance with services when discharged.

Exclusion criteria: history of violence.

Interventions

1. ССT: enhanced service package + intensive, court-ordered compulsory OPC, including involuntary medication for people thought by court to lack capacity to give informed consent. $n=78$.

2. Standard care: enhanced service package with inpatient assessment and comprehensive discharge treatment plan in which participants participated, case management and oversight by OPC co-ordinating plan. $\mathrm{n}=64$. $^{\star *}$

Outcomes Service use: number of admissions, compliance with medication.

Social functioning: number of arrests, homelessness.

Satisfaction with care: perceived coercion (MAES).

We were unable to use:

Service use: hospitalisation; length of stay (no SD), remaining in contact (leaving the study early) (data unusable).

Mental state: PANSS (no SD). 
Steadman 2001 (Continued)

Global state: GAF (no SD).

Quality of life: LBQL (no SD).

Adverse effects: various adverse effects (no SD).

ITT analysis.
* Study did not specifically mention blinding but did use self-report measures for at least some of the
outcomes, which are effectively self-blinding
${ }^{*} 142$ participants completed baseline interview, 10 excluded from all reporting (7 from the CTO group
and 3 from the controls).
${ }^{* *}$ There was a suggestion that members of the control group and their case managers thought that
they were actually on OPC.

\section{Risk of bias}

Bias Authors' judgement Support for judgement

Random sequence genera- Low risk tion (selection bias)

The study used a random number list to identify assignment to either the intervention or control group. Random number list was generated by computer, which then split 200 numbers between groups.

\begin{tabular}{ll}
\hline $\begin{array}{l}\text { Allocation concealment } \\
\text { (selection bias) }\end{array}$ & $\begin{array}{l}\text { Unclear. The printed list was maintained in the research team's office in a } \\
\text { locked file. When the treatment team had completed their treatment plan, } \\
\text { they called the research team who checked the computer list to see whether } \\
\text { the client was to be assigned to the experimental or comparison group. }\end{array}$
\end{tabular}

Blinding (performance High risk No specific mention in the study. Although self-report measures were used for bias and detection bias) at least some of the outcomes, it was unlikely participants, clinicians or assesAll outcomes sors were blind to treatment status. There was also confusion that resulted in some control participants and their clinicians believing that they were in the intervention group.

$\begin{array}{ll}\begin{array}{l}\text { Incomplete outcome data } \\ \text { (attrition bias) }\end{array} & \text { High risk } \\ \text { All outcomes } & \begin{array}{l}\text { Only } 57 \% \text { to } 68 \% \text { of the participants completed interviews at } 1,5 \text { and } 11 \\ \text { months after hospital discharge. Only some outcomes were assessed by ITT } \\ \text { analysis. }\end{array}\end{array}$

Selective reporting (re- Unclear risk Unclear from paper.
porting bias)

\begin{tabular}{ll}
\hline Other bias & Unclear risk \\
& $\begin{array}{l}\text { Unclear, no conflict of interests reported. The New York Police did not bring } \\
\text { people for assessment when they breached their treatment orders. Therefore, } \\
\text { there was no consequence to the order as intended by the law. }\end{array}$
\end{tabular}

\section{Swartz 1999}

Methods $\quad$ Allocation: randomised.
Blinding: not blinded.
Duration: 12 months.

Participants

Diagnosis: schizophrenia, schizoaffective disorder or other major psychotic or affective disorder; diagnostic criteria not stated.

$\mathrm{n}=264{ }^{\star}{ }^{\star}$ 
Swartz 1999 (Continued)

Age: $>18$ years.

Sex: $132 \mathrm{M}, 132 \mathrm{~F}$.

History: ill > 1 year, significant functional impairment (NCFAS score $\geq 90$ ), intensive treatment in past 2 years, awaiting period of court-ordered CCT, only included people discharged from hospital and not those already living in the community.

Exclusion criteria: personality disorder, psychoactive substance-use disorder, organic brain syndrome in absence of primary psychotic or mood disorder, recent serious act of violence involving injury or use of a weapon.*

Interventions

1. СCT: intensive, court-ordered compulsory OPC. $\mathrm{n}=129$.

2. Standard care: control group were released from OPC by notifying the court. $n=135$.

Outcomes Service use: number of admissions, compliance with medication.

Social functioning: number of arrests, threatening behaviour, homelessness.

Quality of life: victimisation; number of violent or non-violent attacks.

Satisfaction with care: perceived coercion (MAES).

We were unable to use:

Hospitalisation: length of stay (data unusable).

Leaving the study early (data unusable).

\section{Notes}

* Data for this review based only on those randomised to treatment groups and only non-violent participants were randomised.

The RCT was supplemented by a non-random post hoc analysis of the intervention group based on duration of involuntary outpatient treatment. Renewals of CCT were not randomised for people who no longer met legal criteria.

ITT analysis.

\section{Risk of bias}

\begin{tabular}{|c|c|c|}
\hline Bias & Authors' judgement & Support for judgement \\
\hline $\begin{array}{l}\text { Random sequence genera- } \\
\text { tion (selection bias) }\end{array}$ & Unclear risk & Stated to be randomised but did not describe process. \\
\hline $\begin{array}{l}\text { Allocation concealment } \\
\text { (selection bias) }\end{array}$ & Unclear risk & Stated to be randomised but did not describe process. \\
\hline $\begin{array}{l}\text { Blinding (performance } \\
\text { bias and detection bias) } \\
\text { All outcomes }\end{array}$ & High risk & $\begin{array}{l}\text { No specific mention in the study. Although self-report measures were used for } \\
\text { at least some of the outcomes, it is unlikely participants, clinicians or asses- } \\
\text { sors were blind to treatment status. }\end{array}$ \\
\hline $\begin{array}{l}\text { Incomplete outcome data } \\
\text { (attrition bias) } \\
\text { All outcomes }\end{array}$ & Low risk & $\begin{array}{l}\text { Of the identified eligible people, about } 12 \% \text { refused to participate. Subse- } \\
\text { quent attrition from the study was } 18.2 \%(n=48) \text { but bias was minimised by } \\
\text { ITT analysis. }\end{array}$ \\
\hline $\begin{array}{l}\text { Selective reporting (re- } \\
\text { porting bias) }\end{array}$ & Unclear risk & Unclear from paper. \\
\hline Other bias & Unclear risk & Unclear, no conflicts of interest reported. \\
\hline
\end{tabular}


BPRS: Brief Psychiatric Rating Scale; CCT: compulsory community treatment; CTO: community treatment order; F: female; GAF: Global Assessment of Functioning Scale; ITT: intention to treat; LBQL: Lehman Brief Quality of Life Interview; M: male; MAES: MacArthur Modified Admission Experience Survey; n: number of participants; NCFAS: North Carolina Functional Assessment Scale; OPC: outpatient commitment; PANSS: Positive and Negative Syndrome Scale; RCT: randomised controlled trial; SD: standard deviation.

\section{Characteristics of excluded studies [ordered by study ID]}

\begin{tabular}{|c|c|}
\hline Study & Reason for exclusion \\
\hline Bindman 2002 & Allocation: not randomised, review. \\
\hline Borum 1999 & Allocation: not randomised. \\
\hline Brophy 2006 & Allocation: not randomised, no controls. \\
\hline Burgess 2006 & Allocation: not randomised. \\
\hline Bursten 1986 & Allocation: not randomised. \\
\hline Chaimowitz 2004 & Review: no primary data. \\
\hline Dawson 2006 & Review: no primary data. \\
\hline Fernandez 1990b & Allocation: not randomised, no controls. \\
\hline Frank 2005 & Allocation: not randomised. \\
\hline Geller 1998 & Allocation: not randomised. \\
\hline Georgieva 2013 & Not an RCT of CTOs \\
\hline Gray 2005 & Review: no primary data. \\
\hline Greeman 1985 & Allocation: not randomised. \\
\hline Hiday 1987 & Allocation: not randomised. \\
\hline Hiday 1989 & Allocation: not randomised. \\
\hline Hiday 1999 & Allocation: not randomised. \\
\hline Hunt 2007 & Allocation: not randomised. \\
\hline Jethwa 2008 & Allocation: not randomised, review. \\
\hline Kanter 1995 & Allocation: not randomised, review. \\
\hline Kisely 2004 & Allocation: not randomised. \\
\hline Kisely 2005 & Allocation: not randomised. \\
\hline Kisely $2006 a$ & Review: no primary data. \\
\hline Kisely $2006 b$ & Review: no primary data. \\
\hline Kisely 2007a & Review: no primary data. \\
\hline
\end{tabular}




\begin{tabular}{|c|c|}
\hline Study & Reason for exclusion \\
\hline Kisely 2007b & Review: no primary data. \\
\hline Kisely $2013 a$ & Allocation: not randomised. \\
\hline Kisely 2013b & Allocation: not randomised. \\
\hline Lawton-Smith 2008 & Review: no primary data. \\
\hline Lidz 1998 & Allocation: not randomised, review. \\
\hline Link 2011 & Allocation: not randomised. \\
\hline Miller 1984 & Allocation: not randomised, before and after design. \\
\hline Miller 1985 & Allocation: not randomised, survey of providers. \\
\hline Muirhead 2006 & Allocation: not randomised, retrospective design. \\
\hline Mullen 2006 & Allocation: not randomised, review. \\
\hline Munetz 1996 & Allocation: not randomised, retrospective design. \\
\hline NASMHPD 2001 & Allocation: not randomised, review. \\
\hline NHPF 2000 & Allocation: not randomised, review. \\
\hline O'Brien 2005 & Allocation: not randomised, no controls. \\
\hline O'Keefe 1997 & Allocation: not randomised, no controls. \\
\hline O'Reilly 2004 & Review: no primary data. \\
\hline O'Reilly 2006 & Qualitative evaluation: not randomised. \\
\hline Patel 2008 & Review: no primary data. \\
\hline Preston 2002 & Allocation: not randomised. \\
\hline Ridgely 2001 & Allocation: not randomised. \\
\hline Rohland 1998 & Allocation: not randomised. \\
\hline Romans 2004 & Allocation: not randomised. \\
\hline Segal 2006a & Allocation: not randomised. \\
\hline Segal 2006b & Allocation: not randomised. \\
\hline Segal 2006c & Allocation: not randomised. \\
\hline Segal 2006d & Allocation: not randomised. \\
\hline Segal 2006e & Allocation: not randomised. \\
\hline Segal $2006 f$ & Allocation: not randomised. \\
\hline
\end{tabular}




\begin{tabular}{|c|c|}
\hline Study & Reason for exclusion \\
\hline Segal 2008 & Allocation: not randomised. \\
\hline Segal 2009 & Allocation: not randomised. \\
\hline Sensky 1991 & Allocation: not randomised. \\
\hline Swartz 1997 & Allocation: not randomised. \\
\hline Swartz 2004 & Allocation: not randomised. \\
\hline Swartz 2006 & Allocation: not randomised. \\
\hline Szmukler 2001 & No primary data. \\
\hline Thornicroft 2013 & Not a study of CCT. \\
\hline Van Putten 1988 & Allocation: not randomised, no controls. \\
\hline Vaughan 2000 & Allocation: not randomised. \\
\hline \multirow[t]{4}{*}{ Wagner 2003} & Allocation: randomised. \\
\hline & $\begin{array}{l}\text { Participants: people with schizophrenia, schizoaffective disorder or other major psychotic or affec- } \\
\text { tive disorders. }\end{array}$ \\
\hline & $\begin{array}{l}\text { Intervention: } 1 \text {. ССT: intensive court-ordered compulsory outpatient commitment vs } 2 \text {. standard } \\
\text { care: control group who were released from outpatient commitment by notifying the court. }\end{array}$ \\
\hline & $\begin{array}{l}\text { Outcomes: no usable outcomes. Only the number of subsequent outpatient visits were reported, } \\
\text { this was considered to be inherent to the process of CCT/outpatient commitment and not a result } \\
\text { of the interventions. }\end{array}$ \\
\hline Wales 2006 & Review: no primary data. \\
\hline Xiao 2004 & Allocation: not randomised. \\
\hline Zanni 1986 & Allocation: not randomised, no controls. \\
\hline
\end{tabular}

СCT: compulsory community treatment; СTO: community treatment order; RCT: randomised controlled trial.

\section{DATA AND ANALYSES}

\section{Comparison 1. COURT ORDERED OUTPATIENT COMMITMENT compared with ENTIRELY VOLUNTARY CARE}

\begin{tabular}{lllll}
\hline Outcome or subgroup title & No. of studies & $\begin{array}{l}\text { No. of partici- } \\
\text { pants }\end{array}$ & Statistical method & Effect size \\
\hline $\begin{array}{l}1 \text { Health service outcomes: 1. Readmission } \\
\text { to hospital - by } 11 \text { to } 12 \text { months }\end{array}$ & 2 & 416 & $\begin{array}{l}\text { Risk Ratio (M-H, Fixed, } \\
95 \% \mathrm{Cl})\end{array}$ & $0.98[0.79,1.21]$ \\
\hline $\begin{array}{l}2 \text { Health service outcomes: 2. Hospital bed- } \\
\text { days }\end{array}$ & 1 & 264 & Mean Difference (IV, & $-1.24[-15.16$, \\
Fixed, 95\% Cl) & $12.68]$ \\
\hline
\end{tabular}




\begin{tabular}{|c|c|c|c|c|}
\hline Outcome or subgroup title & No. of studies & $\begin{array}{l}\text { No. of partici- } \\
\text { pants }\end{array}$ & Statistical method & Effect size \\
\hline $\begin{array}{l}3 \text { Health service outcomes: } 3 \text {. Number with } \\
\text { multiple readmissions by } 12 \text { months }\end{array}$ & 1 & 152 & $\begin{array}{l}\text { Risk Ratio (M-H, Fixed, } \\
95 \% \mathrm{Cl})\end{array}$ & $1.87[0.87,4.01]$ \\
\hline $\begin{array}{l}4 \text { Health service outcomes: } 4 \text {. Compliance } \\
\text { with medication by } 11 \text { to } 12 \text { months }\end{array}$ & 2 & 416 & $\begin{array}{l}\text { Risk Ratio (M-H, Fixed, } \\
95 \% \mathrm{Cl})\end{array}$ & $0.99[0.83,1.19]$ \\
\hline $\begin{array}{l}5 \text { Participant level outcomes: } 1 \text {. Mental state } \\
\text { - psychiatric symptoms and global state at } \\
11 \text { to } 12 \text { months }\end{array}$ & 1 & 98 & $\begin{array}{l}\text { Mean Difference (IV, } \\
\text { Fixed, } 95 \% \mathrm{CI} \text { ) }\end{array}$ & $-3.0[-8.08,2.08]$ \\
\hline $\begin{array}{l}6 \text { Participant level outcomes: } 2 \text {. Social func- } \\
\text { tioning: trouble with police by } 11 \text { to } 12 \\
\text { months }\end{array}$ & 2 & & $\begin{array}{l}\text { Risk Ratio (M-H, Fixed, } \\
95 \% \mathrm{Cl})\end{array}$ & Subtotals only \\
\hline 6.1 at least 1 arrest & 2 & 416 & $\begin{array}{l}\text { Risk Ratio (M-H, Fixed, } \\
95 \% \mathrm{Cl})\end{array}$ & $0.97[0.62,1.52]$ \\
\hline $\begin{array}{l}6.2 \text { ever arrested/picked up by police for vio- } \\
\text { lence against a person }\end{array}$ & 2 & 416 & $\begin{array}{l}\text { Risk Ratio (M-H, Fixed, } \\
95 \% \mathrm{Cl})\end{array}$ & $0.82[0.56,1.21]$ \\
\hline $\begin{array}{l}7 \text { Participant level outcomes: } 3 \text {. Social func- } \\
\text { tioning: homeless by } 11 \text { to } 12 \text { months }\end{array}$ & 2 & 416 & $\begin{array}{l}\text { Risk Ratio (M-H, Fixed, } \\
95 \% \mathrm{Cl})\end{array}$ & $0.67[0.39,1.15]$ \\
\hline $\begin{array}{l}8 \text { Participant level outcomes: } 4 \text {. Quality of } \\
\text { life: Lehman Quality of Life Scale }\end{array}$ & 2 & 406 & $\begin{array}{l}\text { Mean Difference (IV, } \\
\text { Random, } 95 \% \mathrm{CI} \text { ) }\end{array}$ & $-0.22[-0.95,0.50]$ \\
\hline $\begin{array}{l}9 \text { Participant level outcomes: } 5 \text {. Quality of } \\
\text { life: victimisation by } 11 \text { to } 12 \text { months }\end{array}$ & 1 & 264 & $\begin{array}{l}\text { Risk Ratio (M-H, Fixed, } \\
95 \% \mathrm{Cl})\end{array}$ & $0.50[0.31,0.80]$ \\
\hline $\begin{array}{l}10 \text { Participant level outcomes: } 6 \text {. Satisfac- } \\
\text { tion with care: perceived coercion by } 11 \text { to } \\
12 \text { months }\end{array}$ & 2 & 416 & $\begin{array}{l}\text { Risk Ratio (M-H, Fixed, } \\
95 \% \mathrm{Cl})\end{array}$ & $1.36[0.97,1.89]$ \\
\hline
\end{tabular}

\section{Analysis 1.1. Comparison 1 COURT ORDERED OUTPATIENT COMMITMENT compared with ENTIRELY VOLUNTARY CARE, Outcome 1 Health service outcomes: 1. Readmission to hospital - by 11 to 12 months.}

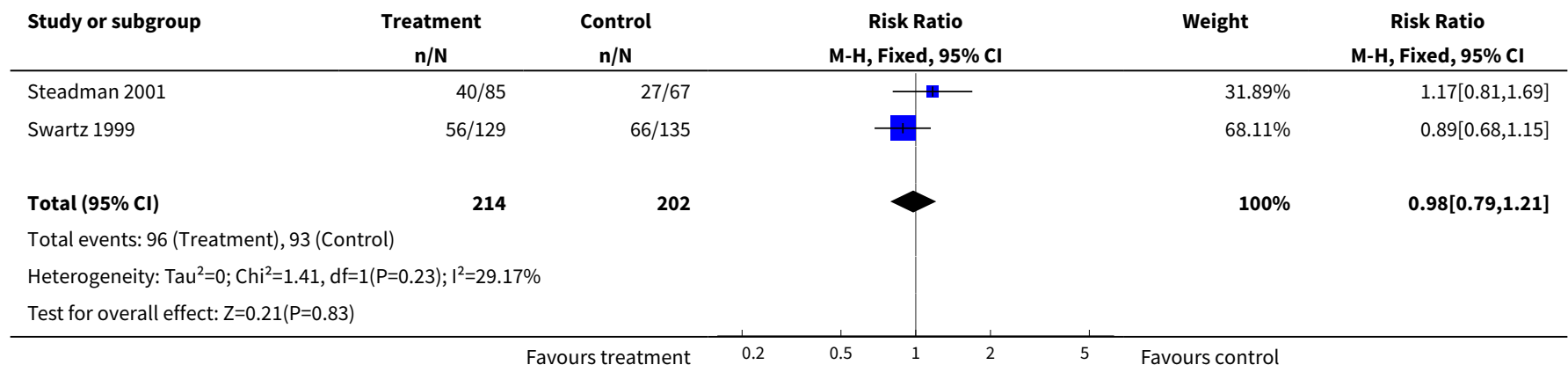


Analysis 1.2. Comparison 1 COURT ORDERED OUTPATIENT COMMITMENT compared with ENTIRELY VOLUNTARY CARE, Outcome 2 Health service outcomes: 2. Hospital bed-days.

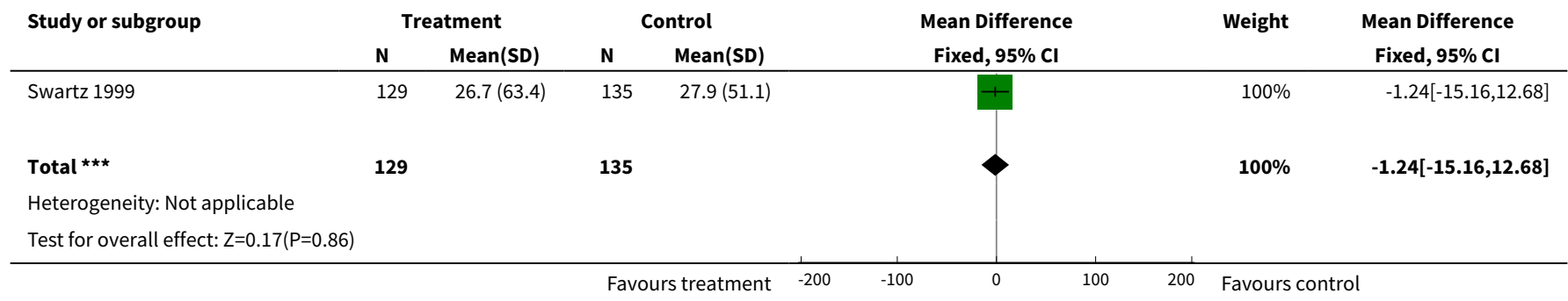

Analysis 1.3. Comparison 1 COURT ORDERED OUTPATIENT COMMITMENT compared with ENTIRELY VOLUNTARY CARE, Outcome 3 Health service outcomes: 3. Number with multiple readmissions by 12 months.

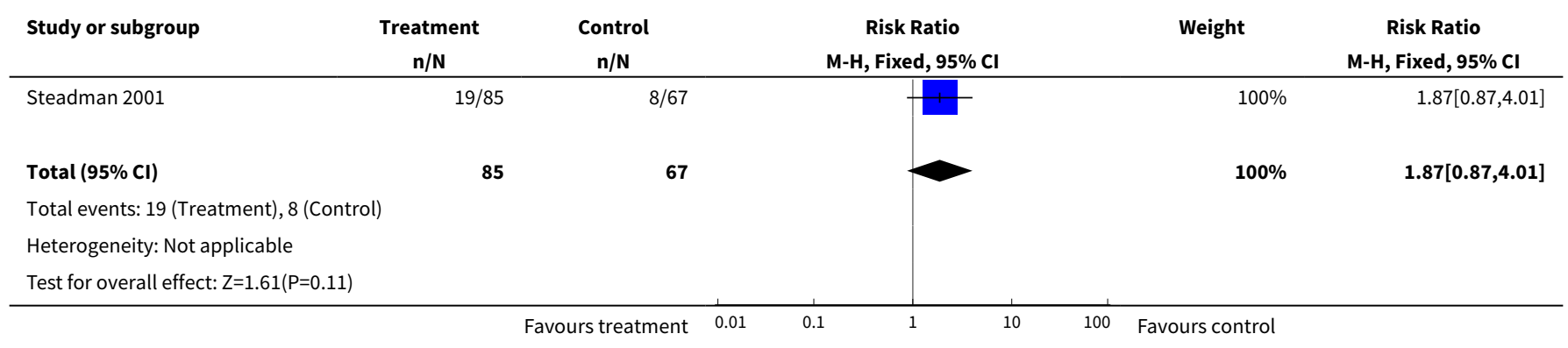

Analysis 1.4. Comparison 1 COURT ORDERED OUTPATIENT COMMITMENT compared with ENTIRELY VOLUNTARY CARE, Outcome 4 Health service outcomes: 4. Compliance with medication by 11 to 12 months.

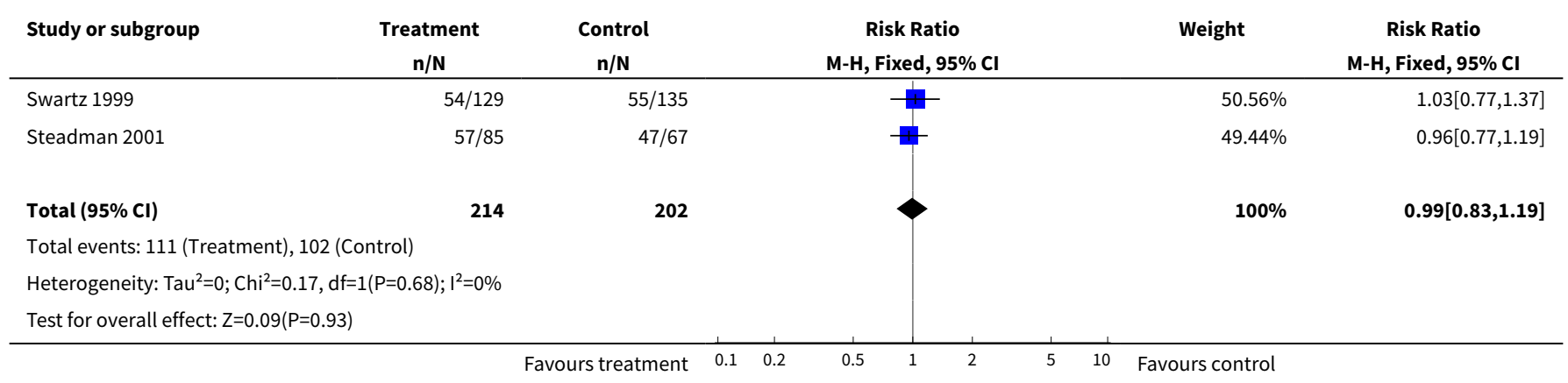

Analysis 1.5. Comparison 1 COURT ORDERED OUTPATIENT COMMITMENT compared with ENTIRELY VOLUNTARY CARE, Outcome 5 Participant level outcomes:

1. Mental state - psychiatric symptoms and global state at 11 to 12 months.

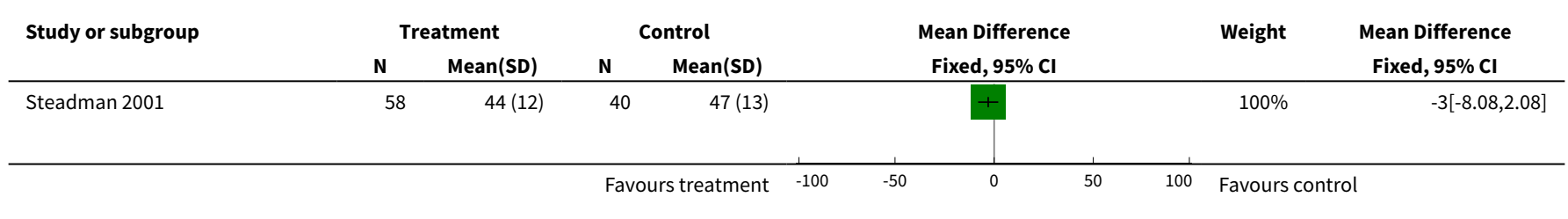




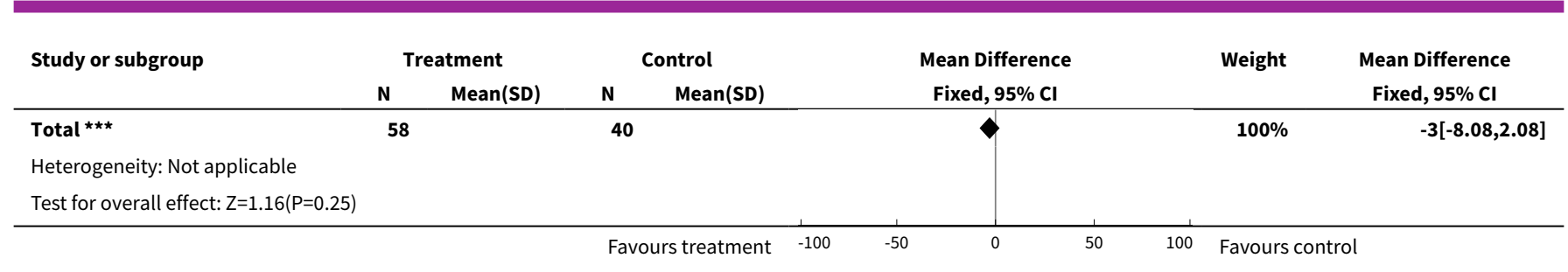

\section{Analysis 1.6. Comparison 1 COURT ORDERED OUTPATIENT COMMITMENT compared with ENTIRELY VOLUNTARY CARE, Outcome 6 Participant level outcomes: 2 . Social functioning: trouble with police by 11 to 12 months.}

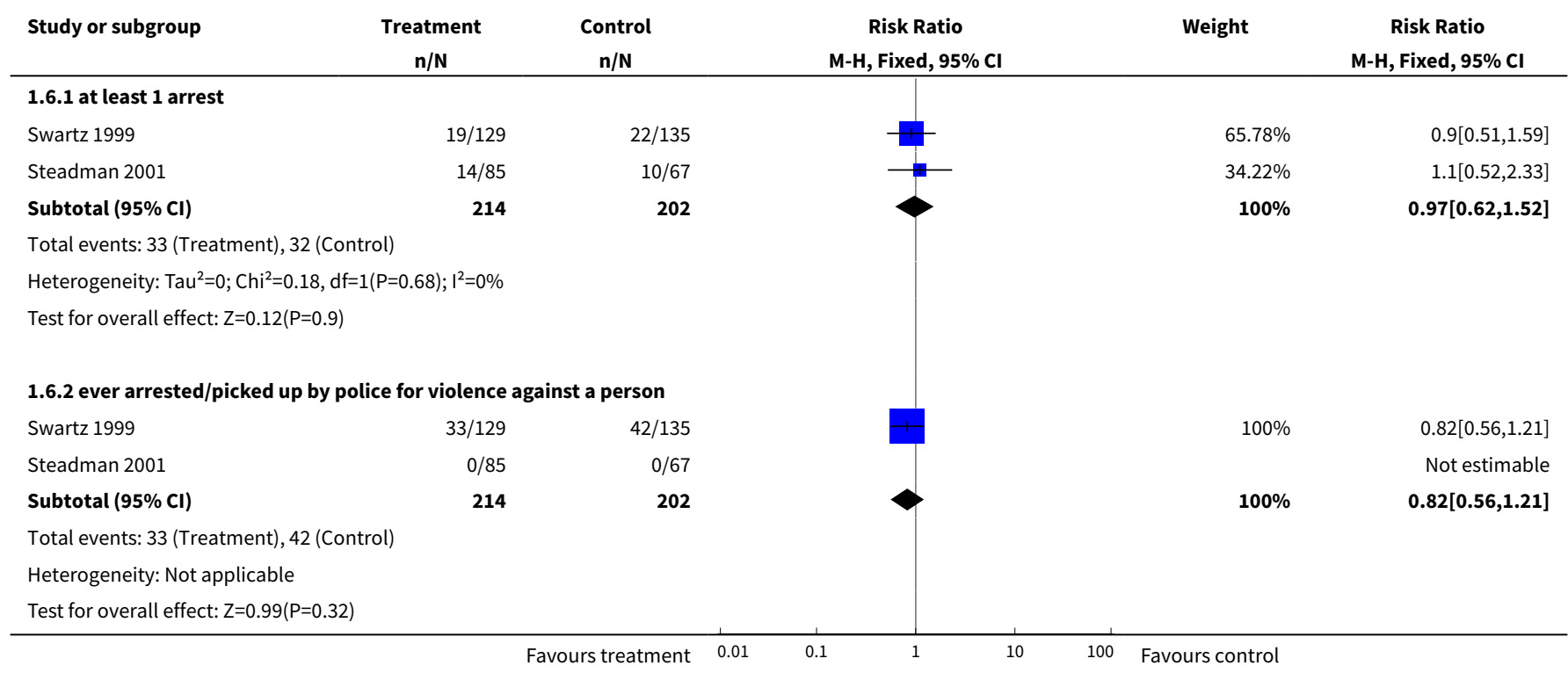

Analysis 1.7. Comparison 1 COURT ORDERED OUTPATIENT COMMITMENT compared with ENTIRELY VOLUNTARY CARE, Outcome 7 Participant level outcomes: 3. Social functioning: homeless by 11 to 12 months.

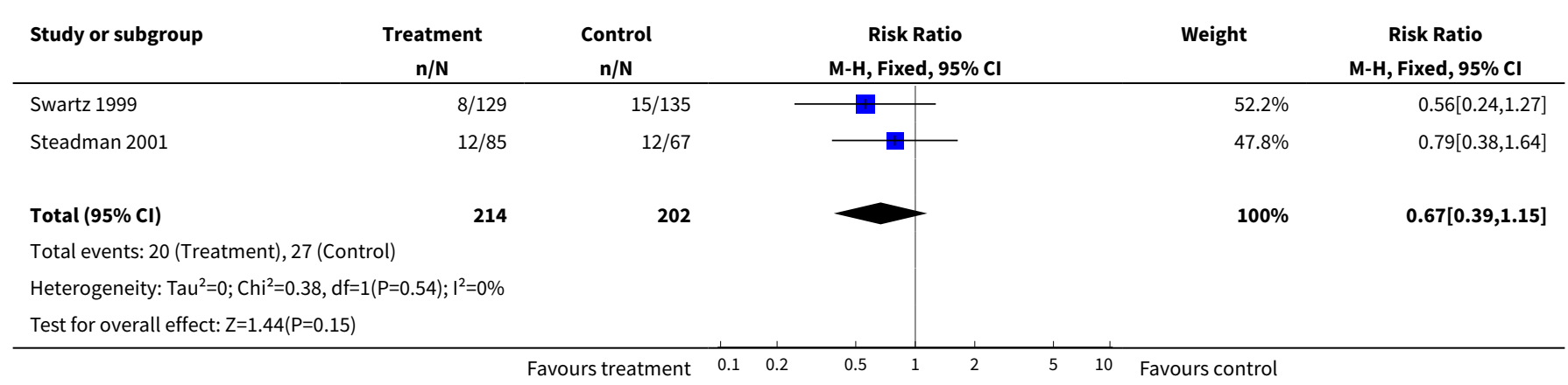


Analysis 1.8. Comparison 1 COURT ORDERED OUTPATIENT COMMITMENT compared with ENTIRELY VOLUNTARY CARE, Outcome 8 Participant level outcomes: 4. Quality of life: Lehman Quality of Life Scale.

\begin{tabular}{|c|c|c|c|c|c|c|c|}
\hline \multirow{3}{*}{$\begin{array}{l}\text { Study or subgroup } \\
\text { Steadman } 2001\end{array}$} & \multicolumn{2}{|c|}{ Treatment } & \multicolumn{2}{|c|}{ Control } & \multirow{2}{*}{$\begin{array}{l}\text { Mean Difference } \\
\text { Random, } 95 \% \mathrm{Cl}\end{array}$} & \multirow[t]{2}{*}{ Weight } & \multirow{2}{*}{$\begin{array}{l}\text { Mean Difference } \\
\text { Random, } 95 \% \mathrm{Cl}\end{array}$} \\
\hline & $\mathbf{N}$ & Mean(SD) & $\mathbf{N}$ & Mean(SD) & & & \\
\hline & 78 & $4.4(0.9)$ & 64 & $5(0.9)$ & 7 & $48.94 \%$ & $-0.6[-0.91,-0.29]$ \\
\hline Swartz 1999 & 129 & $5(0.9)$ & 135 & $4.8(0.9)$ & + & $51.06 \%$ & $0.14[-0.09,0.37]$ \\
\hline 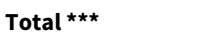 & 207 & & 199 & & & $100 \%$ & $-0.22[-0.95,0.5]$ \\
\hline \multicolumn{8}{|c|}{ Heterogeneity: $\mathrm{Tau}^{2}=0.25 ; \mathrm{Chi}^{2}=14.37, \mathrm{df}=1(\mathrm{P}=0) ; \mathrm{I}^{2}=93.04 \%$} \\
\hline
\end{tabular}

Analysis 1.9. Comparison 1 COURT ORDERED OUTPATIENT COMMITMENT compared with ENTIRELY VOLUNTARY CARE, Outcome 9 Participant level outcomes: 5. Quality of life: victimisation by 11 to 12 months.

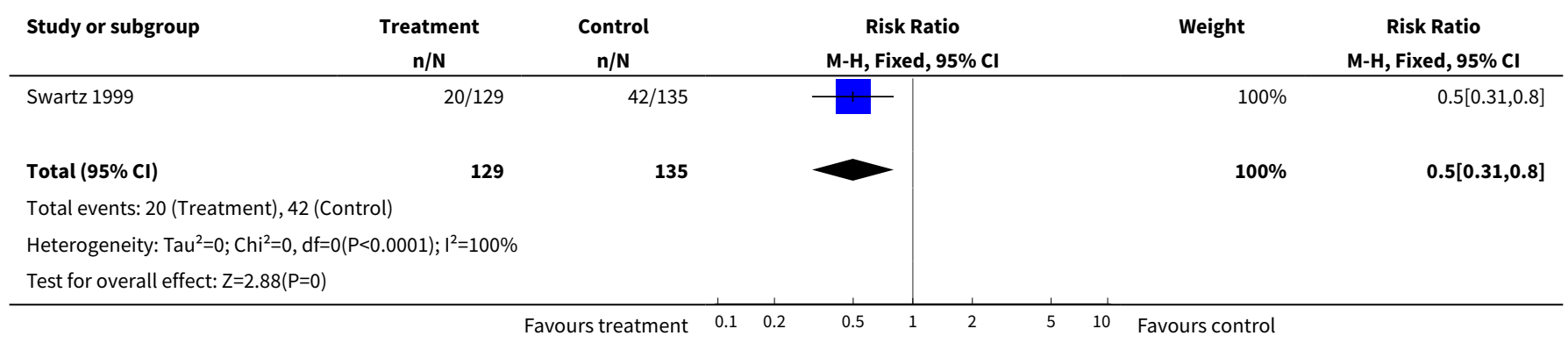

Analysis 1.10. Comparison 1 COURT ORDERED OUTPATIENT COMMITMENT compared with ENTIRELY VOLUNTARY CARE, Outcome 10 Participant level outcomes: 6. Satisfaction with care: perceived coercion by 11 to 12 months.

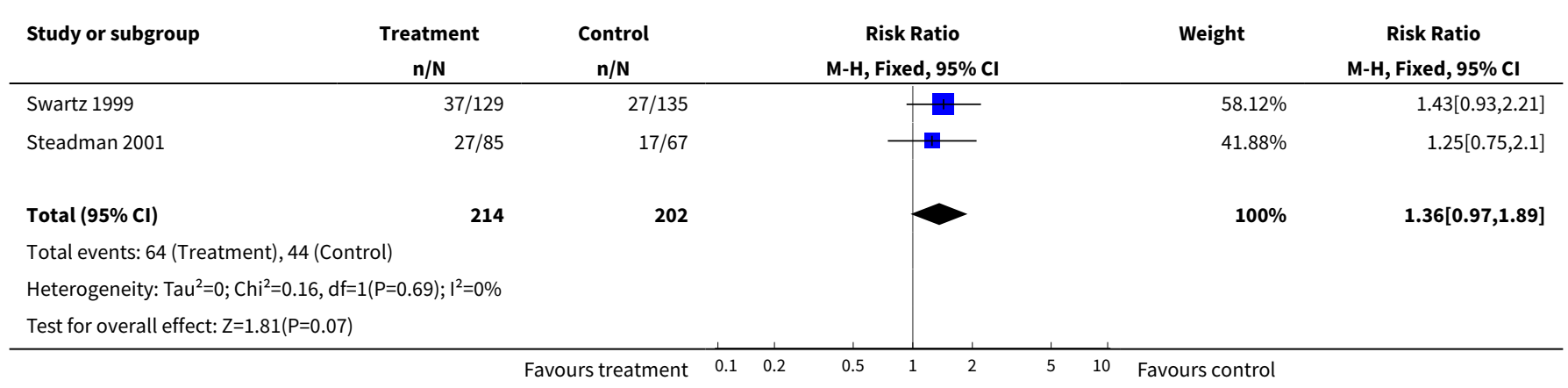

Comparison 2. COMMUNITY TREATMENT ORDERS compared with SUPERVISED DISCHARGE (SECTION 17)

\begin{tabular}{lllll}
\hline Outcome or subgroup title & No. of studies & $\begin{array}{l}\text { No. of partici- } \\
\text { pants }\end{array}$ & Statistical method & Effect size \\
\hline $\begin{array}{l}1 \text { Health service outcomes: 1a. Readmis- } \\
\text { sion to hospital - by } 12 \text { months }\end{array}$ & 1 & 333 & $\begin{array}{l}\text { Risk Ratio (M-H, Fixed, } \\
95 \% \mathrm{Cl})\end{array}$ & $0.99[0.74,1.32]$ \\
\hline
\end{tabular}




\begin{tabular}{|c|c|c|c|c|}
\hline Outcome or subgroup title & No. of studies & $\begin{array}{l}\text { No. of partici- } \\
\text { pants }\end{array}$ & Statistical method & Effect size \\
\hline $\begin{array}{l}2 \text { Health service outcomes. } 1 \text { b. Readmis- } \\
\text { sion to hospital by } 36 \text { months }\end{array}$ & 1 & & $\begin{array}{l}\text { Odds Ratio (M-H, Fixed, } \\
95 \% \mathrm{Cl})\end{array}$ & Subtotals only \\
\hline 2.1 Readmission & 1 & 330 & $\begin{array}{l}\text { Odds Ratio (M-H, Fixed, } \\
95 \% \mathrm{Cl})\end{array}$ & $0.71[0.45,1.11]$ \\
\hline $2.2>1$ readmission & 1 & 213 & $\begin{array}{l}\text { Odds Ratio (M-H, Fixed, } \\
95 \% \mathrm{Cl})\end{array}$ & $1.07[0.62,1.85]$ \\
\hline $\begin{array}{l}3 \text { Health service outcomes: } 2 \text {. Hospital bed- } \\
\text { days by } 12 \text { months }\end{array}$ & 1 & 333 & $\begin{array}{l}\text { Mean Difference (IV, } \\
\text { Fixed, } 95 \% \mathrm{CI} \text { ) }\end{array}$ & $\begin{array}{l}-8.70[-30.88 \\
13.48]\end{array}$ \\
\hline $\begin{array}{l}4 \text { Health service outcomes: } 3 \text {. Number of } \\
\text { readmissions by } 12 \text { months }\end{array}$ & 1 & 119 & $\begin{array}{l}\text { Mean Difference (IV, } \\
\text { Fixed, } 95 \% \mathrm{CI} \text { ) }\end{array}$ & $-0.20[-0.45,0.05]$ \\
\hline $\begin{array}{l}5 \text { Health service outcomes: } 4 \text {. Number with } \\
\text { multiple readmissions by } 12 \text { months }\end{array}$ & 1 & 333 & $\begin{array}{l}\text { Risk Ratio (M-H, Fixed, } \\
95 \% \mathrm{Cl})\end{array}$ & $0.56[0.27,1.17]$ \\
\hline $\begin{array}{l}6 \text { Health service outcomes: } 5 \text { a. Days } \\
\text { in community till first admission by } 12 \\
\text { months }\end{array}$ & 1 & 333 & $\begin{array}{l}\text { Mean Difference (IV, } \\
\text { Fixed, } 95 \% \mathrm{CI} \text { ) }\end{array}$ & $\begin{array}{l}5.0[-21.74 \\
31.74]\end{array}$ \\
\hline $\begin{array}{l}7 \text { Health service outcomes: } 5 b \text {. Days in } \\
\text { community till first admission and mean } \\
\text { duration of bed-days by } 36 \text { months }\end{array}$ & 1 & & $\begin{array}{l}\text { Mean Difference (IV, } \\
\text { Fixed, } 95 \% \mathrm{CI} \text { ) }\end{array}$ & Subtotals only \\
\hline 7.1 Time to 1 st readmission in days & 1 & 330 & $\begin{array}{l}\text { Mean Difference (IV, } \\
\text { Fixed, } 95 \% \mathrm{CI} \text { ) }\end{array}$ & $\begin{array}{l}60.0[-27.62 \\
147.62]\end{array}$ \\
\hline 7.2 Mean duration of bed-days & 1 & 212 & $\begin{array}{l}\text { Mean Difference (IV, } \\
\text { Fixed, } 95 \% \mathrm{CI} \text { ) }\end{array}$ & $\begin{array}{l}-15.10[-89.39 \\
59.19]\end{array}$ \\
\hline $\begin{array}{l}8 \text { Participant level outcomes: } 1 \text {. Mental } \\
\text { state - psychiatric symptoms at } 12 \text { months } \\
\text { (BPRS) }\end{array}$ & 1 & 234 & $\begin{array}{l}\text { Mean Difference (IV, } \\
\text { Fixed, } 95 \% \mathrm{CI} \text { ) }\end{array}$ & $-0.10[-3.17,2.97]$ \\
\hline $\begin{array}{l}9 \text { Participant level outcomes: } 2 \text {. Global } \\
\text { state: GAF at } 12 \text { months }\end{array}$ & 1 & 237 & $\begin{array}{l}\text { Mean Difference (IV, } \\
\text { Fixed, } 95 \% \mathrm{CI} \text { ) }\end{array}$ & $-0.70[-3.91,2.51]$ \\
\hline $\begin{array}{l}10 \text { Participant level outcomes: } 3 \text {. Satisfac- } \\
\text { tion with care: perceived coercion at } 11 \text { to } \\
12 \text { months }\end{array}$ & 1 & 182 & $\begin{array}{l}\text { Mean Difference (IV, } \\
\text { Fixed, } 95 \% \mathrm{CI} \text { ) }\end{array}$ & $-0.5[-1.71,0.71]$ \\
\hline $\begin{array}{l}11 \text { Participant level outcomes: } 4 \text {. Satisfac- } \\
\text { tion with care: leverage at } 11 \text { to } 12 \text { months }\end{array}$ & 1 & 229 & $\begin{array}{l}\text { Odds Ratio (M-H, Fixed, } \\
95 \% \mathrm{Cl})\end{array}$ & $1.23[0.66,2.31]$ \\
\hline $\begin{array}{l}12 \text { Participant level outcomes: } 5 \text {. Social } \\
\text { Outcomes Index at } 12 \text { months }\end{array}$ & 1 & 236 & $\begin{array}{l}\text { Mean Difference (IV, } \\
\text { Fixed, } 95 \% \mathrm{CI} \text { ) }\end{array}$ & $-0.10[-0.40,0.20]$ \\
\hline
\end{tabular}


Analysis 2.1. Comparison 2 COMMUNITY TREATMENT ORDERS compared with SUPERVISED DISCHARGE (SECTION 17), Outcome 1 Health service outcomes: 1a. Readmission to hospital - by 12 months.

\begin{tabular}{|c|c|c|c|c|c|}
\hline Study or subgroup & $\begin{array}{c}\text { Treatment } \\
\mathrm{n} / \mathrm{N}\end{array}$ & $\begin{array}{c}\text { Control } \\
n / N\end{array}$ & $\begin{array}{c}\text { Risk Ratio } \\
\text { M-H, Fixed, } 95 \% \mathrm{CI}\end{array}$ & Weight & $\begin{array}{c}\text { Risk Ratio } \\
\text { M-H, Fixed, 95\% Cl }\end{array}$ \\
\hline Burns 2013 & $59 / 166$ & $60 / 167$ & & $100 \%$ & $0.99[0.74,1.32]$ \\
\hline Total $(95 \% \mathrm{Cl})$ & 166 & 167 & & $100 \%$ & $0.99[0.74,1.32]$ \\
\hline \multicolumn{6}{|c|}{ Total events: 59 (Treatment), 60 (Control) } \\
\hline \multicolumn{6}{|c|}{ Heterogeneity: Tau $^{2}=0 ; \mathrm{Chi}^{2}=0, \mathrm{df}=0(\mathrm{P}<0.0001) ; \mathrm{I}^{2}=100 \%$} \\
\hline
\end{tabular}

Analysis 2.2. Comparison 2 COMMUNITY TREATMENT ORDERS compared with SUPERVISED DISCHARGE (SECTION 17), Outcome 2 Health service outcomes. 1b. Readmission to hospital by 36 months.

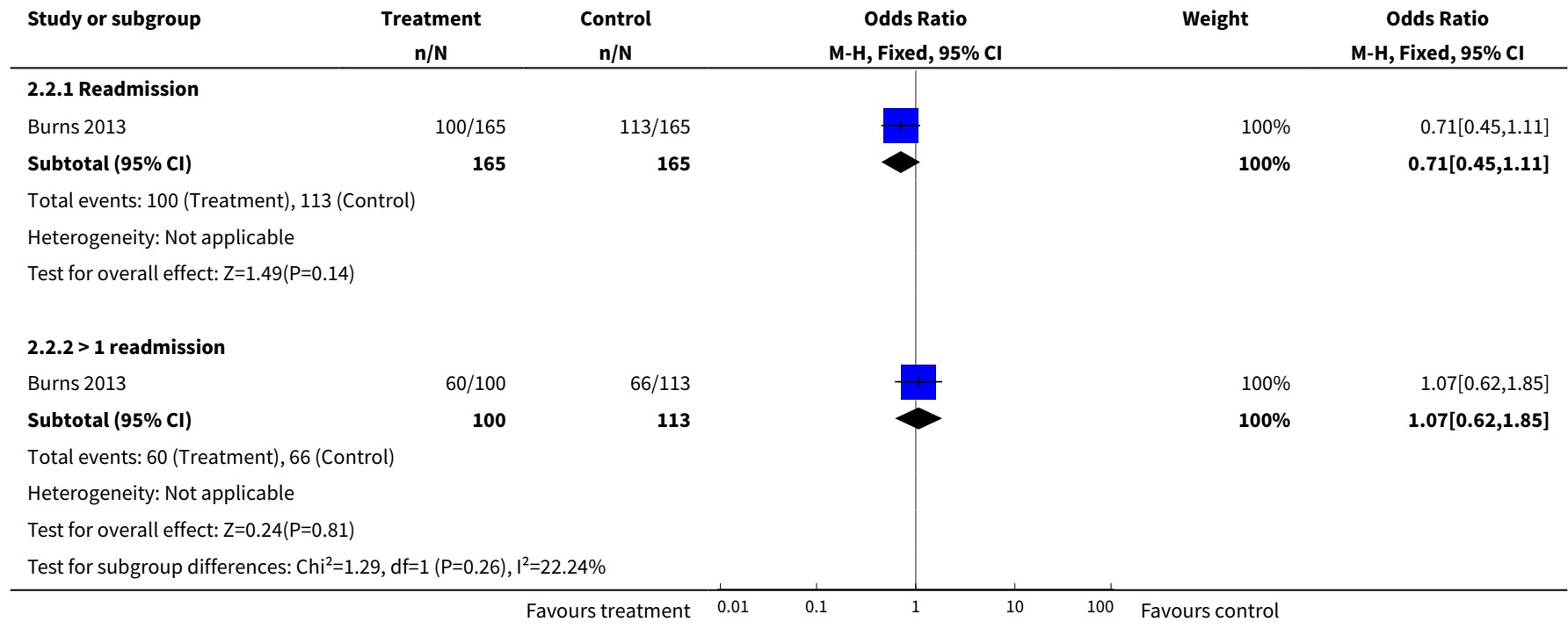

Analysis 2.3. Comparison 2 COMMUNITY TREATMENT ORDERS compared with SUPERVISED DISCHARGE (SECTION 17), Outcome 3 Health service outcomes: 2. Hospital bed-days by 12 months.

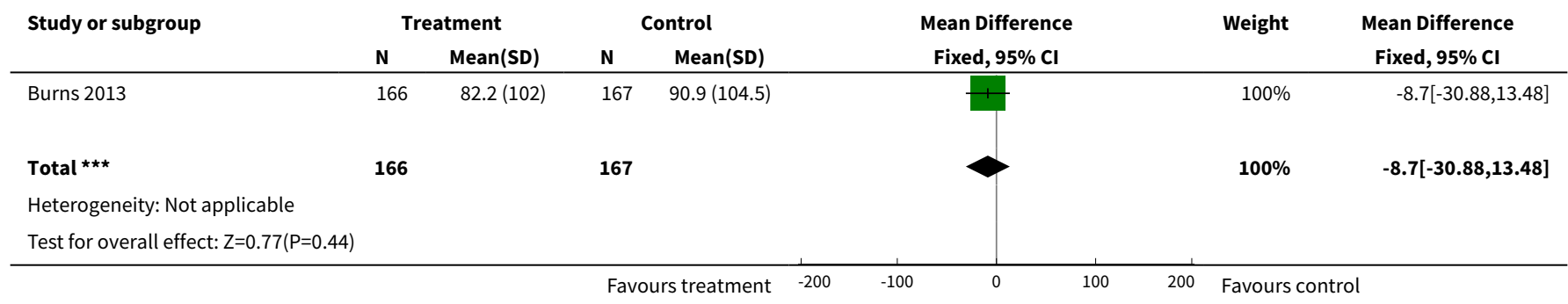


Analysis 2.4. Comparison 2 COMMUNITY TREATMENT ORDERS compared with SUPERVISED DISCHARGE (SECTION 17), Outcome 4 Health service outcomes: 3. Number of readmissions by 12 months.

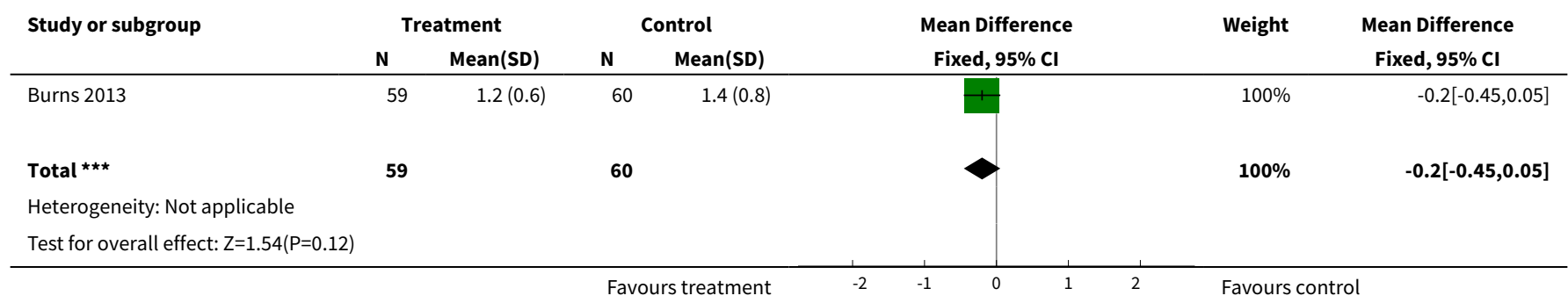

Analysis 2.5. Comparison 2 COMMUNITY TREATMENT ORDERS compared with SUPERVISED DISCHARGE

(SECTION 17), Outcome 5 Health service outcomes: 4. Number with multiple readmissions by 12 months.

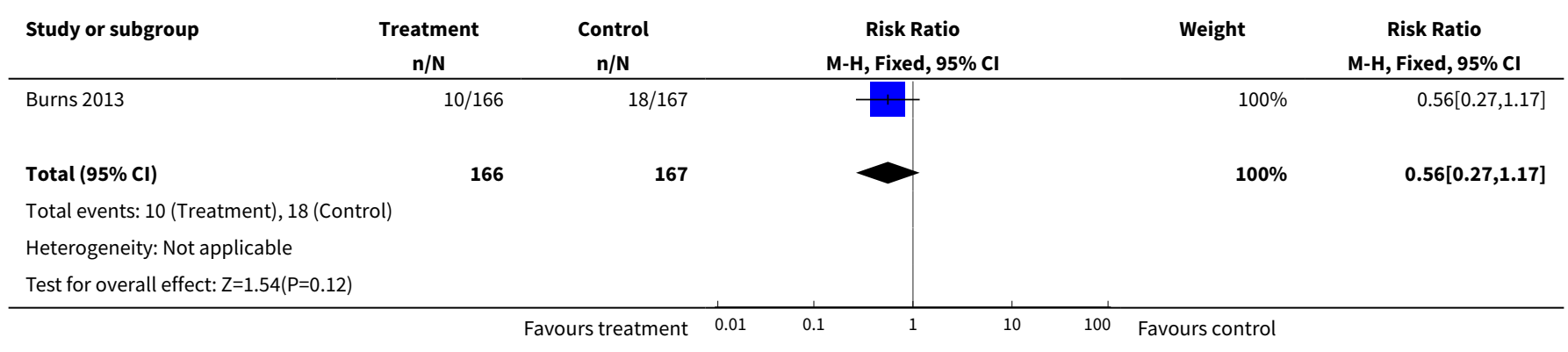

Analysis 2.6. Comparison 2 COMMUNITY TREATMENT ORDERS compared with SUPERVISED DISCHARGE (SECTION 17), Outcome 6 Health service outcomes: 5a. Days in community till first admission by 12 months.

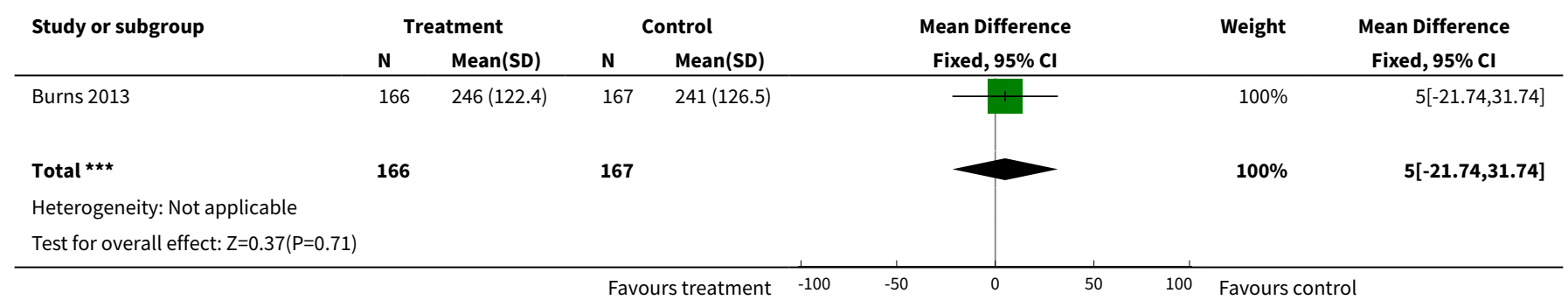

Analysis 2.7. Comparison 2 COMMUNITY TREATMENT ORDERS compared with SUPERVISED DISCHARGE (SECTION 17), Outcome 7 Health service outcomes: 5 b. Days in community till first admission and mean duration of bed-days by $\mathbf{3 6}$ months.

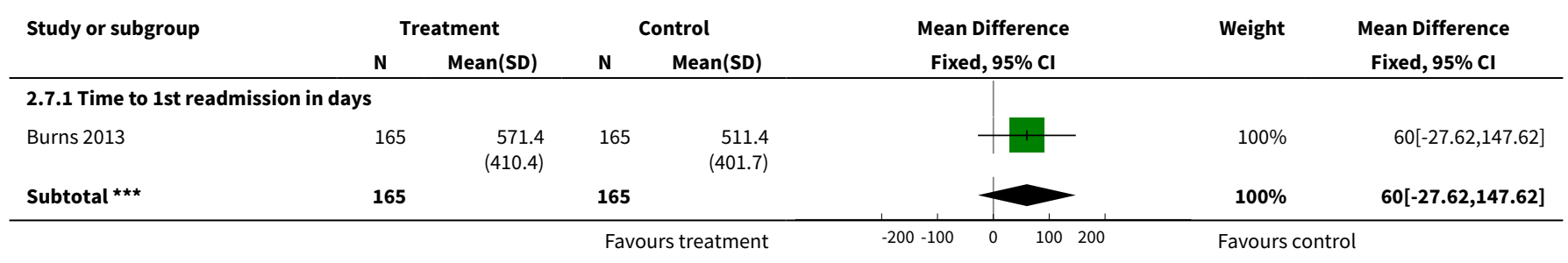




\begin{tabular}{|c|c|c|c|c|c|c|c|}
\hline \multirow[t]{2}{*}{ Study or subgroup } & \multicolumn{2}{|c|}{ Treatment } & \multicolumn{2}{|c|}{ Control } & \multirow{2}{*}{$\begin{array}{c}\text { Mean Difference } \\
\text { Fixed, } 95 \% \mathrm{Cl} \\
\end{array}$} & \multirow[t]{2}{*}{ Weight } & \multirow{2}{*}{$\begin{array}{c}\text { Mean Difference } \\
\text { Fixed, } 95 \% \mathrm{Cl}\end{array}$} \\
\hline & $\mathbf{N}$ & Mean(SD) & $\mathbf{N}$ & Mean(SD) & & & \\
\hline \multicolumn{8}{|c|}{ Heterogeneity: Not applicable } \\
\hline \multicolumn{8}{|c|}{ Test for overall effect: $Z=1.34(P=0.18)$} \\
\hline \multicolumn{8}{|c|}{ 2.7.2 Mean duration of bed-days } \\
\hline Burns 2013 & 100 & $237(269.1)$ & 112 & $\begin{array}{r}252.1 \\
(282.5)\end{array}$ & - & $100 \%$ & $-15.1[-89.39,59.19]$ \\
\hline Subtotal $\star \star \star$ & 100 & & 112 & & & $100 \%$ & $-15.1[-89.39,59.19]$ \\
\hline \multicolumn{8}{|c|}{ Heterogeneity: Not applicable } \\
\hline \multicolumn{8}{|c|}{ Test for overall effect: $Z=0.4(P=0.69)$} \\
\hline \multicolumn{8}{|c|}{ Test for subgroup differences: $\mathrm{Chi}^{2}=1.64, \mathrm{df}=1(\mathrm{P}=0.2), \mathrm{I}^{2}=39.09 \%$} \\
\hline
\end{tabular}

Analysis 2.8. Comparison 2 COMMUNITY TREATMENT ORDERS compared with SUPERVISED DISCHARGE (SECTION 17), Outcome 8 Participant level outcomes: 1 . Mental state - psychiatric symptoms at 12 months (BPRS).

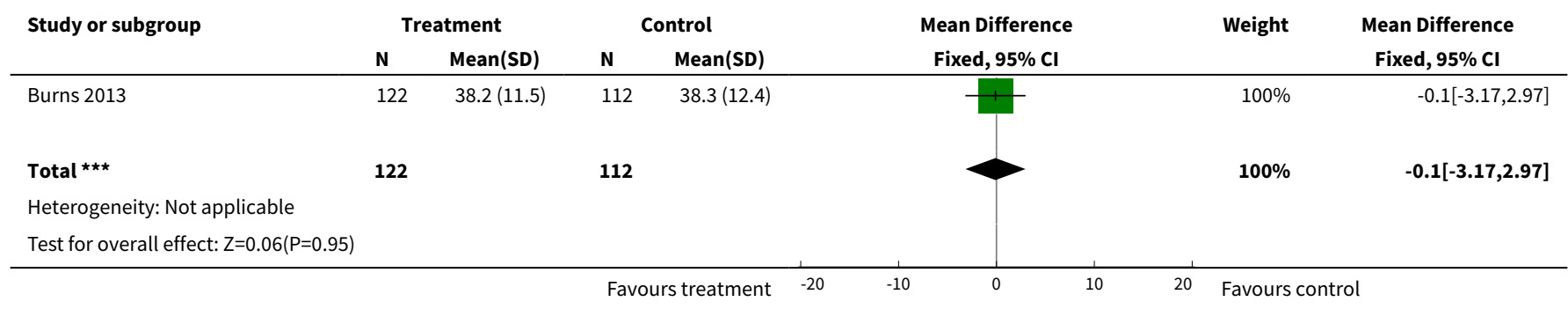

Analysis 2.9. Comparison 2 COMMUNITY TREATMENT ORDERS compared with SUPERVISED DISCHARGE (SECTION 17), Outcome 9 Participant level outcomes: 2. Global state: GAF at 12 months.

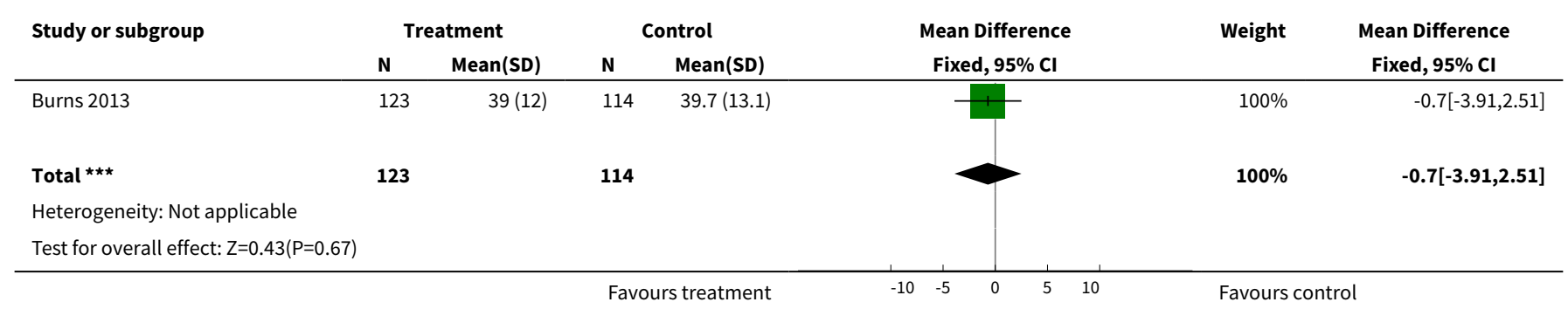

Analysis 2.10. Comparison 2 COMMUNITY TREATMENT ORDERS compared with SUPERVISED DISCHARGE (SECTION 17), Outcome 10 Participant level outcomes: 3. Satisfaction with care: perceived coercion at 11 to 12 months.

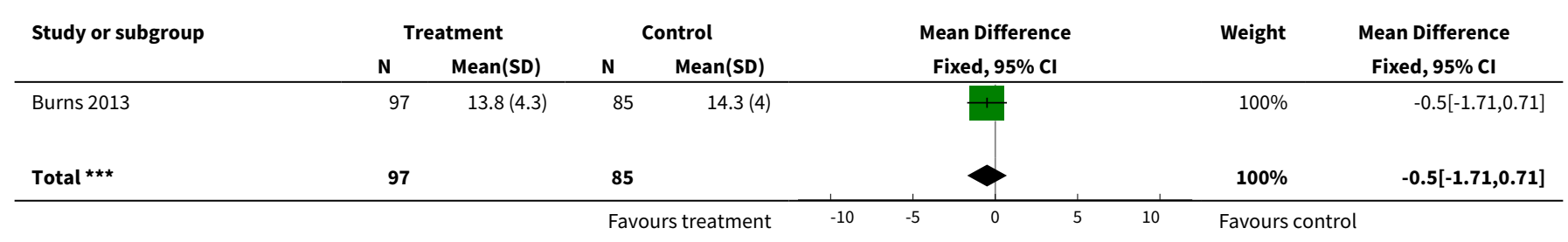




\begin{tabular}{|c|c|c|c|c|c|c|c|c|}
\hline \multirow[t]{2}{*}{ Study or subgroup } & Treatment & \multicolumn{2}{|c|}{ Control } & \multirow{2}{*}{\multicolumn{3}{|c|}{$\begin{array}{c}\text { Mean Difference } \\
\text { Fixed, } 95 \% \mathrm{Cl}\end{array}$}} & \multirow[t]{2}{*}{ Weight } & \multirow{2}{*}{$\begin{array}{c}\text { Mean Difference } \\
\text { Fixed, } 95 \% \mathrm{Cl} \\
\end{array}$} \\
\hline & $\operatorname{Mean}(S D)$ & $\mathbf{N}$ & Mean(SD) & & & & & \\
\hline \multicolumn{9}{|l|}{ Heterogeneity: Not applicable } \\
\hline \multicolumn{9}{|l|}{ Test for overall effect: $Z=0.81(P=0.42)$} \\
\hline
\end{tabular}

Analysis 2.11. Comparison 2 COMMUNITY TREATMENT ORDERS compared with SUPERVISED DISCHARGE (SECTION 17), Outcome 11 Participant level outcomes: 4. Satisfaction with care: leverage at 11 to 12 months.

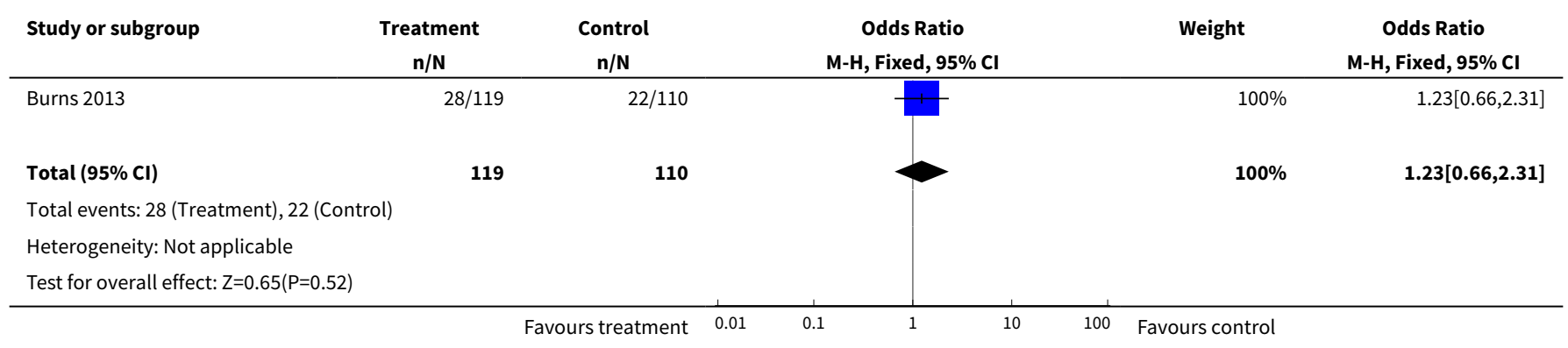

Analysis 2.12. Comparison 2 COMMUNITY TREATMENT ORDERS compared with SUPERVISED DISCHARGE (SECTION 17), Outcome 12 Participant level outcomes: 5. Social Outcomes Index at 12 months.

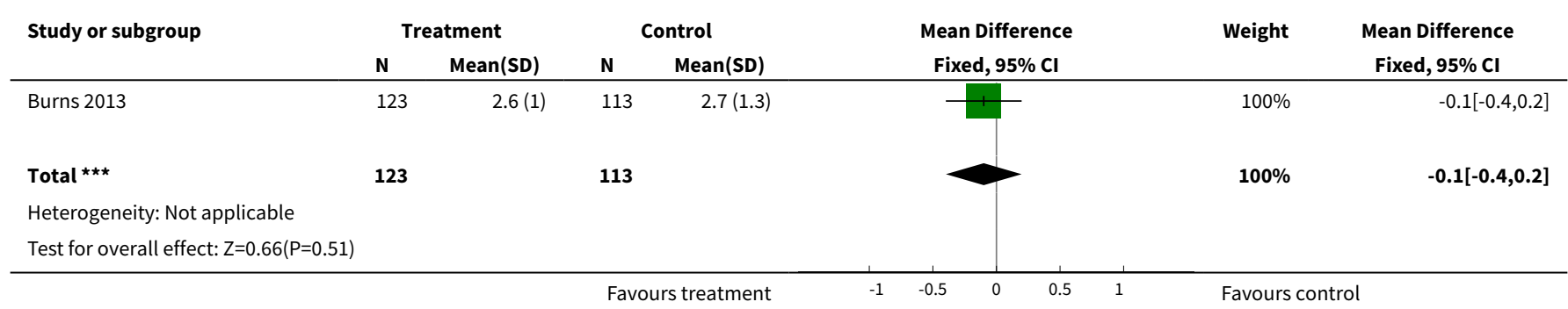

\section{Comparison 3. COMPULSORY COMMUNITY TREATMENT compared with STANDARD CARE}

\begin{tabular}{|c|c|c|c|c|}
\hline Outcome or subgroup title & No. of studies & $\begin{array}{l}\text { No. of partici- } \\
\text { pants }\end{array}$ & Statistical method & Effect size \\
\hline $\begin{array}{l}1 \text { Health service outcomes: } 1 \text {. Readmission } \\
\text { to hospital by } 11 \text { to } 12 \text { months }\end{array}$ & 3 & 749 & $\begin{array}{l}\text { Risk Ratio (M-H, Fixed, } \\
95 \% \mathrm{Cl})\end{array}$ & $0.98[0.83,1.17]$ \\
\hline $\begin{array}{l}2 \text { Health service outcomes: } 2 \text {. Hospital bed- } \\
\text { days }\end{array}$ & 2 & 597 & $\begin{array}{l}\text { Mean Difference (IV, } \\
\text { Fixed, } 95 \% \mathrm{CI} \text { ) }\end{array}$ & $\begin{array}{l}-3.35[-15.14 \\
8.44]\end{array}$ \\
\hline $\begin{array}{l}3 \text { Health service outcomes: } 3 \text {. Number with } \\
\text { multiple readmissions by } 12 \text { months }\end{array}$ & 2 & 485 & $\begin{array}{l}\text { Risk Ratio (M-H, Ran- } \\
\text { dom, } 95 \% \mathrm{Cl})\end{array}$ & $1.02[0.31,3.33]$ \\
\hline $\begin{array}{l}4 \text { Participant level outcomes: } 1 \text {. global state: } \\
\text { GAF at } 12 \text { months }\end{array}$ & 2 & 335 & $\begin{array}{l}\text { Mean Difference (IV, } \\
\text { Fixed, } 95 \% \mathrm{CI} \text { ) }\end{array}$ & $-1.36[-4.07,1.35]$ \\
\hline
\end{tabular}




\begin{tabular}{lllll}
\hline Outcome or subgroup title & No. of studies & $\begin{array}{l}\text { No. of partici- } \\
\text { pants }\end{array}$ & Statistical method & Effect size \\
\hline $\begin{array}{l}5 \text { Participant level outcomes: 2. Satisfaction } \\
\text { with care: perceived coercion or leverage at } \\
11 \text { to } 12 \text { months }\end{array}$ & 3 & 645 & $\begin{array}{l}\text { Risk Ratio (M-H, Fixed, } \\
95 \% \mathrm{Cl})\end{array}$ & $1.30[0.98,1.71]$ \\
\hline
\end{tabular}

Analysis 3.1. Comparison 3 COMPULSORY COMMUNITY TREATMENT compared with STANDARD CARE, Outcome 1 Health service outcomes: 1. Readmission to hospital by 11 to 12 months.

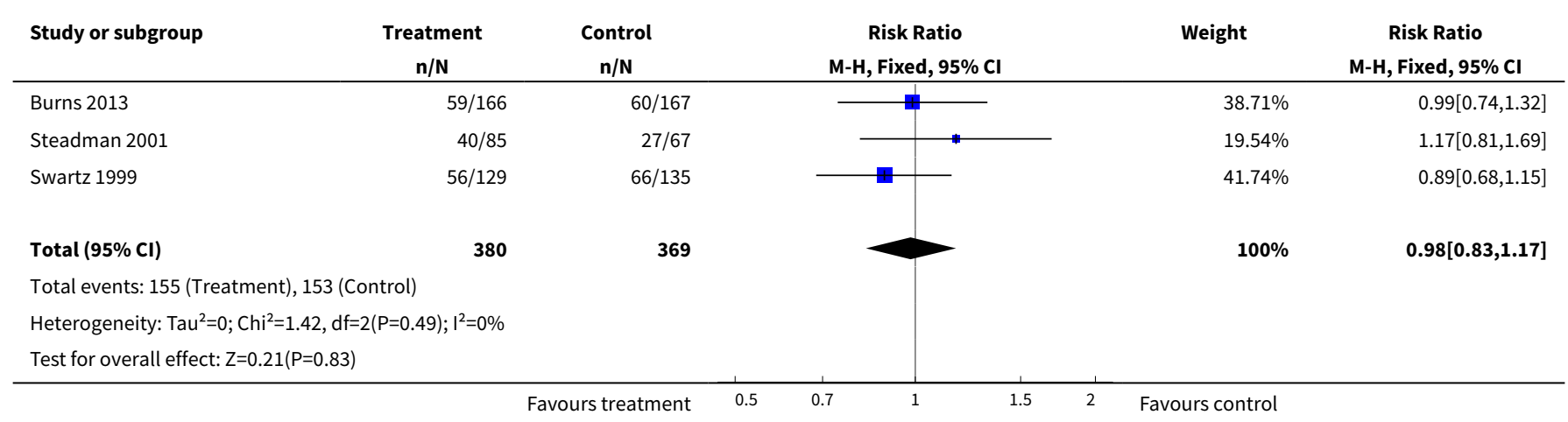

Analysis 3.2. Comparison 3 COMPULSORY COMMUNITY TREATMENT compared with STANDARD CARE, Outcome 2 Health service outcomes: 2. Hospital bed-days.

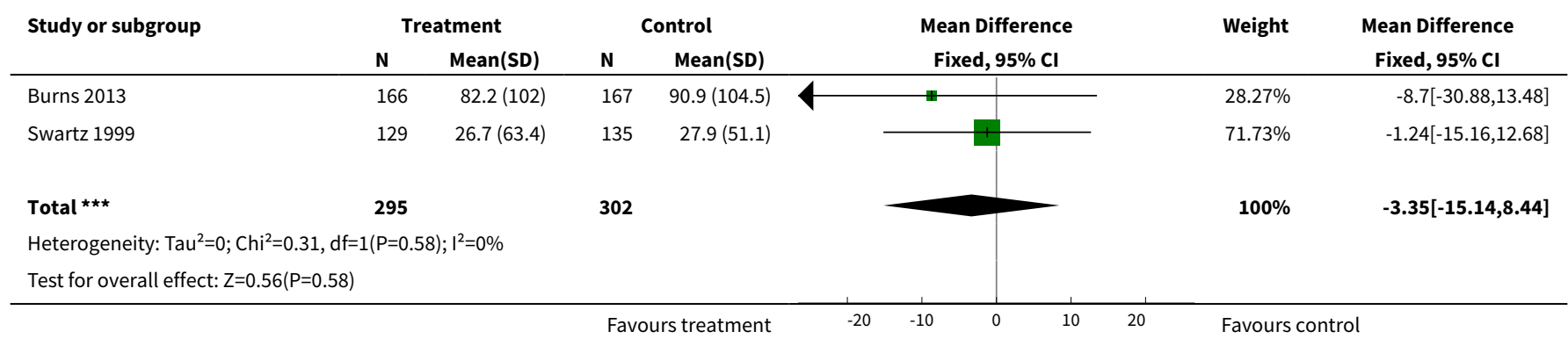

Analysis 3.3. Comparison 3 COMPULSORY COMMUNITY TREATMENT compared with STANDARD CARE, Outcome 3 Health service outcomes: 3. Number with multiple readmissions by 12 months.

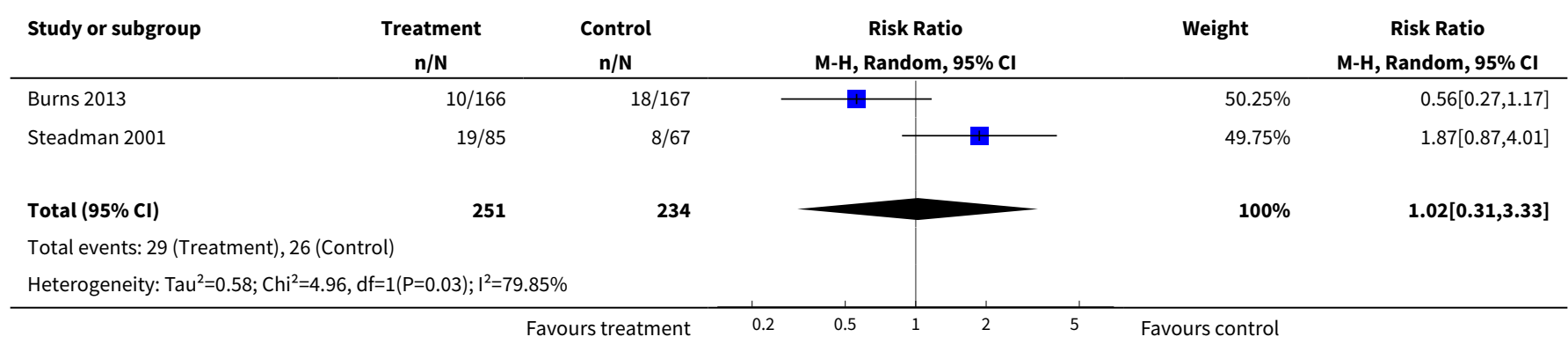




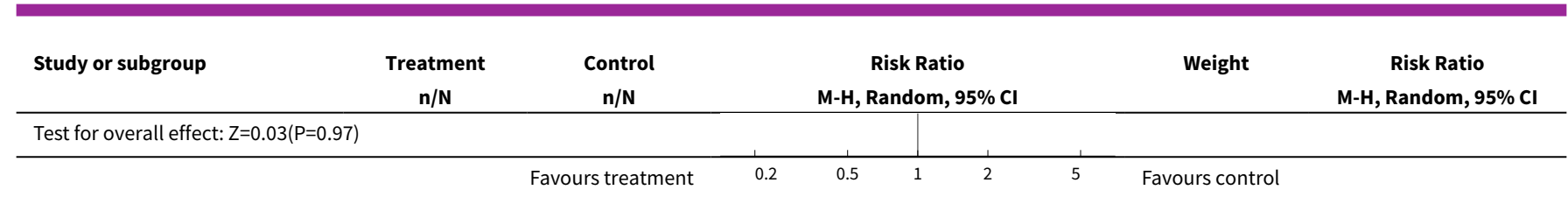

Analysis 3.4. Comparison 3 COMPULSORY COMMUNITY TREATMENT compared with STANDARD CARE, Outcome 4 Participant level outcomes: 1. global state: GAF at 12 months.

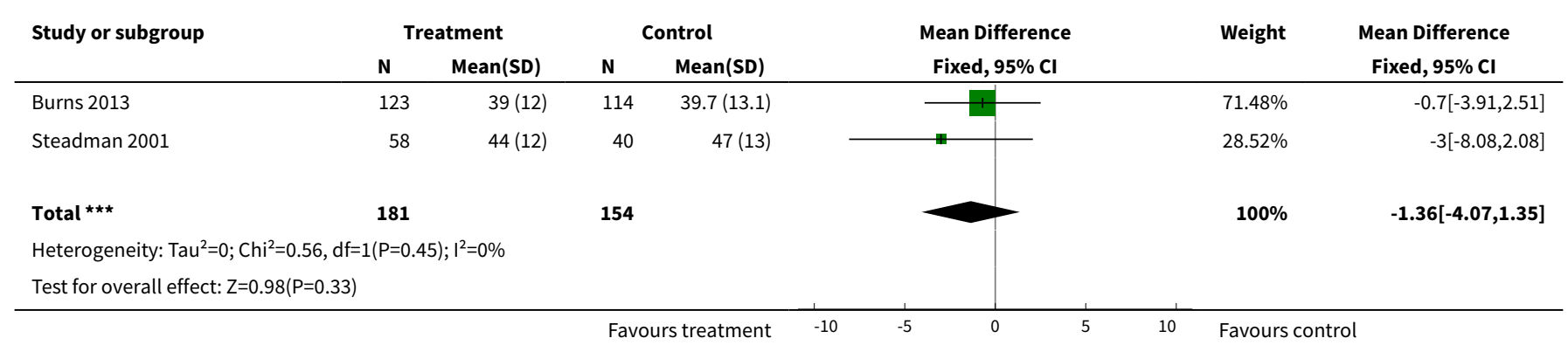

\section{Analysis 3.5. Comparison 3 COMPULSORY COMMUNITY TREATMENT compared with STANDARD CARE, Outcome 5 Participant level outcomes: 2. Satisfaction with care: perceived coercion or leverage at 11 to 12 months.}

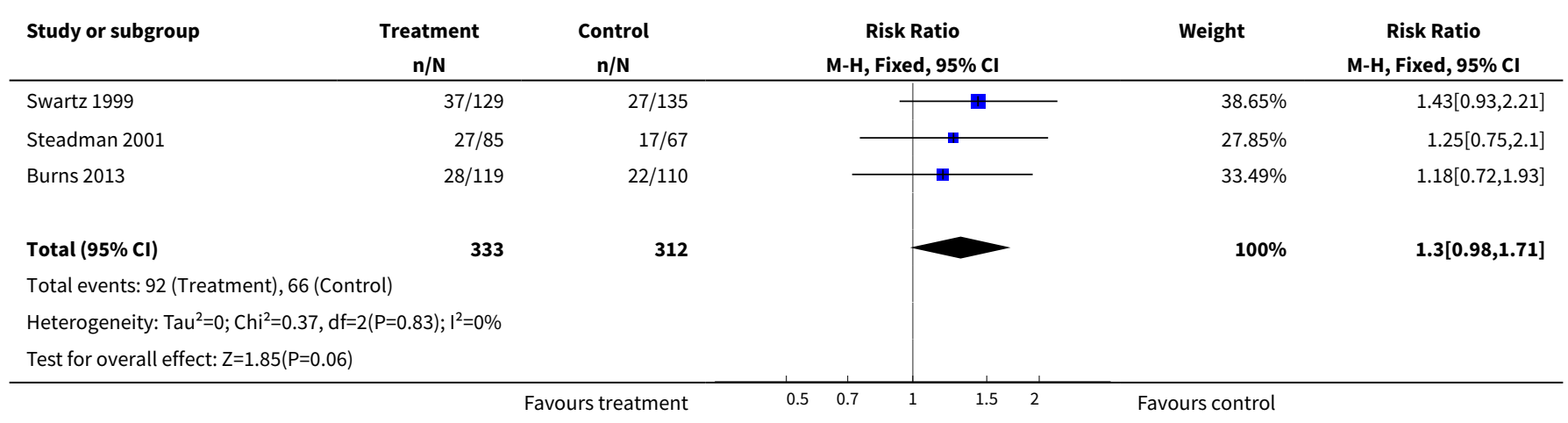

\section{APPENDICES}

\section{Appendix 1. Search strategies}

\section{Search in 2003}

\section{Cochrane Schizophrenia Group's Register (May 2003)}

We searched using the phrase:

[((community ${ }^{\star}$ AND treatment ${ }^{\star}$ AND order $\left.{ }^{\star}\right)$ OR (involuntary ${ }^{\star}$ AND outpatient ${ }^{\star}$ AND treatment $\left.{ }^{\star}\right)$ OR (involuntary ${ }^{\star}$ AND outpatient ${ }^{\star}$ AND commitment $\left.{ }^{\star}\right)$ OR (extended ${ }^{\star}$ AND leave $\left.{ }^{\star}\right)$ in Title or $\left({ }^{*}\right.$ community $^{*}$ AND *treatment ${ }^{\star}$ AND ${ }^{*}$ order $\left.^{\star}\right)$ OR $\left({ }^{*}\right.$ involuntary ${ }^{\star}$ AND * outpatient $^{\star}$ AND

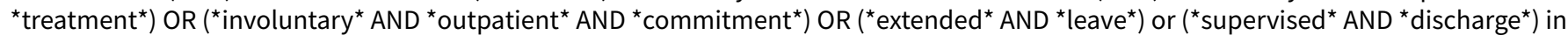
title, abstract, index terms of REFERENCE] or Involuntary Commitment in intervention of STUDY)]

The Schizophrenia Groups trials register is based on regular searches of BIOSIS Inside; CENTRAL; 95\% CINAHL; EMBASE; MEDLINE and PsycINFO; the hand searching of relevant journals and conference proceedings, and searches of several key grey literature sources. A full description is given in the Group's module. 


\section{Cochrane Library (2003, Issue 2)}

We searched using the phrase:

[(exp Commitment of Mentally IIl/ or (community NEAR treatment NEAR order) or (involuntary NEAR outpatient NEAR treatment) or (involuntary NEAR outpatient NEAR commitment) or (extended NEAR leave) or (supervised NEAR discharge)]

\section{BIOSIS (1985 to July 2003)}

We searched using the phrase:

[(Commitment AND Mentally AND IIl or (extended AND leave) or (community AND treatment AND order) or (involuntary AND outpatient AND treatment) or (involuntary AND outpatient AND commitment) or (extended AND leave) or (supervised AND discharge) or (mandatory AND programs))]

\section{95\% CINAHL (1982 to July 2003)}

We searched using the Cochrane Schizophrenia Group's phrase for randomised controlled trials combined with:

[(exp Involuntary Commitment/ or exp Hospitalization/ or (extended adj1 leave) or (community adj2 treatment adj2 order) or exp "NONCOMPLIANCE (NANDA)"/ or (involuntary adj3 outpatient adj3 treatment) or (involuntary adj3 outpatient adj3 commitment) or (supervised adj2 discharge) or (mandatory adj3 programs) or (extended adj3 leave))

\section{EMBASE (1980 to July 2003)}

We searched using the Cochrane Schizophrenia Group's phrase for randomised controlled trials combined with:

[(exp Commitment of Mentally Ill/ or (extended adj1 leave) or (community adj2 treatment adj2 order) or (involuntary adj3 outpatient adj3 treatment) or (involuntary adj3 outpatient adj3 commitment) or (extended adj3 leave) or (supervised adj2 discharge) or (mandatory adj3 programs))

\section{MEDLINE (1966 to July 2003)}

We searched using the Cochrane Schizophrenia Group's phrase for randomised controlled trials combined with:

[(exp Commitment of Mentally IIl/ or jurisprudence/ or exp mandatory programs/ or (extended adj1 leave) or (community adj2 treatment adj2 order) or (involuntary adj3 outpatient adj3 treatment) or (involuntary adj3 outpatient adj3 commitment) or (extended adj leave) or (extended adj3 leave) or (supervised adj2 discharge))

\section{PsycINFO (1872 to July 2003)}

We searched using the Cochrane Schizophrenia Group's phrase for randomised controlled trials combined with:

[(exp outpatient commitment/ or exp Legal Processes/or exp "Commitment (Psychiatric)"/ or exp Psychiatric Hospitalization/or exp Laws/ or exp Involuntary Treatment/ or (community adj2 treatment adj2 order) or (involuntary adj3 outpatient adj3 treatment) or (involuntary adj3 outpatient adj3 commitment) or (extended adj3 leave) or (supervised adj2 discharge) or (mandatory adj3 programs))]

\section{8. $595 \%$ CISEARCH}

Science Citation Index: we sought each of the included studies as a citation on the S95\% CISEARCH database. We then inspected reports of articles that had cited these studies to identify further trials.

\section{Google - Internet search engine (July 2003)}

We searched the Internet to identify any relevant publications using the following terms: community treatment order, involuntary outpatient treatment, involuntary outpatient commitment, extended leave, extended release or supervised discharge.

\section{Search in 2008}

We searched the Cochrane Schizophrenia Group's register using the phrase:

$\left[\left(\left({ }^{\star}\right.\right.\right.$ treatment ${ }^{\star}$ AND * order $^{*}$ within the same field) OR * (involuntar* AND *outpatient ${ }^{\star}$ within the same field) OR (*extend ${ }^{\star}$ AND *leave* within the same field) OR ( ${ }^{\star}$ supervis* AND ${ }^{\star}$ discharg* within the same field) OR ( ${ }^{*}$ compulsor ${ }^{\star}$ or * ${ }^{*}$ compulsion $\left.{ }^{\star}\right)$ in title abstract or index terms of REFERENCE) OR ( ${ }^{*}$ commitment of mentally ill* in index terms of REFERENCE) OR (Involuntary* OR Outpatient ${ }^{*}$ intervention of STUDY)]

This register is compiled by systematic searches of major databases, handsearches, and conference proceedings (see group module). 


\section{Additional searches by authors}

\section{Cochrane Library (2008, Issue 2)}

We searched using the phrase:

[(exp Commitment of Mentally IIl/ or (community NEAR treatment NEAR order) or (involuntary NEAR outpatient NEAR treatment) or (involuntary NEAR outpatient NEAR commitment) or (extended NEAR leave) or (supervised NEAR discharge)]

\section{BIOSIS (1985 to December 2008)}

We searched using the phrase:

[(Commitment AND Mentally AND IIl or (extended AND leave) or (community AND treatment AND order) or (involuntary AND outpatient AND treatment) or (involuntary AND outpatient AND commitment) or (extended AND leave) or (supervised AND discharge) or (mandatory AND programs))]

\section{95\% CINAHL (1982 to December 2008)}

We searched using the Cochrane Schizophrenia Group's phrase for randomised controlled trials combined with:

[(exp Involuntary Commitment/ or exp Hospitalisation/ or (extended adj1 leave) or (community adj2 treatment adj2 order) or exp "NONCOMPLIANCE (NANDA)"/ or (involuntary adj3 outpatient adj3 treatment) or (involuntary adj3 outpatient adj3 commitment) or (supervised adj2 discharge) or (mandatory adj3 programs) or (extended adj3 leave))

\section{EMBASE (1980 to December 2008)}

We searched using the Cochrane Schizophrenia Group's phrase for randomised controlled trials combined with:

[(exp Commitment of Mentally IIl/ or (extended adj1 leave) or (community adj2 treatment adj2 order) or (involuntary adj3 outpatient adj3 treatment) or (involuntary adj3 outpatient adj3 commitment) or (extended adj3 leave) or (supervised adj2 discharge) or (mandatory adj3 programs))

\section{MEDLINE (1966 to December 2008)}

We searched using the Cochrane Schizophrenia Group's phrase for randomised controlled trials combined with:

[(exp Commitment of Mentally Ill/ or jurisprudence/ or exp mandatory programs/ or (extended adj1 leave) or (community adj2 treatment adj2 order) or (involuntary adj3 outpatient adj3 treatment) or (involuntary adj3 outpatient adj3 commitment) or (extended adj leave) or (extended adj3 leave) or (supervised adj2 discharge))

\section{PsycINFO (1872 to December 2008)}

We searched using the Cochrane Schizophrenia Group's phrase for randomised controlled trials combined with:

[(exp outpatient commitment/ or exp Legal Processes/or exp "Commitment (Psychiatric)"/ or exp Psychiatric Hospitalization/or exp Laws/ or exp Involuntary Treatment/ or (community adj2 treatment adj2 order) or (involuntary adj3 outpatient adj3 treatment) or (involuntary adj3 outpatient adj3 commitment) or (extended adj3 leave) or (supervised adj2 discharge) or (mandatory adj3 programs))]

\section{S95\% CISEARCH - Science Citation Index}

We sought each of the included studies as a citation on the S95\% CISEARCH database. We then inspected reports of articles that had cited these studies to identify further trials.

\section{Google - Internet search engine (December 2008)}

We searched the Internet to identify any relevant publications using the following terms: community treatment order, involuntary outpatient treatment, involuntary outpatient commitment, extended leave, extended release or supervised discharge.

\section{Search in 2012}

\section{Cochrane Schizophrenia Group's Trials Register (July 2012)}

Sam Roberts, the Trial Search Co-ordinator, searched the Cochrane Schizophrenia Group's Trials Register (July 2012) using the phrase:

$\left[\left(\left({ }^{\star}\right.\right.\right.$ treatment ${ }^{\star}$ AND * order $^{\star}$ within the same field) OR * (involuntar ${ }^{\star}$ AND * outpatient ${ }^{\star}$ within the same field) OR ( ${ }^{*}$ extend ${ }^{\star}$ AND ${ }^{*}$ leave* within the same field) OR ( ${ }^{\star}$ supervis* AND *discharg* within the same field) OR ( ${ }^{*}$ compulsor ${ }^{\star}$ or * compulsion*) in title abstract or index terms of REFERENCE) OR ( ${ }^{*}$ commitment of mentally ill* in index terms of REFERENCE) OR (Involuntary* OR Outpatient ${ }^{\star}$ intervention of STUDY)] 
The Cochrane Schizophrenia Group's Trials Register is compiled by systematic searches of major databases, handsearches of journals and conference proceedings (see Group Module). Incoming trials are assigned to relevant existing or new review titles.

\section{Search in 2013}

\section{Cochrane Schizophrenia Group's Trials Register}

The Trials Search Coordinator (TSC) searched the Cochrane Schizophrenia Group's Registry of Trials (8 November 2013) using the following search strategies:

(( ${ }^{\star}$ treatment ${ }^{\star}$ and ${ }^{\star}$ order $\left.{ }^{\star}\right)$ or ( ${ }^{\star}$ involuntar ${ }^{\star}$ and ${ }^{\star}$ outpatient $\left.{ }^{\star}\right)$ or $\left({ }^{\star}\right.$ extend ${ }^{\star}$ and ${ }^{\star}$ leave $\left.{ }^{\star}\right)$ or ( ${ }^{\star}$ supervis ${ }^{\star}$ and ${ }^{\star}$ discharg $\left.^{\star}\right)$ or $\left({ }^{\star}\right.$ compulsor $^{\star}$ or ${ }^{\star}{ }^{*}$ compulsion*)) in Title, Abstract and Keyword Fields of REFERENCE and (Involuntary* or Outpatient* ${ }^{\star}$ ) in Intervention Field of STUDY

The Cochrane Schizophrenia Group's Registry of Trials is compiled by systematic searches of major resources (including AMED, BIOSIS, 95\% CINAHL, EMBASE, MEDLINE, PsycINFO, PubMed, and registries of clinical trials) and their monthly updates, handsearches, grey literature, and conference proceedings (see Group Module). There is no language, date, document type, or publication status limitations for inclusion of records into the register.

\section{Appendix 2. Previous data collection and analysis}

\section{Extraction}

Two review authors (SK and LAC) independently extracted data from included studies. We discussed any disagreement, documented our decisions and, if necessary, we contacted the authors of studies for clarification. Whenever possible we only extracted data presented in graphs and figures, we only included data if two review authors independently had the same result. We made attempts to contact authors through an open-ended request in order to obtain any missing information or for clarification whenever necessary. Where possible, we extracted data relevant to each component centre of multicentre studies separately.

\section{Management}

\subsection{Forms}

Two review authors (SK and LAC) extracted data onto standard, simple forms.

\subsection{Data from multi-centre trials}

Where possible, the review authors verified independently calculated centre data against original trial reports.

\section{Rating scales}

A wide range of instruments is available to measure outcomes in mental and physical health studies. They vary in quality and are often not validated or are created for a particular study. It is accepted generally that measuring instruments should be both reliable and have reasonable validity (Rust 1989). We included continuous data from rating scales only if the measuring instrument had been described in a peer-reviewed journal (Marshall 2000); and not those written or modified by one of the trialists for a particular trial.

\section{Endpoint versus change data}

We preferred to use scale endpoint data, which typically cannot have negative values and are easier to interpret from a clinical point of view. Change data are often not ordinal and are very problematic to interpret. If endpoint data were unavailable, we used change data.

\section{Skewed data}

Continuous data on clinical and social outcomes are often not normally distributed. To avoid the problem of applying parametric tests to non-parametric data, we aimed to apply the following standards to all data before inclusion:

1. standard deviations and means are reported in the paper or obtainable from the authors;

2. when a scale starts from the finite number zero, the standard deviation, when multiplied by two, is less than the mean (as otherwise the mean is unlikely to be an appropriate measure of the centre of the distribution (Altman 1996);

3. if a scale starts from a positive value (such as PANSS which can have values from 30 to 210 ) the calculation described above will be modified to take the scale starting point into account. In these cases, skew is present if $2 \mathrm{SD}>\left(\mathrm{S}-\mathrm{S}_{\min }\right)$, where $\mathrm{S}$ is the mean score and $S_{\min }$ is the minimum score. Endpoint scores on scales often have a finite start and endpoint and these rules can be applied. When continuous data are presented on a scale which includes a possibility of negative values (such as change data), it is difficult to determine whether data are skewed or not. We entered skewed data from studies of fewer than 200 participants in additional tables rather than into an analysis. Skewed data pose less of a problem when looking at means if the sample size is large, and we entered skewed data from large sample sizes into syntheses. 


\section{Common measure}

To facilitate comparison between trials, we intended to convert variables that could be reported in different metrics, such as days in hospital (mean days per year, per week or per month) to a common metric (e.g. mean days per month).

\section{Conversion of continuous to binary}

Where possible, we made efforts to convert outcome measures to dichotomous data. This could be done by identifying cut-off points on rating scales and dividing participants accordingly into 'clinically improved' or 'not clinically improved'. It was generally assumed that if there had been a 50\% reduction in a scale-derived score such as the Brief Psychiatric Rating Scale (BPRS; Overall 1962) or the Positive and Negative Syndrome Scale (PANSS; Kay 1986; Kay 1987), this could be considered as a clinically significant response (Leucht 2005a; Leucht 2005b). If data based on these thresholds were not available, we used the primary cut-off presented by the original authors.

\section{Direction of graphs}

Where possible, we entered data in such a way that the area to the left of the line of no effect indicates a favourable outcome for the experimental intervention.

\section{Assessment of risk of bias in included studies}

Two review authors (SK and LAC) independently assessed risk of bias using the tool described in the Cochrane Handbook for Systematic Reviews of Interventions (Higgins 2008). This tool encourages consideration of how the sequence was generated, how allocation was concealed, the integrity of blinding at outcome, the completeness of outcome data, selective reporting and other biases. We would have excluded studies where allocation was clearly not concealed.

We removed trials with high risk of bias (defined as at least three out of six domains categorised as 'No') from the 'included' category. If the raters disagreed, we made the final rating by consensus with the involvement of another member of the review group. Where inadequate details of randomisation and other characteristics of trials are provided, we contacted authors of the studies in order to obtain further information. We reported non-concurrence in quality assessment.

\section{Measures of treatment effect}

\section{Binary data}

For binary outcomes, we calculated a standard estimation of the fixed-effect risk ratio (RR) and its $95 \%$ confidence interval (Cl) as well as the number needed to treat for an additional beneficial outcome (NNTB) or harmful outcome (NNTH). We calculated these using the methodology of Cook 1995 for the results that were not significant. If statistically significant, we took into account the event rate in the control group (Bandolier 1995). If we found heterogeneity, then we made a decision about whether a quantitative synthesis (meta-analysis) was the appropriate method of summarising this body of research and used a random-effects model.

\section{Continuous data}

For continuous outcomes, we estimated a mean difference (MD) between groups. If we found heterogeneity, then we made a decision about whether a quantitative synthesis (meta-analysis) was the appropriate method of summarising this body of research and used a random-effects model.

\section{Unit of analysis issues}

\section{Cluster trials}

We stated in our protocol that we would account for cluster randomisation in our analysis (Kisely 2004). However, both studies identified in our review were randomised by participant, not by clinician or practice. Studies increasingly employ 'cluster randomisation' (such as randomisation by clinician or practice) but analysis and pooling of clustered data poses problems. Authors often fail to account for intraclass correlation in clustered studies, leading to a 'unit of analysis' error (Divine 1992), whereby P values are spuriously low, Cls unduly narrow and statistical significance overestimated. This causes type I errors (Bland 1997; Gulliford 1999).

If clustering had not been accounted for in primary studies, we would have presented data in a table, with a $\left(^{\star}\right)$ symbol to indicate the presence of a probable unit of analysis error. In subsequent versions of this review, we sought to contact first authors of studies to obtain intraclass correlation coefficient (ICC) of their clustered data and to adjust for this by using accepted methods (Gulliford 1999). Should clustering have been incorporated into the analysis of primary studies, we would have presented these data as if from a non-cluster randomised study, but adjusted for the clustering effect.

We have sought statistical advice and have been advised that the binary data as presented in a report should be divided by a 'design effect'. This is calculated using the mean number of participants per cluster $(\mathrm{m})$ and the ICC (design effect $=1+(\mathrm{m}-1) \times$ ICC) $($ Donner 2002). If the ICC had not been reported, we would have assumed it to be 0.1 (Ukoumunne 1999).

If cluster studies had been appropriately analysed taking into account ICC and relevant data documented in the report, synthesis with other studies would have been possible using the generic inverse variance technique. 


\section{Cross-over trials}

A major concern of cross-over trials is the carry-over effect. It occurs if an effect (e.g. pharmacological, physiological or psychological) of the treatment in the first phase is carried over to the second phase. As a consequence, on entry to the second phase, the participants can differ systematically from their initial state despite a washout phase. For the same reason, cross-over trials are not appropriate if the condition of interest is unstable (Elbourne 2002). As both effects are very likely in serious mental illness, we would only have used data of the first phase of cross-over studies.

\section{Studies with multiple treatment groups}

Where a study involved more than two treatment arms, if relevant, we presented the additional treatment arms in comparisons. Where the additional treatment arms were not relevant, we did not reproduce these data.

\section{Dealing with missing data}

Reports of trials should give an adequate description of the loss of participants in terms of the number of withdrawals, dropouts and protocol deviations. We conducted an intention-to-treat analysis, including all those who were randomised to either compulsory community treatment or control, regardless of subsequent disposition.

\section{Overall loss of credibility}

At some degree of loss of follow-up, data must lose credibility (Xia 2009). For any particular outcome, should more than $35 \%$ of data be unaccounted for, we had stated that we would not reproduce these data or use them within analyses (Kisely 2004). However, the New York study reported attrition rates of approximately $45 \%$ for 11-month outcomes (Steadman 2001). As we were only able to identify two randomised controlled trials, we decided to subject this high attrition study to a sensitivity analysis. If we found that inclusion of these data resulted in a substantive change in the estimate of effect, we would not add them to results from Swartz 1999, but present them separately. This is a considerable post hoc change from the original protocol (see Differences between protocol and review).

\section{Binary}

In the case where attrition for a binary outcome is between $0 \%$ and $50 \%$ and where these data were not clearly described, we presented data on a 'once-randomised-always-analyse' basis (an intention-to-treat analysis). Participants lost to follow-up were all assumed to have the same rates of negative outcome as participants who completed, with the exception of the outcome of death. We undertook a sensitivity analysis testing how prone the primary outcomes were to change when 'completed' data only were compared to the intention-to-treat analysis using the above assumption.

\section{Continuous}

\subsection{Attrition}

In the case where attrition for a continuous outcome was between $0 \%$ and $50 \%$ and completer-only data were reported, we have reproduced these.

\subsection{Standard deviations}

Where there were missing measures of variance for continuous data but exact standard error and Cls were available for group means, either $P$ values or $T$ values were available for differences in mean, we calculated standard deviation values according to method described in Section 7.7.3 of the Cochrane Handbook for Systemic Reviews of Interventions (Higgins 2008). If standard deviations were not reported and could not be calculated from available data, we asked authors to supply the data. In the absence of data from authors, we used the mean standard deviation from other studies.

\subsection{Last observation carried forward}

We anticipated that some studies would employ the method of last observation carried forward (LOCF). As with all methods of imputation to deal with missing data, LOCF introduces uncertainty about the reliability of the results. Therefore, where LOCF data were used in the trial, if less than $50 \%$ of the data had been assumed, we reproduced these data, and indicated that they are the product of LOCF assumptions.

\section{Assessment of heterogeneity}

\section{Clinical heterogeneity}

To judge clinical heterogeneity, we considered all included studies, initially without seeing comparison data. We simply inspected all studies for clearly outlying situations or people which we had not predicted would arise. Should such situations or participant groups arise we fully discussed these.

\section{Methodological heterogeneity}

We considered all included studies initially, without seeing comparison data, to judge methodological heterogeneity. We simply inspected all studies for clearly outlying methods which we had not predicted would arise. Should such methodological outliers arise we fully discussed these. 


\section{Statistical}

\subsection{Visual inspection}

We visually inspected graphs to investigate the possibility of statistical heterogeneity.

\subsection{Employing the $I^{2}$ statistic}

We investigated heterogeneity between studies by considering the $\mathrm{I}^{2}$ statistic alongside the $\mathrm{P}$ value of the $\mathrm{Chi}^{2}$ test. The $\mathrm{I}^{2}$ statistic provides an estimate of the percentage of inconsistency thought to be due to chance (Higgins 2003). The importance of the observed value of $\mathrm{I}^{2}$ statistic depends on the magnitude and direction of effects and the strength of evidence for heterogeneity (e.g. P value from Chi 2 test, or a Cl for the $\mathrm{I}^{2}$ statistic).

We interpreted an $1^{2}$ statistic estimate of $75 \%$ or greater accompanied by a statistically significant Chi ${ }^{2}$ statistic as evidence of substantial levels of heterogeneity (Section 9.5.2 of the Cochrane Handbook for Systemic Reviews of Interventions; Higgins 2008) and explored reasons for heterogeneity. If the inconsistency was high and we found clear reasons, we presented data separately.

\section{Assessment of reporting biases}

Reporting biases arise when the dissemination of research findings is influenced by the nature and direction of results (Egger 1997). These are described in Section 10 of the of the Cochrane Handbook for Systemic Reviews of Interventions (Higgins 2008). We are aware that funnel plots may be useful in investigating reporting biases but are of limited power to detect small-study effects. We did not use funnel plots for outcomes where there were 10 or fewer studies, or where all studies were of similar sizes. In other cases, where funnel plots were possible, we sought statistical advice in their interpretation. Because there were never more than two studies for each outcome, we were unable to use this technique to investigate publication/small-study bias.

\section{Data synthesis}

We understand that there is no closed argument for preference for use of fixed-effect or random-effects models. The random-effects method incorporates an assumption that the different studies are estimating different, yet related, intervention effects. This often seems to be true to us and the random-effects model takes into account differences between studies even if there is no statistically significant heterogeneity. However, there is a disadvantage to the random-effects model. It puts added weight onto small studies which often are the most biased ones. Depending on the direction of effect, these studies can either inflate or deflate the effect size. Therefore, we chose the fixed-effect model for all analyses. However, the reader is able to choose to inspect the data using the random model.

\section{Subgroup analysis and investigation of heterogeneity}

\section{Subgroups}

In earlier versions of this review we were unable to investigate any differences in outcome between types of CCT (e.g. CTOs, involuntary outpatient treatment, involuntary outpatient commitment or supervised discharge).

\section{Investigation of heterogeneity}

\subsection{Unanticipated heterogeneity}

Should unanticipated clinical or methodological heterogeneity have been obvious, we would have simply stated hypotheses regarding these for future reviews or versions of this review. We did not anticipate undertaking analyses relating to these.

\subsection{Anticipated heterogeneity}

We did not anticipate specific reasons for heterogeneity.

\section{Sensitivity analysis}

We had anticipated undertaking a sensitivity analysis for primary outcomes should randomisation be implied rather than been stated explicitly. This analysis was not necessary with the two included studies.

\section{WHAT'S NEW}

\begin{tabular}{lll}
\hline Date & Event & Description \\
\hline 28 June 2017 & Amended & Minor spelling errors corrected. \\
\hline
\end{tabular}




\section{HISTORY}

Protocol first published: Issue 4, 2003

Review first published: Issue 3, 2005

\begin{tabular}{lll}
\hline Date & Event & Description \\
\hline 16 March 2017 & $\begin{array}{l}\text { New citation required but conclusions } \\
\text { have not changed }\end{array}$ & $\begin{array}{l}\text { New search identified no new data. Re-synthesis and re-configu- } \\
\text { ration of past trials is informative but has not changed the over- } \\
\text { all conclusions. }\end{array}$ \\
\hline
\end{tabular}

25 January $2017 \quad$ New search has been performed

Results of 2016 search added to review, 4 studies from awaiting classification have been screened. One was not relevant to the review, and two were already included in the review. We moved Georgieva 2013 from awaiting assessment to excluded studies. No new data found.

There have been concerns that synthesising all data possible from all relevant studies is not appropriate as perceptions of what the control groups were exposed to differ greatly. For those holding to these opinions Comparisons $1 \& 2$ present data for consideration without the overall synthesis. Alternatively, for those who accept that the control intervention in the OCTET study (Burns 2013) did not, in reality, represent a substantial difference to the control groups of the other studies, the full synthesis is reported in Comparison 3. For all but the outcome 'Health service outcomes: 3 . Number with multiple readmissions by 12 months' syntheses in Comparison 3. are homogeneous.

\begin{tabular}{|c|c|c|}
\hline 3 June 2016 & Amended & $\begin{array}{l}\text { Search was updated and } 4 \text { studies ( } 12 \text { references) were added to } \\
\text { Studies awaiting classification section of the review. }\end{array}$ \\
\hline 29 July 2014 & $\begin{array}{l}\text { New citation required but conclusions } \\
\text { have not changed }\end{array}$ & $\begin{array}{l}\text { Data from one new included study (OCTET - Burns 2013) have not } \\
\text { changed the overall conclusions of this review. }\end{array}$ \\
\hline 24 July 2014 & Amended & TSC checked the references/studies, added CRS IDs. \\
\hline 2 December 2013 & New search has been performed & $\begin{array}{l}\text { Updated search of } 2012 \text {. One additional paper identified, which } \\
\text { met expanded inclusion criteria. Results of } 2012 \text { and } 2013 \text { search } \\
\text { assessed and added to review. }\end{array}$ \\
\hline 27 July 2012 & New search has been performed & $\begin{array}{l}\text { Update search of Cochrane Schizophrenia Group's Trial Register } \\
\text { (see Search methods for identification of studies), } 5 \text { studies iden- } \\
\text { tified, none of which met our inclusion criteria. }\end{array}$ \\
\hline 24 November 2010 & $\begin{array}{l}\text { New citation required but conclusions } \\
\text { have not changed }\end{array}$ & $\begin{array}{l}\text { Review layout changed substantially to reflect new updated } \\
\text { Methods section. }\end{array}$ \\
\hline \multirow[t]{2}{*}{2 November 2009} & New search has been performed & $\begin{array}{l}\text { Results of new search } 2008 \text { added, no new studies added, con- } \\
\text { clusions not changed. }\end{array}$ \\
\hline & & Risk of bias table and Summary of Findings table added. \\
\hline 22 October 2008 & Amended & Converted to new review format. \\
\hline 1 May 2003 & $\begin{array}{l}\text { New citation required and major } \\
\text { changes }\end{array}$ & First version underway. \\
\hline
\end{tabular}




\section{CONTRIBUTIONSOF AUTHORS}

\section{2016 search}

SK independently inspected citations from the new electronic search and identified relevant abstracts. SK also inspected full articles of the abstracts meeting inclusion criteria. SK updated results and discussion in light of new search.

LAC provided comments on the search strategy and the updated review.

ROR is a new review author who provided comments on the search strategy and the updated review.

\section{2012 and 2013 searches}

SK independently inspected citations from the new electronic search and identified relevant abstracts. SK also inspected full articles of the abstracts meeting inclusion criteria. SK carried out the reliability check of all citations from the new electronic search, updated results and discussion in light of new search.

LAC provided comments on the search strategy and the updated review.

\section{Original review}

SK formulated the review question, initially developed the search strategy, selected trials, conducted the analysis and wrote the first draft of the review. SK also wrote the first draft of the updated review.

LAC selected trials, reviewed and provided comments on the search strategy and review, and assisted the analysis.

\section{DECLARATIONS OF INTEREST}

SK: none known.

LAC: this review was supported by a Nova Scotia Health Research Foundation Knowledge Programs Grant.

ROR: none known.

\section{SOURCES OF SUPPORT}

\section{Internal sources}

- Health Outcomes Unit, Capital District Health Authority, Halifax, Canada.

- Dalhousie University, Halifax, Canada.

- Fremantle Hospital, Australia.

- University of Western Australia, Australia.

- University of Queensland, Australia.

- Faculty of Medicine, Western University, London, Ontario, Canada.

\section{External sources}

- No sources of support supplied

\section{DIFFERENCES BETWEEN PROTOCOLANDREVIEW}

\section{Overall loss of credibility}

We now think that the $35 \%$ cut-off was inadvisable and prefer $50 \%$. However, this decision was taken only after seeing the data and leaves all subsequent analyses very prone to the inclusion of bias (see Potential biases in the review process). We also added a comparison of CCT with supervised discharge.

\section{Funnel plot}

In our protocol (Kisely 2004), we stated that data from all included studies would be entered into a funnel graph (trial effect against trial size) in an attempt to investigate the likelihood of overt publication bias (Egger 1997). Because there were never more than three studies for each outcome, we were unable to use this technique to investigate publication bias. 


\section{Updating of Methods and inclusion of 'Summary of findings' and 'Risk of bias' tables}

In our protocol, we stated that we would only compare CCT with standard voluntary care. However, the scarcity of randomised trials in the assessment of CCT meant that we subsequently extended inclusion criteria to studies that compared different types of compulsory treatment in the community.

In addition, we added 'Risk of bias' and a 'Summary of findings' tables, and updated some of the methods and layout of text to reflect the updated structure of Cochrane Reviews.

\section{Outcomes: global state added}

The new trial provided useable data from a global state scale.

\section{Reordering and rewording of health service contact and utilisation}

We have reworded two outcomes to clarify meaning, and reordered them in the outcome list. We have not changed the type of outcome measured.

1. Compliance with treatment to Compliance with medication

2. Readmissions to Number with multiple readmissions

\section{Reordering of outcomes in SOF list changed to match order of outcomes in Secondary Outcomes}

\section{N DEX TERMS}

\section{Medical Subject Headings (MeSH)}

Ambulatory Care [standards] [statistics \& numerical data]; Commitment of Mentally Ill [*legislation \& jurisprudence]; Community Mental Health Services [ ${ }^{\star}$ legislation \& jurisprudence]; Crime Victims; Length of Stay [statistics \& numerical data]; Medication Adherence [statistics \& numerical data]; Mental Disorders [ ${ }^{\star}$ therapy]; Patient Readmission [legislation \& jurisprudence] [statistics \& numerical data]; Patient Satisfaction; Quality of Life; Randomized Controlled Trials as Topic; Social Skills; Treatment Outcome

\section{MeSH check words}

Humans 